\title{
RIQUEZA E DIVERSIDADE DE MAMÍFEROS NÃO-VOADORES EM UM MOSAICO FORMADO POR PLANTIOS DE Eucalyptus saligna E REMANESCENTES DE FLORESTA ATLÂNTICA NO MUNICÍPIO DE PILAR DO SUL, SP.
}

\author{
CLÁUDIA REGINA DA SILVA
}

Dissertação apresentada à Escola Superior de Agricultura "Luiz de Queiroz", Universidade de São Paulo, para obtenção do título de mestre em Ciências, Área de Concentração: Ciências Florestais .

PIRACICABA

Estado de São Paulo - Brasil

Dezembro - 2001 


\title{
RIQUEZA E DIVERSIDADE DE MAMÍFEROS NÃO-VOADORES EM UM MOSAICO FORMADO POR PLANTIOS DE Eucalyptus saligna E REMANESCENTES DE FLORESTA ATLÂNTICA NO MUNICÍPIO DE PILAR DO SUL, SP.
}

\author{
CLÁUDIA REGINA DA SILVA
}

Aprovada em: 04.03.2002

Comissão Julgadora

Prof. Dr. Álvaro Fernando de Almeida

ESALQ/USP

Prof. Dr. Luciano Martins Verdade

ESALQ/USP

Prof. Dr. Mário de Vivo

MZUSP/USP

Prof. Dr. ÁLVARO FERNANDO DE ALMEIDA

Orientador

PIRACICABA

Estado de São Paulo - Brasil

Dezembro - 2001 
Dados Internacionais de Catalogação na Publicação (CIP)
DIVISÃO DE BIBLIOTECA E DOCUMENTAÇÃO - ESALQ/USP

Silva, Cláudia Regina da

Riqueza e diversidade de mamíferos não-voadores em um mosaico

formado por plantios de Eucalyptus saligna e remanescentes de Floresta

Atlântica no município de Pilar do Sul, SP / Cláudia Regina da Silva. - -

Piracicaba, 2001.

$81 \mathrm{p.}$

Dissertação (mestrado) - - Escola Superior de Agricultura Luiz de Queiroz, 2001.

Bibliografia.

1. Biodiversidade 2. Ecologia animal 3. Eucalipto 4. Florestas 5. Inventário 6. Mamíferos selvagens I. Título

CDD 634.9734

\section{"Permitida a cópia total ou parcial deste documento, desde que citada a fonte - $O$ autor"}


Dedico:

àminha avó Alzira, pela firmeza de caráter e força que sempre demonstrou a todos nós, seus descendentes;

aos meus pais, pelo amor com que conduziram nossa educação; sempre nos levando de encontro àterra, aos rios, ஷ̀ matas, aos animais... ; 


\section{AGRADECIMENTOS}

Ao meu orientador Prof. Dr. Álvaro Fernando de Almeida pela orientação e pela sugestão da Fazenda João XXIII;

ao Prof. Dr. Mário de Vivo, Alexandre Percequilo, Gilson Ximenes e todos os pesquisadores da Seção de Mamíferos do Museu de Zoologia da USP, pela amizade, hospitalidade e auxílios incomensuráveis;

ao Prof. Dr. Luciano Verdade pela amizade, e pelas simpáticas discussões e sugestões que muito auxiliaram no término desta dissertação;

ao Prof. Dr. Mota Júnior, pela utilização de seu laboratório e pelos conselhos dados. Com carinho agradeço ao Diego Queirolo pela amizade e pelos auxílios a este trabalho;

ao Dr. João de Oliveira do Museu Nacional do Rio de Janeiro pela identificação de Oxymycterus judex;

ao amigo Ivo Rosa, que com simpatia e eficiência auxiliou nos problemas mais diversos, desde arrumar o computador à escolha de fotos;

à Profa Yatyo, Maria José Silva e Valéria Fagundes do Laboratório de Citogenética da USP de São Paulo pelos exames de cariótipo dos espécimes coletados;

à Lucila Manzatti pela amizade, sugestões e apoio e ao CEMASI pelo apoio logístico no início desta pesquisa;

ao meu irmão Francisco pelo desenho do pitfall;

à Silvia Helena pela amizade, companheirismo e imensa ajuda prestada no trabalho de campo. Agradeço também pela permissão de utilizar as coletas de mamíferos realizadas em seu estudo com anfíbios, dados estes que enriqueceram o inventário de mamíferos na Fazenda João XXIII; aos pesquisadores que complementaram o inventário da Fazenda João XXIII: Silvia $\mathrm{H}$. de Oliveira, Fábio (Tropico), George Camargo, Alexandre Vogliotti e Alexandre Almeida; 
com muito carinho, agradeço a ajuda no trabalho de campo de: Tatiana Bagatin, Sandro (Kbão), George, Márcio (Alemão), Alexandre (Gordo), Cassio (Nero), Carla Gheler,, Gustavo, Paulo, Lucas, Ana Carolina, Alexandre Vogliotti (Bororo), Márcio e Eric. Em especial agradeço a Jovercino, meu fiel escudeiro, que esteve em todos aos dias de coleta com chuva ou sol...; aos queridos amigos e eficiente equipe: Marcio Stutman, Carla Gheler, Adriana (Bolaxa), Gilson (Bakunin) e Thiago (Comfort), pela coleta dos dados de vegetação e pelo incrível bom humor durante nossos dias na Fazenda João XXIII. Em especial ao Marcinho (Marcio Stutman) pelo auxílio na identificação das morfo-espécies vegetais coletadas;

ao Prof. Luciano Verdade e ao Prof. Décio Barbin pelos auxílios estatísticos, aos amigos Gustavo (Beija-flor) e Adriana (Bolaxa) também pelos auxílios estatísticos mas, principalmente pelas discussões sugestões e consolos oferecidos; à Marcelino Guedes pelo auxílio com a Análise de Correspondência;

aos amigos que leram, corrigiram e opinaram no manuscrito; Luciano (Bahia), Márcia Messias, Cristiana Simão, Zilvanir e Gustavo (Beija-Flor);

a todas as casas e companheiros de moradia, que me propiciaram carinho, apoio e amizade, ou seja, tudo que se precisa para um bom convívio: Adriana, Rosely, Rodrigo e Ronaldo, nas casas de São Paulo e nas casas de Piracicaba: Pati, Vivi, Carla, Carla Gheler, Adriana (Bolaxa), Daniela, Andressa e Marina (Paraíba).

ao Henrique (Ekiss) pelos agrados e carinhos tão...necessários;

aos meus pais, meus irmãos: Márcia, Cristina e Francisco e ao meu sobrinho: Thiago, pelo amor, carinho, amizade, apoio...tantas coisas... que me faltam formas de agradecer;

à Helaine por todos esses anos de amizade e companheirismo, que nos tornou irmãs e também pela nova vida que colocará em nossas vidas e agradeço ao meu afilhadinho por nos tornar mais alegres;

a todos os meus amigos, envolvidos ou não neste trabalho, que estiveram sempre ao meu lado, cobraram a defesa, sugeriram e me agradaram nas horas mais difíceis;

à CAPES pela bolsa de mestrado, a Eucatex SIA e ao IPEVS pelo apoio logístico dado à pesquisa. 


\section{SUMÁRIO}

\section{Página}

LISTA DE FIGURAS.................................................................................. viii

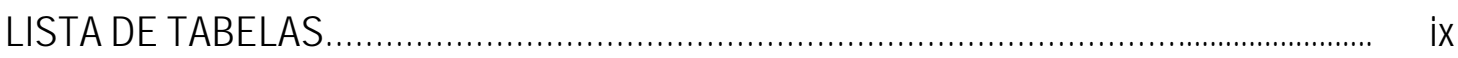

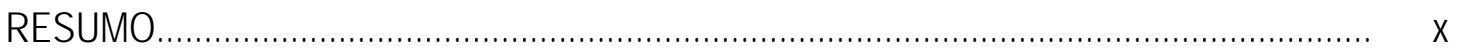

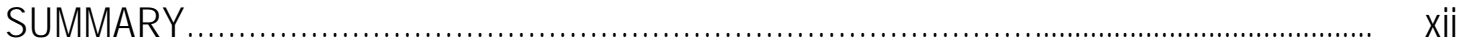

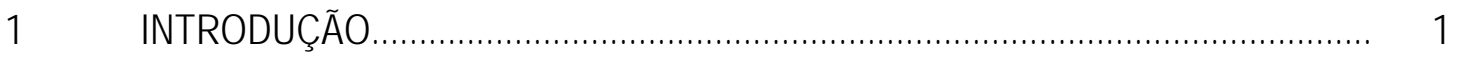

2 REVISÃO DE LITERATURA..................................................................... 4

2.1 Inventários de mamíferos em Floresta Atlântica...................................................... 4

2.2 Plantios de Eucalyptus spp como habitat para mamíferos não-voadores no Brasil 6

2.3 A fragmentação e o uso de habitat por mamíferos não-voadores........................ 7

3 MATERIAL E MÉTODOS............................................................................ 9

$3.1 \quad$ Área de estudo

3.2 Métodos de levantamentos............................................................................. 12

3.2.1 Captura de pequenos mamíferos.................................................................. 12

3.2.2 Registro de mamíferos de médio e grande portes............................................... 15

3.3 Variáveis ambientais amostradas...................................................................... 17

3.4 Análise dos resultados.......................................................................... 18

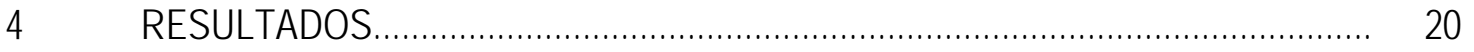

4.1 Espécies inventariadas na Fazenda João XXIII................................................ 20

4.2 Abundância relativa da comunidade de pequenos mamíferos................................. 44

4.3 Comparação entre os métodos utilizados na captura de pequenos mamíferos...... 45

4.4 A influência do período na captura de pequenos mamíferos................................. 47

4.5 Riqueza, diversidade e abundância relativa das espécies de pequenos 
mamíferos em floresta contínua, plantios de $E$. saligna e fragmentos.................. 48

4.6 Relação entre estrutura de habitat e a ocorrência de pequenos mamíferos em floresta contínua, fragmentos e plantios de E. saligna na Fazenda João XXIII..... 52

4.7 Recaptura de pequenos mamíferos em floresta secundária, plantios de E. saligna e fragmentos....................................................................... 55

4.8 O uso do ambiente por mamíferos de médio e grande portes............................. 56

$5 \quad$ DISCUSSÃO

$5.1 \quad$ Captura de pequenos mamíferos em floresta tropical.......................................... 58

5.2 Utilização das plantações de eucalipto como habitat por pequenos mamíferos..... 60

5.3 Mamíferos de médio e grande portes e o uso do habitat.................................... 63

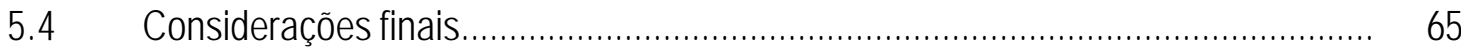

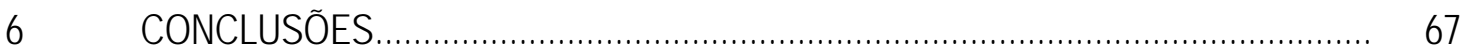

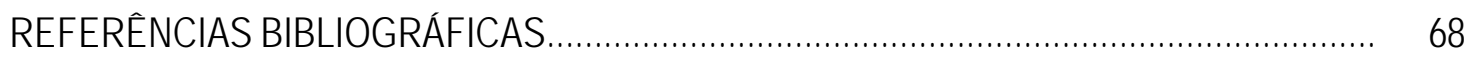




\section{LISTA DE FIGURAS}

1 Localização da área de estudo no Estado de São Paulo.................................. 11

2 Visualização da área de estudo e seu entorno...................................................... 11

3 Pluviosidade mensal em milímetros no período de agosto de 1998 a julho de 1999

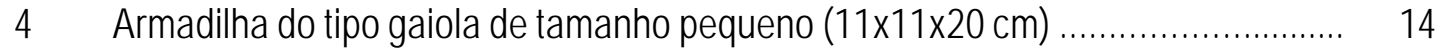

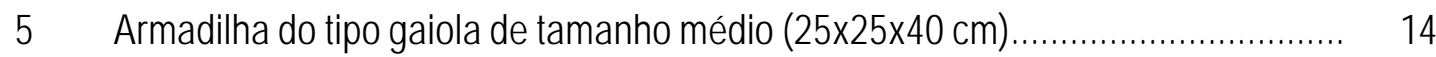

6 Armadilha de intercepção seguido de queda (pitfall) com baldes de $30 \mathrm{~cm}$ de profundidade e $28 \mathrm{~cm}$ de diâmetro com $1 \mathrm{~m}$ de tela guia..................................... 15

7 Mapa da Fazenda João XXIII com a localização das trilhas utilizadas para amostragem de pequenos mamíferos e de pegadas de mamíferos de médio e grande portes.......

8 Capturas totais e abundância relativa (\%) das espécies de pequenos mamíferos, no período de setembro de 1998 à agosto de 1999, na Fazenda João XXIII

$9 \quad$ Número de capturas totais e utilizando pitfall, para pequenos mamíferos na Fazenda João XXIII

10 Capturas totais e com a utilização de pitfall durante o período de setembro de 1998 a julho de 1999, na Fazenda João XXIII, Município de Pilar do Sul.

11 Curva de espécies capturadas durante os nove meses de coleta com a utilização de gaiolas e pitfall......

12 Ordenação dos ambientes e das espécies nos dois primeiros eixos resultantes da Análise de Correspondência.

13 Abundância relativa das espécies de pequenos mamíferos em floresta contínua, fragmentos e plantios de $E$. saligna. 


\section{LISTA DE TABELAS}

1 Mamíferos não-voadores na Fazenda João XXIII no período de julho de 1998 à

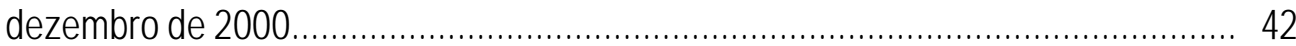

2 A eficiência de armadilhas do tipo gaiola e pitfall, testado com o uso de Quiquadrado, na captura das 7 espécies de pequenos mamíferos mais abundantes na Fazenda João XXIII ......

3 Riqueza e abundância relativa de marsupiais e roedores nos ambientes estudados na Fazenda João XXIII.................................................................... 49

$4 \quad$ Valores médios de heterogeneidade ambiental nos três ambientes estudados..... 54

5 Correlação entre as características do ambiente e a ocorrência de pequenos mamíferos............................................................................................. 54

6 Capturas totais, primeiras capturas e índice de recaptura de pequenos mamíferos em floresta contínua....................................................................... 55

7 Capturas totais, primeiras capturas e índice de recaptura de pequenos mamíferos em fragmento........................................................................... 56

8 Capturas totais, primeiras capturas e índice de recaptura de pequenos mamíferos em plantios de E saligna...................................................................... 56 


\title{
RIQUEZA E DIVERSIDADE DE MAMÍFEROS-NÃO-VOADORES EM UM MOSAICO FORMADO POR PLANTIOS DE EUCALYPTUS SALIGNA E REMANESCENTES DE FLORESTA ATLÂNTICA NO MUNICÍPIO DE PILAR DO SUL, SP
}

\author{
Autora: Cláudia Regina da Silva \\ Orientador: Prof. Dr. Álvaro Fernando de Almeida
}

\section{RESUMO}

A Floresta Atlântica apresenta alta diversidade de mamíferos com muitas espécies endêmicas. No entanto, poucos estudos enfocam a distribuição, os padrões ecológicos e a utilização por estes animais, de ambientes alterados por ação antrópica em remanescentes de Floresta Atlântica. O Estado de São Paulo apresenta uma extensa área de reflorestamento com Eucalyptus spp mas nenhum estudo sobre a exploração destes ambientes pelas espécies de mamíferos silvestres havia sido realizado neste Estado. Este estudo desenvolvido em um mosaico formado por remanescentes de Floresta Atlântica em contato com plantios de $E$. saligna teve o objetivo de verificar a riqueza, a composição específica e a diversidade das espécies de mamíferos existentes na área, com especial atenção para o uso dos plantios de $E$. saligna pelos animais estudados. Para a coleta de pequenos-mamíferos utilizou-se armadilhas do tipo gaiola e pitfalls. Para o registro do uso dos plantios de E. saligna por mamíferos de médio e grande portes utilizou-se, durante 36 noites, parcelas de areia. Ambos os métodos foram utilizados nos três ambientes que compõem a paisagem local: floresta contínua, fragmentos circundados pelos plantios de E. saligna e os próprios plantios. Na área de estudo foram registradas 47 espécies e dentre estas, espécies ameaçadas de extinção como Puma concolor e Myrmecophaga trydactyla, espécies raras em levantamentos como Brucepattersonius igniventris e Monodelphis 
brevicaudata e uma nova ocorrência para o Estado de São Paulo: Blarynomys breviceps. Durante nove meses de coleta de pequenos mamíferos com um esforço amostral de 7290 dias-armadilhas e 3888 dias-pitfall, foram realizadas 537 capturas de pequenos mamíferos. As espécies com maior abundância relativa em ambientes de foresta nativa foram: Philander frenata, Oryzomys russatus e Marmosops incanus. Nos plantios de E. saligna, Oligoryzomys nigripes foi responsável por $55 \%$ da abundância relativa de pequenos mamíferos. A diversidade de espécies foi semelhante nos dois ambientes de floresta nativa e menor nas plantios de E. saligna. Dentre os mamíferos de médio e grande portes, felinos utilizaram em maior proporção os plantios de $E$. saligna estudados. Os registros mais frequentes nas parcelas de areia foram de Mazama sp seguido por Tapirus terrestris. Estes resultados mais o atual contexto de fragmentação e degradação da Floresta Atlântica demonstram que os plantios de $E$. saligna na Fazenda João XXIII, se devidamente manejados, podem ser localmente importantes na conservação de mamíferos não-voadores, visto que este ambiente é utilizado como habitat ou mesmo para deslocamento por muitas espécies verificadas na área. 
RICHNESS AND DIVERSITY OF NONVOLANT MAMMALS IN MOSAIC OF EUCALYPTUS SALIGNA PLANTATIONS AND ATLANTIC FOREST REMNANTS ON PILAR DO SUL, SP

Author: Cláudia Regina da Silva

Adviser: Prof. Dr. Álvaro Fernando de Almeida

\section{SUMMARY}

The Atlantic Forest presents high endemism, diversity and richness. However, with the continuous devastation it became one of the most endangered ecosystems of the world. In spite of the high diversity of mammals with many endemic species, the distribution, the ecological patterns and the use of altered environments are practically ignored. The State of São Paulo presents an extensive reforestation area with Eucalyptus spp. However, any studies about the species of mammals that explore this environment were realized. This study was developed in Fazenda João XXIII, located in Pilar do Sul City - São Paulo State, where the landscape is characterized by a mosaic of fragments surrounded by Eucalyptus saligna plantations and an extensive area of Atlantic Forest continuous to Parque Estadual Carlos Botelho. The goal of this study was to survey the species of mammals and to verify its richness and diversity in the forest remainders and in the $E$. saligna plantations. During nine months of study with a sampling effort of 7290 trap-day and 3888 pitfall-day, 537 captures of small mammals were accomplished. Sand plots were used during 36 nights, to record the use of $E$. saligna plantations by medium and large size mammals. All methods were used in the three environments that are present the local landscape: continuous forest, fragments surrounded by E. saligna and E. saligna plantations. In 
the studied area, 47 mammal species were registered. Among these, species listed as endangered such as Puma concolor and Myrmecophaga tetradactyla; rare species in inventories such as Brucepattersonius igniventris and Monodelphis brevicaudata; and the Blarynomys breviceps, a new occurrence for the State of São Paulo. The higher relative abundance of small mammals verified at continuous forest, were the marsupials Philander frenata, and M. incanus, and the rodent Oryzomys russatus. The same species were also found as more abundant in the fragments surrounded by eucalyptus plantations. And in the eucalyptus plantations, Oligoryzomys nigripes was responsible for $55 \%$ of the relative abundance of small mammals. The diversity of species was similar in both sampled areas of native forest and lower in the eucalyptus plantations. Among the medium and large size mammals, L. pardalis and Leopardus sp used the eucalyptus plantation in larger proportion than other environments. The species more frequently registered in the plots of sand was Tapirus terrestris. In the present context of fragmentation and degradation of the Atlantic Forest, the eucalyptus plantations in Fazenda João XXIII represent an important role in the local conservation of the species of mammals, because most of these species use this environment as habitat or even for displacement. 


\section{INTRODUÇÃO}

A Floresta Atlântica é referenciada como um dos ecossistemas mais ameaçados do mundo, restando aproximadamente $7 \%$ de sua cobertura original (Fonseca 1985 e Fund. SOS Mata Atlântica, 1995). Esta formação florestal compreendia uma faixa litorânea do Rio Grande do Sul ao Rio Grande do Norte, ocupando cerca de $12 \%$ do território brasileiro (Brown e Brown, 1992). A redução desta cobertura florestal se iniciou com a chegada dos primeiros europeus em 1500. Começando com a extração do pau-brasil, seguida de exploração de madeira e diversos produtos florestais, culminando com intensa ocupação humana. Hoje vivem aproximadamente 80 milhões de pessoas nas áreas anteriormente cobertas pela exuberante Floresta Atlântica (Miranda e Mattos, 1992).

Segundo Mittermeier et al. (1982), menos de 1 \% dos fragmentos de Floresta Atlântica se encontram em estado não perturbado e maioria destes são pequenos e isolados, atualmente as maiores extensões estão localizadas em Unidades de Conservação na região Sudeste do Brasil, nos Estados de São Paulo e Rio de Janeiro. Muitos destes remanescentes, se encontram em áreas íngremes de difícil acesso e matas ciliares. No entanto, a degradação destes ambientes é contínua, os remanescentes são regularmente explorados pela caça predatória e extração ilegal de produtos florestais.

A paisagem que envolve a maioria destes remanescentes no Estado de São Paulo é um grande mosaico formado por fragmentos de floresta secundária e áreas cultivadas, o que resultou em redução de habitats e limitação da área de uso da fauna silvestre. Taylor et al. (1993), enfatizaram a necessidade de uma conectividade entre as diferentes formações vegetais existentes em uma paisagem em mosaico. A vegetação que circunda o fragmento, favorecendo ou impedindo esta conectividade, é de extrema importância para a sobrevivência de uma metapopulação em paisagens fragmentadas (Metzger and Decamps, 1997). 
No Brasil os plantios de Eucalyptus spp se iniciaram de forma experimental no ano de 1909 (Sampaio, 1961), concentrando-se principalmente nas regiões Sul e Sudeste, que nessa época já apresentavam pouca cobertura florestal natural (Lima, 1996). No ano de 1965 com a criação do programa federal de incentivos fiscais, iniciaram-se os grandes plantios, extensas áreas de Floresta Atlântica foram substituídas por reflorestamentos com espécies exóticas. É comum que estes plantios estejam em contato direto com remanescentes florestais ou envolvendo fragmentos. A cobertura total de reflorestamentos com Eucalyptus spp no Estado de São Paulo em 1992 era de 812.523,32 ha, o equivalente a 3,27 \% de sua área (Governo do Estado de São Paulo, 1993). Mesmo com esta extensa área, nenhum estudo enfoca o uso destes reflorestamentos por espécies de mamíferos no Estado de São Paulo.

Miranda \& Mattos (1992) ressaltam que devido a alta taxa de endemismo e à atual situação de degradação, a Floresta Atlântica tem sido considerada uma das três áreas prioritárias para a conservação no mundo. Na Floresta Atlântica ocorrem cerca de 130 espécies de mamíferos de um total de 471 ocorrentes no território brasileiro. Dessas espécies, 51 são endêmicas deste ecossistema (Vieira, 1955; Cabrera, 1957; Fonseca \& Kierulf, 1989; Stallings, 1989). Segundo Fonseca et al. (1996), das 77 espécies de roedores e das 24 espécies de marsupiais da Floresta Atlântica, 45 \% e 37,5 \% respectivamente, são endêmicas neste bioma. Apesar da alta diversidade de mamíferos na Floresta Atlântica, sustentada por roedores, marsupiais e quirópteros, são poucas as informações ecológicas sobre as espécies.

No Brasil apenas quatro trabalhos, realizados no Estado de Minas Gerais, estudaram 0 uso de plantios de E. saligna por mamíferos silvestres (Dietz et al., 1979; Stallings, 1989 e 1991; Fonseca, 1997). Os três últimos trabalhos, concluíram que os plantios de E. saligna com subbosque desenvolvido servem como expansão de habitat para algumas espécies de pequenos mamíferos. Para a implantação de alternativas de manejo que favoreçam as espécies de mamíferos não voadores em remanescentes de Floresta Atlântica e mesmo em cultivos de espécies florestais exóticas, é necessário o conhecimento das espécies que utilizam estes ambientes. 
Neste contexto de profunda alteração dos ambientes naturais e do grande número de espécies de mamíferos não-voadores ameaçados por estas alterações, é que o presente trabalho tem como objetivo:

a) inventariar as espécies de mamíferos não voadores em uma paisagem em mosaico, formada por remanescentes de Floresta Atlântica e plantios de E. saligna;

b) comparar 0 uso de armadilhas do tipo gaiola e pitfall na captura de pequenos mamíferos;

c) elucidar riqueza, diversidade e abundância relativa de pequenos mamíferos em floresta nativa e plantios de E. saligna;

d) verificar o uso dos plantios de E. saligna, como habitat ou área de deslocamento, por mamíferos não voadores. 


\section{REVISÃO DE LITERATURA}

\subsection{Inventário de mamíferos em Floresta Atlântica.}

Segundo Voss e Emmons (1996), informações referentes à magnitude e distribuição geográfica de mamíferos nas florestas tropicais, são importantes na avaliação de prioridades para pesquisa e conservação na América do Sul e Central.

Os principais trabalhos sobre diversidade em florestas neotropicais tem se limitado sobretudo a árvores, borboletas, anfíbios, répteis e aves (Prance, 1984 citado por Voss \& Emmons, 1996; Beccaloni \& Gaston, 1995; Silva \& Sites, 1995).

A fauna de mamíferos das florestas tropicais apresenta 170 gêneros de 9 ordens e 35 famílias (com exceção de espécies domesticadas, sirênios e cetáceos) (Voss \& Emmons, 1996). A Floresta Atlântica tem alta diversidade de flora e fauna, com muitas espécies endêmicas de árvores (Mori et al., 1981 citado por Stallings, 1989), répteis (Muller, 1973), e aves (Haffer, 1974), os marsupiais Didelphídeos e roedores perfazem 78\% de espécies e 82\% de gêneros endêmicos neste bioma (Honacki et al., 1982).

Entretanto inventários são escassos e a fauna de mamíferos é pouco conhecida. Geralmente os levantamentos contemplam taxons definidos, sendo pequenos roedores e marsupiais os grupos mais estudados. Mesmo assim, dentro desses dois grupos são encontradas grandes lacunas sobre a distribuição de várias espécies. Stallings (1989) ressalta que são necessários inventários completos para a Floresta Atlântica, o que resolveria muitos dos problemas taxonômicos.

Os mamíferos neotropicais variam de poucos gramas a centenas de quilogramas, as espécies diferem na dieta, habitat, locomoção e comportamento social. Métodos e equipamentos destinados a coletar ou observar uma família ou ordem, dificilmente são efetivos para outro taxon (Voss e Emmons, 1996), sendo um dos motivos pelos quais poucos inventários são completos ou mesmo realizados. 
Um dos primeiros autores a estudar a fauna de mamíferos em Floresta Atlântica foi Davis $(1945,1947)$. Nestes dois trabalhos 0 autor apresenta resultados obtdos em floresta primária e secundária no município de Teresópolis, Estado do Rio de Janeiro, contemplando aspectos ecológicos sobre as espécies de pequenos mamíferos capturados. No entanto, em nenhum desses estudos o autor realizou inventário completo do grupo, enfocou principalmente a riqueza de pequenos mamíferos e aspectos ecológicos dos mesmos.

Ávila-Pires \& Gouveia (1977) apresentam uma listagem de 62 espécies de mamíferos, incluindo 13 espécies de morcegos no Parque Nacional de Itatiaia. Stallings et al. (1991) registraram 58 espécies para o Parque Estadual do Vale do Rio Doce, incluindo 14 espécies de morcegos.

No Estado de São Paulo, com exceção do trabalho de Von Pelzeln, que publicou em 1883 as coletas de Johan Natterer para a Fazenda Ipanema, resultando em 62 espécies, incluindo 13 espécies de morcegos (citado por Vivo \& Gregorim ${ }^{1}$ ), todos os outros inventários de espécies são recentes.

Hershkovitz (1998) apresenta o resultado de quatro levantamentos de mamíferos realizados entre 1986 e 1992, em Floresta Atlântica. As localidades estudadas foram Parque Nacional de Caparaó no Estado de Minas Gerais (dados obtidos de Ruschi, 1978 e Blair, 1989), Centro de Primatas do Rio de Janeiro e Parque Estadual de Teresópolis, Estado do Rio de Janeiro. Junto a esses dados o autor apresentou uma listagem de espécies do Parque Estadual Turístico do Alto Ribeira (PETAR), no Estado de São Paulo. Nesse trabalho são reunidos os dados de pequenos mamíferos para as quatro localidades, resultando em 31 espécies e a descrição de um novo gênero Brucepattersonius, coletado no PETAR (Iporanga).

Vivo \& Gregorim (no prelo) apresentaram lista de espécies de mamíferos para 0 Parque Estadual de Intervales, um dos remanescentes de Floresta Atlântica mais preservado do Estado. Os autores registraram, 9 espécies de marsupiais, 23 de roedores e 30 espécies de mamíferos de médio e grande portes.

\footnotetext{
${ }^{1}$ VIVO M. \& GREGORIN, A. The Mammal Fauna of the Intervales State Park, Atlantic Forest of Southeastern Brazil
} 


\subsection{Plantios de Eucalyptus spp como habitat para mamíferos não-voadores no Brasil.}

Apesar das extensas áreas plantadas com Eucalyptus spp no Brasil e na maioria das situações estas plantações estarem contíguas a remanescentes florestais, o estudo sobre as espécies de mamíferos nestes ambientes são incipientes. Dietz et al. (1979), desenvolveram o primeiro trabalho sobre pequenos mamíferos em áreas de reflorestamento no município de Viçosa em Minas Gerais. Comparando quatro ambientes, sendo dois deles em fragmentos de Floresta Atlântica, um plantio deEucalyptus saligna e um plantio deAraucaria angustifolia, os autores encontraram maior número de espécies em áreas naturais e menor, na área de plantio de E. saligna.

Os três outros trabalhos enfocando mamíferos em plantações de eucaliptos foram realizados próximos ao Parque Estadual do Vale do Rio Doce em Minas Gerais. O primeiro trabalho no referido Parque foi realizado por Stallings (1989), que comparou a riqueza de espécies de pequenos mamíferos em floresta nativa, plantios deEucaliptus saligna e campos abertos, concluindo que a floresta $E$. saligna com espécies nativas no sub-bosque auxilia na manutenção da diversidade de espécies de pequenos mamíferos, em uma paisagem fortemente alterada por atividades humanas como a área estudada por ele.

Stallings (1991) comparou em dois talhões de $E$. saligna, um homogêneo e o outro com sub-bosque de espécies nativas, a riqueza de espécies de mamíferos não-voadores e algumas espécies de aves. Esse autor encontrou uma maior riqueza de espécies de mamíferos no talhão com sub-bosque e ausência de primatas nas duas áreas, argumentou que essas plantações com espécies nativas no sub-bosque podem providenciar habitat suficiente para suportar algumas espécies que desapareceram rapidamente dos fragmentos de Floresta Atlântica, no Vale do Rio Doce.

Fonseca (1997), estudando roedores em um fragmento de 60 ha e em um talhão de eucaliptos, distantes aproximadamente $20 \mathrm{Km}$ do Parque Estadual do Vale do Rio Doce, encontrou semelhanças na composição, riqueza e diversidade de espécies. A autora ressaltou que o reflorestamento com eucaliptos, como matriz de habitat para pequenos mamíferos, pode representar um importante papel na conservação da fauna regional visto a situação de isolamento, entre plantações de eucaliptos, do fragmento estudado. 
2.3 A fragmentação e o uso de habitat por mamíferos não-voadores.

August (1983, 1984); Fonseca (1989), Mares \& Ernest (1995) estudaram populações de marsupiais e roedores em pequenos fragmentos na Floresta Atlântica e encontraram uma redução da diversidade de espécies. Malcolm, (1988) estudou quantitativamente os efeitos do tamanho e do isolamento dos fragmentos sobre a comunidade de mamíferos na Floresta Amazônica. Malcolm (1991) relata que a fragmentação na Amazônia Central tem alterado sistematicamente a abundância, a biomassa e a diversidade de pequenos mamíferos, ocorrendo redução da diversidade e incremento na abundância de espécies terrestres na borda dos fragmentos. Malcolm (1995) encontrou maior abundância, biomassa e riqueza de espécies em fragmentos com 8 anos de idade do que em floresta contínua.

Fonseca (1989) estudou a riqueza e a diversidade de pequenos mamíferos em fragmentos de Floresta Atlântica de diferentes tamanhos. $O$ autor encontrou riqueza e diversidade maiores em fragmentos grandes de vegetação secundária, concluindo que 0 tamanho do fragmento é o principal fator para a diminuição desses índices. Fonseca (1991) observou que entre pequenos mamíferos ocorre decréscimo na diversidade de espécies proporcionalmente ao tamanho e isolamento da área, verificando aumento nas populações de espécies generalistas, como as do gênero Didelphis.

Chiarello (1998); estudando mamíferos maiores que $1 \mathrm{~kg}$ em fragmentos grandes (>20.000 ha), médios (2.000 ha) e pequenos (200 ha) no norte do Espírito Santo, encontrou riqueza de espécies alta nos fragmentos grandes e média a baixa nos fragmentos pequenos. Nos fragmentos médios foi verificado um predomínio de frugívoros de copa e predomínio de herbívoros nos pequenos fragmentos.

Os primeiros trabalhos enfocando a seleção de habitat foram com avifauna (MacArthur et al., 1966, James, 1971, Price, 1978, Rotenberry \& Wiens, 1980). Nestes trabalhos o principal enfoque foi a importância do habitat na estruturação da comunidade. MacArthur e MacArthur (1961) e Rosenweig e Winakur (1969) estudando comunidades de aves, ressaltam que a riqueza de espécies está relacionada à complexidade estrutural dos habitats. Dueser \& Shugart (1978) realizaram o primeiro estudo quantitativo de microhabitat com pequenos mamíferos.

Os estudos sobre o uso de habitat por mamíferos não-voadores no Brasil se iniciaram no final da década de 1970 e início de 1980 (Alho, 1981; Alho \& Pereira, 1985; Alho et al., 1986; Dietz, 1983; Fonseca \& Redford, 1984; Karimi et al, 1976; Mello, 1980; Mello \& 
Moojen, 1979; Nitikan \& Mares, 1987; Streilein, 1982). A maioria desses estudos foi realizada em áreas de cerrado, principalmente no Brasil Central.

Malcolm (1995), correlacionando diferenças no habitat através de medidas da distribuição vertical da folhagem com características da fauna de pequenos mamíferos, encontrou importância das clareiras na estruturação dessas comunidades, segundo o autor ocorre um incremento na densidade populacional em ambientes contendo clareiras.

Estudos sobre uso de habitat na Floresta Atlântica encontraram uma relação positiva entre a diversidade de pequenos mamíferos e a heterogeneidade de habitats (Fonseca \& Redford, 1984; Fonseca, 1989; Stallings, 1989; Stallings, 1991; Fonseca \& Robinson, 1990, Gentile \& Fernandez, 1999). Paglia et al. (1995) no entanto, estudando um fragmento fortemente alterado na região de Viçosa, Minas Gerais, encontrou uma relação negativa entre a diversidade de pequenos mamíferos e a heterogeneidade de habitat.

O estudo de matriz de habitat é relativamente novo em florestas tropicais. Medellín \& Equihua (1998), compararam a riqueza de espécies de mamíferos entre plantações abandonadas e remanescentes de floresta nativa no México. Seus resultados demonstram que 0 uso da terra para monoculturas não perenes pode ser positivo para muitas espécies de mamíferos se for efetuado em mosaico com áreas florestais, sendo uma boa alternativa para conservacionistas e fazendeiros. 


\section{MATERIAL E MÉTODOS}

\section{1 Área de estudo}

O presente estudo foi desenvolvido na Fazenda João XXIII, de propriedade da Eucatex S/A Indústria e Comércio localizada no Município de Pilar do Sul no Estado de São Paulo (Figura 1). A área possui 2.250 ha de plantios de Eucalyptus saligna intercalados com remanescentes de Floresta Atlântica. A Fazenda está localizada na maior porção de Floresta Atlântica do Estado de São Paulo, dentro da Área de Proteção Ambiental da Serra de Tapiraí e nos arredores do Parque Estadual de Carlos Botelho (Figura 2).

Os remanescentes florestais estudados sofreram interferências até o final dos anos 60 , quando as árvores de maior porte eram aproveitadas para a produção de carvão. A área da fazenda, hoje ocupada com plantios de E. saligna, teve até o final dos anos 70 uso agrícola, a partir do início da década de 80 as atividades na Fazenda restringiram-se ao plantio e extração de E. saligna.

Os solos da região são classificados por Pfeifer et al. (1986), como Latossolos Vermelhoamarelo, reconhecidos como argilosos, profundos, pouco ácidos, coesos e de coloração vermelha-amarelada relativamente homogênea. Segundo os autores ocorrem em altitudes superiores a $600 \mathrm{~m}$, preferencialmente entre $700 \mathrm{~m}$ e $800 \mathrm{~m}$. As altitudes nos ambientes estudados variam de $750 \mathrm{~m}$ à $980 \mathrm{~m}$.

A temperatura média do mês mais quente para o município de Pilar do Sul é de $22,4^{\circ} \mathrm{C}$ e do mês mais frio é de $15,4^{\circ} \mathrm{C}$. A precipitação média anual é de $1683,2 \mathrm{~mm}$, a menor precipitação mensal durante os anos de 1998 e 1999 foi de $37 \mathrm{~mm}$ e a maior de $380 \mathrm{~mm}$. Através da figura 3 percebe-se que os meses de outubro, novembro e dezembro, durante o período deste estudo, tiveram uma pluviosidade atípica apresentando uma pluviosidade mensal maior de $300 \mathrm{~mm}$, 
enquanto as médias dos últimos 10 anos para estes meses foram entre 100 e $150 \mathrm{~mm}$. Os outros meses deste estudo acompanharam a média verificada nos últimos 10 anos².

Os dados acima permitem definir o clima como Cfa ou seja, subtropical úmido, segundo Köeppen.

A Fazenda João XXIII pertence à região fitoecológica ou fitossociológica da Floresta Ombrófila ou Floresta Pluvial, também chamada de Floresta Latifoliada Perenifólia ou Floresta Atlântica (Leitão Filho, 1982). Os ambientes da formação Montana da Floresta Ombrófila ocupam os altos dos planaltos e serras nas faixas de altitude de 500 a 1500 m (Veloso, 1991).

Segundo estudos botânicos ${ }^{3}$ realizados nos remanescentes da Fazenda João XXIII, a vegetação encontra-se em transição do estágio sucessional secundário inicial para o secundário tardio. Devido a localização da área no alto da Serra de Paranapiacaba, é possível encontrar um grande número de espécies representantes de Floresta Estacional Semidecidual como: Duguetia lanceolata, Aspidosperma polyneuron, Croton floribundus, Pera glabrata, Cedrela fissilis, Ficus guaranitica, Pisonia ambigua, Matayba elaegnoides e Chrysophyllum gonocarpum. No entanto, os representantes de Floresta Atlântica como: Syagrus pseudococos, Tapirira guianensis, Pseudobombax grandiflorum, Schizolobium parahyba, Alchornea glandulosa, Callophyllum brasiliensis, Nectandra megapotamica, Miconia cinnamomifolia, Tibouchinia granulosa, Attalea dubia, Euterpe edulis, Geonoa gamiova são em maior número. Estes remanescentes caracterizam-se por uma vegetação secundária em regeneração, sendo favorecida pela vizinhança que consiste de grandes extensões de Floresta Atlântica. Nos plantios de E. saligna 0 sub-bosque é formado principalmente por Piperaceas como: Piper aduncun e Piper amalago. Algumas porções são dominadas por Pteridófitas no estrato herbáceo.

\footnotetext{
${ }^{2}$ Dados obtidos na Secretaria de Agricultura do Município de Pilar do Sul.

${ }^{3}$ Relatório Interno da Empresa Eucatex S/A
} 


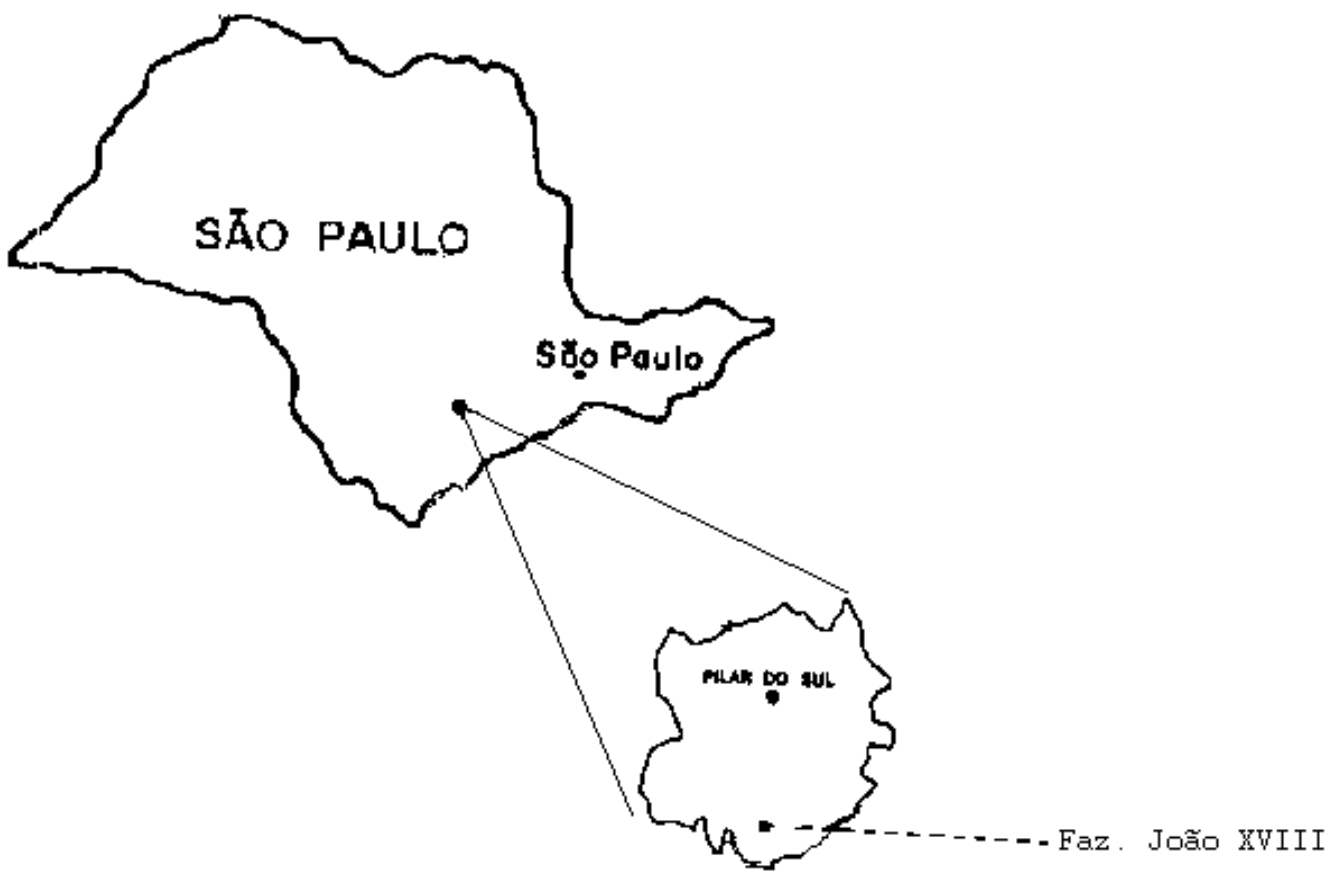

Figura 1 - Localização da área de estudo no Estado de São Paulo.

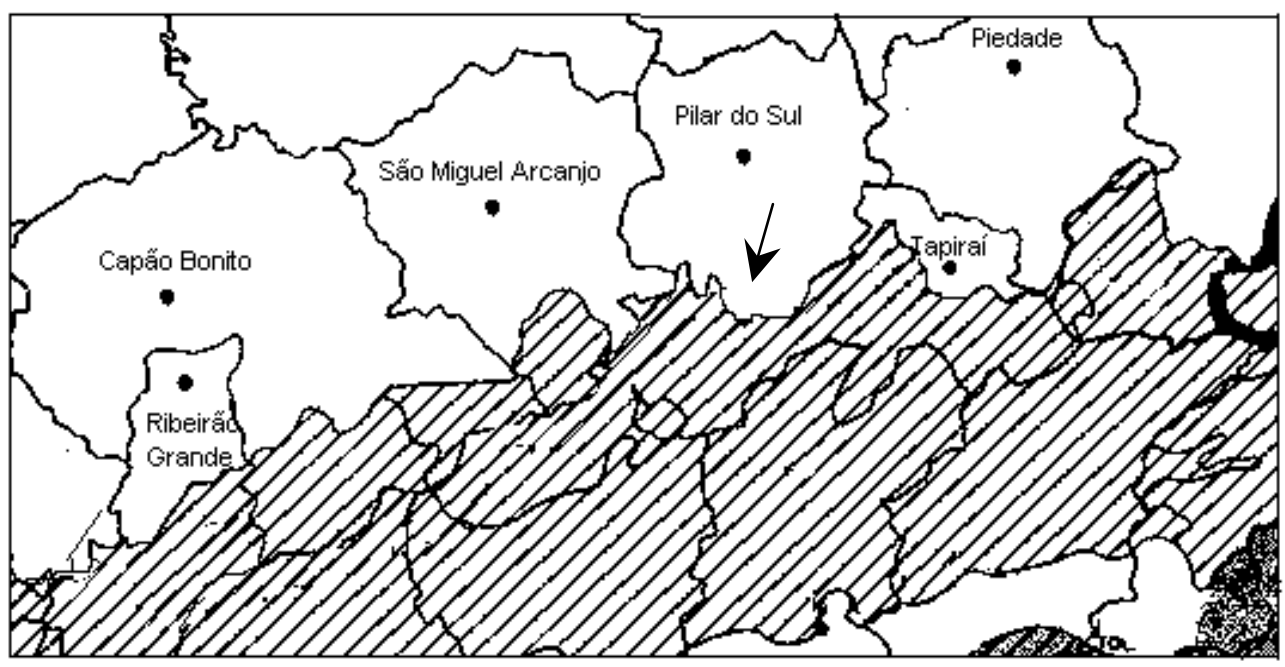

Figura 2 - Visualização da área e seu entorno. As partes toda em preto e riscadas de preto são Unidades de Conservação pertencentes ao Estado de São Paulo. Nelas estão inclusas a APA da Serra de Tapira, o Parque Estadual de Carlos Botelho e o Parque Estadual de Intervales. A flecha aponta para a localização da Fazenda João XXIII. 


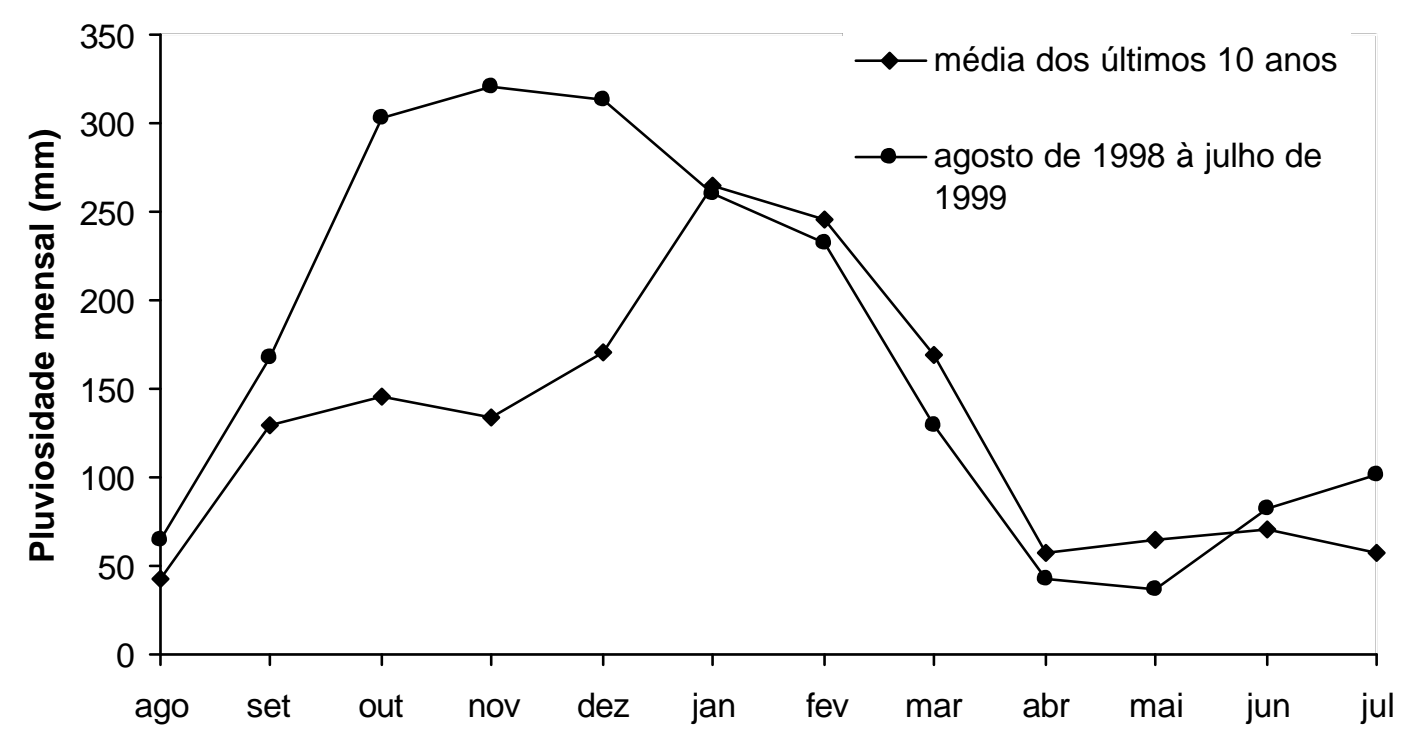

Figura 3 - Pluviosidade mensal em milímetros para o período de agosto de 1998 a julho de 1999.

\subsection{Métodos de levantamentos}

\subsubsection{Captura de Pequenos Mamíferos}

Para a captura de pequenos mamíferos foram utilizados dois métodos: i) captura em armadilhas do tipo gaiola com isca suspensa, nos tamanhos pequeno (Figura 4) e médio (Figura 5); ii) captura em armadilhas de intercepção seguido de queda - pitfall4 (Figura 6). Nestas armadilhas utilizou-se baldes de $30 \mathrm{~cm}$ de profundidade e $28 \mathrm{~cm}$ de diâmetro com $1 \mathrm{~m}$ de tela guia (plástico preto) entre os recipientes e nas suas extremidades.

As amostras foram coletadas em três trilhas por ambiente; floresta contínua, fragmentos circundados por plantios de E. saligna e plantios de E. saligna (Figura 6). Em cada trilha foram distribuídas 15 armadilhas distanciadas por 25 m e três estações de pitfalls, à aproximadamente $120 \mathrm{~m}$.

\footnotetext{
${ }^{4}$ Por se tratar de uma metodologia nova e pouco utilizada no Brasil, ainda não existe um nome padrão em português. Neste trabalho será utilizado apenas pitfall.para se referir a esta metodologia.
} 
Como isca nas armadilhas do tipo gaiola foi utilizada banana com pasta de amendoim. As armadilhas eram vistoriadas pela manhã quando os animais capturados eram identificados, pesados, medidos e marcados com brincos de orelha. Os brincos utilizados neste estudo medem 11 x 2,5 mm, que segundo Le Boulengé-Nguyen \& Le Boulengé (1986), é um bom tamanho para marcação em pequenos mamíferos e apresentam confiabilidade, dispensando o corte de falanges.

Os animais não identificados em campo foram levados ao Museu de Zoologia da Universidade de São Paulo, para identificação segura. Todos os animais coletados neste trabalho foram depositados na coleção deste museu. Os exames de cariótipos de 8 espécies foram realizados pelo Laboratório de Citogenética da Universidade de São Paulo.

Para os animais capturados foram coletadas as seguintes informações: data, número da armadilha, modelo da armadilha (média, pequena ou pitfall), espécie, sexo, informações sobre estágio reprodutivo, presença de parasitas externos e, comportamento de apreensão e soltura. Foram tomadas medidas como: comprimento do corpo, comprimento da cauda, comprimento da orelha, comprimento da pata posterior e peso. 


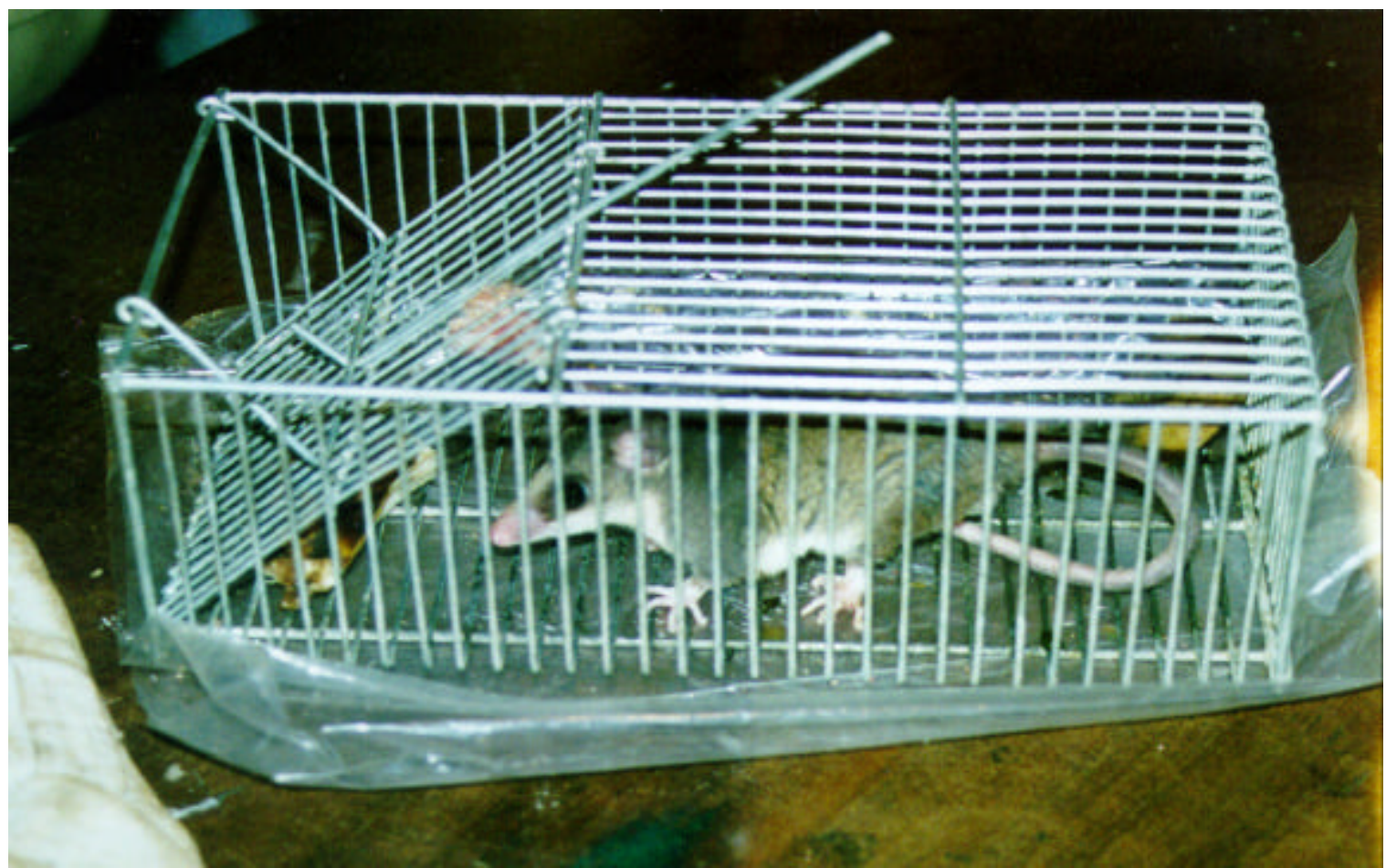

Figura 4 - Armadilha do tipo gaiola de tamanho pequeno $(11 \times 11 \times 20 \mathrm{~cm})$.

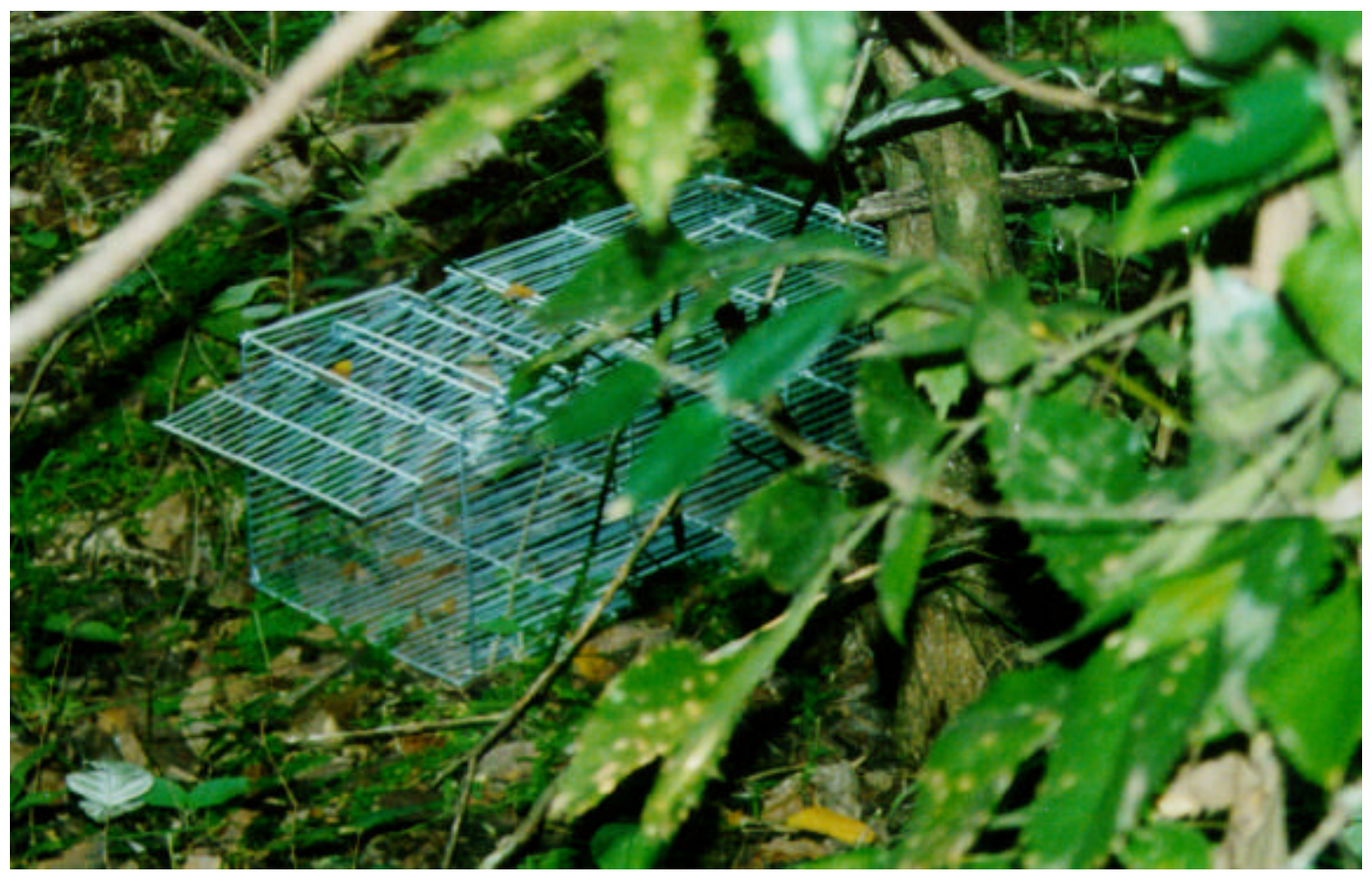

Figura 5 - Armadilha do tipo gaiola de tamanho médio $(25 \times 25 \times 40 \mathrm{~cm})$. 


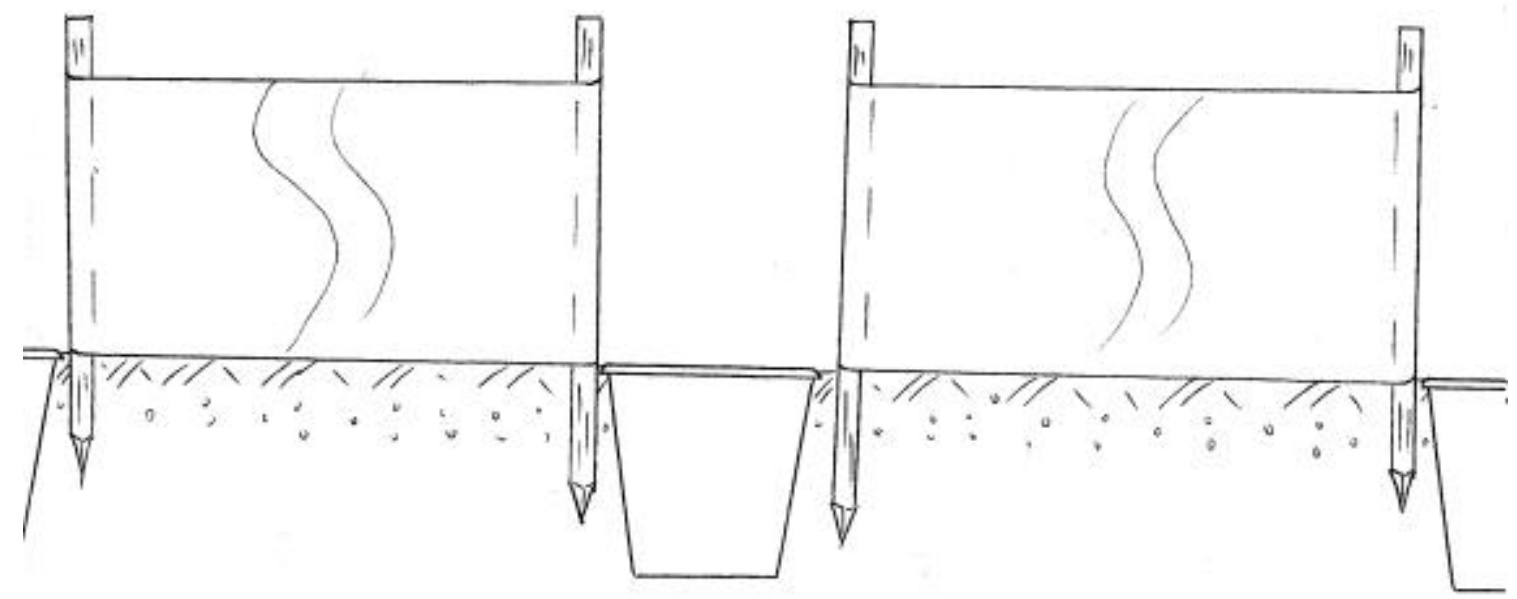

Figura 6 - Armadilha de intercepção seguido de queda pitfall) com baldes de $30 \mathrm{~cm}$ de profundidade e $28 \mathrm{~cm}$ de diâmetro com $1 \mathrm{~m}$ de tela guia.

\subsubsection{Registro de mamíferos de médio e grande portes.}

A ocorrência e o deslocamento das espécies de mamíferos de médio e grande portes foram verificadas através de:

i) levantamento de indícios: durante as incursões pela área foram recolhidos indícios, das espécies de mamíferos de médio e grande portes, encontrados como: fezes, carcaças, ossos e pegadas;

ii) armadilha de pegadas: para a coleta de dados sobre o uso dos plantios de $E$. saligna por mamíferos de médio e grande portes foram montadas duas trilhas em plantios de $E$. saligna e duas em floresta nativa, uma na floresta contínua e outra em um fragmento (Figura 6). Em cada trilha foram montadas 25 parcelas de $50 \times 50 \mathrm{~cm}$ e preenchidas com areia, distanciadas pela trilha, em cada 10 m. Esta metodologia foi baseada em Dirzo e Miranda (1991);

iii) relatos obtidos junto a antigos moradores e funcionários da Fazenda João XXIII. 


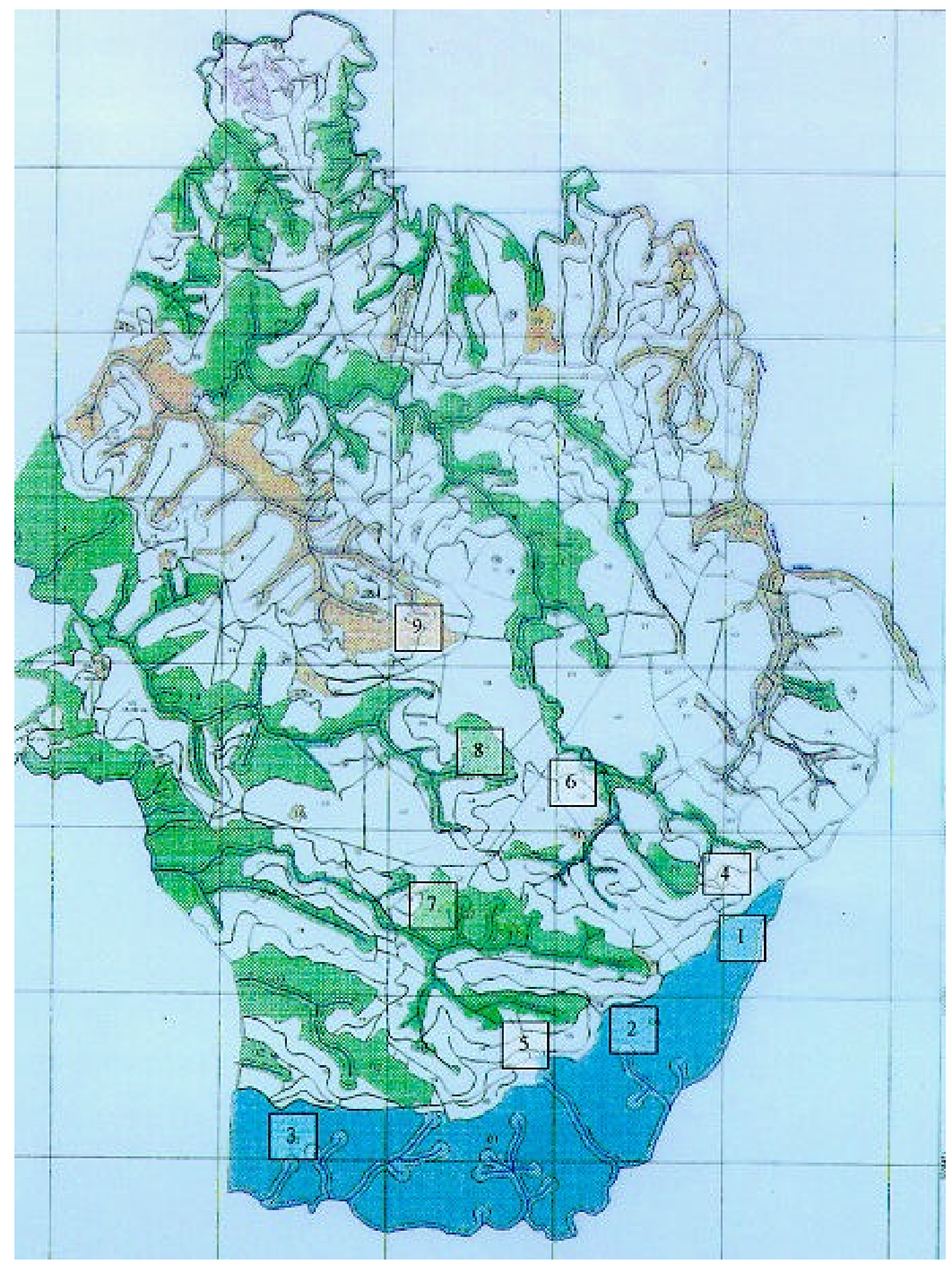

Figura 7 - Mapa da Fazenda João XXIII com a localização das trilhas utilizadas para a amostragem de pequenos mamíferos não-voadores. Os números 1,2 e 3 localizam as trilhas montadas em plantios de E. saligna, 4, 5 e 6 na floresta contínua e 7, 8 e 9 nos fragmentos. 


\subsection{Variáveis ambientais amostradas}

Para documentar a complexidade estrutural dos três ambientes estudados, foram estabelecidas aleatoriamente três parcelas de $10 \times 10 \mathrm{~m}$, em cada trilha utilizada para coleta de pequenos mamíferos, totalizando $2700 \mathrm{~m}^{2}$. Em cada parcela anotou-se: morfo-espécie, altura e CAP de todas as árvores com circunferência à altura do peito (CAP) maior que $15 \mathrm{~cm}$. Em cada parcela estabeleceu-se sub-parcelas de $5 \times 5 \mathrm{~m}$, onde foram amostradas todas as espécies com CAP menor que $15 \mathrm{~cm}$ e altura no mínimo de $1,5 \mathrm{~m}$, totalizando $1350 \mathrm{~m}^{2}$.

Com a utilização de um densitômetro, foram realizadas 16 medidas por parcela da obstrução de luz no dossel e da presença de cobertura herbácea. Nas parcelas estabelecidas nas trilhas em plantios de E. saligna, adaptou-se a metodologia de transectos em losango sugerida por Stumpf (1993), para evitar amostragem seguindo as linhas de plantio. Nos mesmos pontos foi medida a altura da serapilheira com o auxílio de uma régua e a inclinação do terreno com a utilização de um clinômetro, com o qual obteve-se quatro medidas da inclinação do terreno. Para a obtenção destas medidas dividiu-se a parcela em quatro quadrantes e no centro de cada um retirou-se a inclinação do terreno.

Também registrou-se o número de troncos caídos em cada parcela. A presença de espécies oportunistas foram amostradas por parcela seguindo a classificação de "muito", "pouco" ou "ausente". Foram consideradas como espécies oportunistas: bambu, cipó, gramíneas e samambaias. Para esta medida dividiu-se a parcela em quatro partes e verificou-se quanto da parcela era ocupada por estas espécies.

As características da estrutura de habitat coletadas nas 27 parcelas foram:

- altura da serapilheira (cm).

- cobertura do dossel (\%)

- cobertura herbácea $(\%)$

- número de troncos caídos (diâmetro aproximadamente maior que $15 \mathrm{~cm}$ ).

- número de morfoespécies (CAP>15 cm). 
- diâmetro médio das árvores com (CAP >15cm).

- número de morfoespécies no sub-bosque (> 1,5 m de altura)

- diâmetro médio dos arbustos (> 1,5 m de altura)

- média da altura das árvores pertencentes ao dossel, em metros.

- inclinação do terreno em graus.

- espécies oportunistas (samambaias, capins, bambus ou cipós).

\subsection{Análise dos resultados}

O número total de capturas foi calculado pela soma das primeiras capturas com as recapturas subsequentes. 0 esforço amostral foi obtido através da multiplicação do número de armadilhas por dias de coleta, visto que as mesmas se mantiveram abertas durante todo 0 período de coleta. O sucesso de captura foi obtido multiplicando o total de capturas por $100 \mathrm{e}$ dividindo pelo esforço de captura (armadilhas-dia). O mesmo procedimento foi utilizado para estimar o sucesso de captura em armadilha ou pitfall, dividindo-se o número de capturas pelo esforço de captura de cada método. Para obtenção da abundância relativa; o número de capturas de uma determinada espécie foi dividido pelo total de capturas obtidas no ambiente amostrado.

O Teste do Qui-quadrado foi utilizado para verificar se houve diferença na captura das espécies com a utilização dos métodos empregados para pequenos mamíferos, armadilha do tipo gaiola e pitfall. Esta análise foi utilizada apenas nas espécies com mais de dez capturas totais. Esta mesma análise foi utilizada para verificar a diferença entre as capturas nos meses mais secos e meses chuvosos. Para este cálculo comparou-se a diferença mês a mês e após verificada a diferença, realizou-se uma comparação ponderada entre o período mais seco e 0 período mais chuvoso, devido a alta incidência das chuvas nos meses de outubro, novembro e dezembro, estes meses foram analisados juntos com os meses de janeiro, fevereiro e março.

Para a comparação entre a riqueza e a abundância de pequenos mamíferos entre os períodos e os ambientes amostrados, realizou-se uma Análise de Variância Fatorial. Considerouse como riqueza o número total de espécies capturadas em cada ambiente. 
A Análise Fatorial de Correspondência foi realizada buscando-se verificar se houve correlações entre as espécies de pequenos mamíferos e os ambientes estudados. Esta análise reduz o número de variáveis amostradas através de uma tabela de contingência construída a partir dos ambientes estudados e as espécies, representadas pela abundância de cada uma em cada ambiente.

A diversidade de espécies foi calculada através do índice de Shannon-Wiener, um dos índices mais utilizados para caracterização das comunidades silvestres (Fonseca, 1988). A comparação da diversidade entre os três ambientes estudados foi feita através do Teste "t", de acordo com Magurran (1988). Para uma maior confiabilidade nos resultados obtidos utilizou-se também o índice de Simpson, que segundo Magurran (1988) pondera a favor das espécies mais abundantes enquanto é menos sensível à riqueza de espécies.

Para comparar a heterogeneidade entre os ambientes, utilizando-se das variáveis ambientais coletadas em cada trilha onde foram realizadas as amostras de pequenos mamíferos, foi realizada uma comparação entre médias através do Teste "t" de Student, usando graus de liberdade calculados com a aproximação de Satterwaite, de acordo com Snedecor \& Cochram (1980). A correlação de Spearman foi utilizada para testar se houve uma relação, positiva ou negativa, da ocorrência das espécies de pequenos mamíferos em função das variáveis ambientais amostradas em cada ambiente.

O índice de recaptura das espécies para cada ambiente amostrado, foi calculado dividindo-se o número de capturas totais pelo número de primeiras capturas, indivíduos marcados (Stallings, 1988, 1990).

Para verificar se houve diferença entre o uso da floresta natural e os plantios de $E$. saligna pelas espécies de mamíferos de médio e grande portes, das quais se obteve mais de 10 registros, utilizou-se o Teste do Qui-quadrado.

Para todas as análises, as hipóteses nulas foram rejeitadas em valores de $p \leq 0.05$. 


\section{RESULTADOS}

\subsection{Espécies inventariadas na Fazenda João XXIII}

No período de julho de 1998 a julho de 1999, foram realizados nove meses de coletas de pequenos mamíferos e onze meses de coletas de pegadas e indícios de mamíferos de médio e grande porte. Registrou-se na área de estudo 8 ordens e 19 famílias, num total de 47 espécies de mamíferos não voadores (Tabela1).

Abaixo são apresentadas algumas considerações sobre as espécies verificadas na área de estudo:

\section{Ordem Didelphimorphia \\ Família Didelphidae}

\section{Didelphis aurita (Wied-Neuwied, 1826) \\ Gambá-de-orelha-preta}

Esta espécie ocorre em toda a Floresta Atlântica; no Estado de São Paulo a distribuição desta espécie se estende à porção mais interior desta floresta onde pode ser simpátrico com Didelphis albiventris. Esta espécie era classificada como Didelphis marsupialis; Gardner (1993) revisando o gênero aceitou a separação da sub-espécie aurita da Floresta Atlântica, como espécie válida.

D. aurita possui hábitos noturnos e forma ninhos preferencialmente em buracos de árvores (Miles et al., 1981). Segundo Charles-Dominique (1983), a espécie explora o chão da floresta, mas possui hábitos escansórios e é considerada oportunista quanto à alimentação; de 
sua dieta fazem parte principalmente frutos e pequenos animais (Nowak, 1991). Esta espécie pode ser encontrada como dominante em fragmentos de vegetação secundária (Fonseca, 1985 e 1989). Em nenhum dos ambientes estudados na Fazenda João XXIII constatou-se altas densidades desta espécie.

\section{Gracilinanus microtarsus (Wagner, 1842) Marmosa}

O marsupial G. microtarsus é reconhecido como endêmico da Floresta Atlântica, ocorrendo de Minas Gerais ao norte do Rio Grande do Sul (Streilein, 1982 e Hershkovitz, 1992). No entanto foi capturada em área de cerrado no Estado de São Paulo por Talamoni (1996), ressaltando a dificuldade de determinar a distribuição de pequenos mamíferos com o pequeno número de coletas no território brasileiro.

Os marsupiais deste gênero são insetívoros, carnívoros e frugívoros (Hershkovitz, 1992). O mesmo autor afirma que, quando os recursos alimentares são abundantes, 0 acasalamento pode ocorrer durante todo 0 ano; os hábitos alimentares de G. microtarsus são pouco conhecidos. Apresenta cauda longa e pés largos e curtos, sugerindo hábitos arborícolas (Stallings, 1989). Neste estudo foi capturado apenas em pitfall e, das cinco capturas efetuadas, quatro foram em plantios de $E$. saligna.

\section{Marmosops incanus (Lund, 1840)}

\section{Marmosa}

Espécie endêmica da Floresta Atlântica (Streilein, 1982; Emmons \& Feer, 1990), ocorrendo da Bahia ao sul do Estado de São Paulo (Mustrangi \& Patton, 1997). Segundo Stallings (1989), a espécie é insetívora-onívora quanto aos hábitos alimentares. Utiliza-se tanto do chão da floresta quanto da vegetação arbórea (Nowak, 1991); alguns autores classificam-na como de hábitos arborícolas (Freitas et al., 1999). Neste trabalho M. incanus encontra-se entre as quatro espécies mais capturadas, a despeito de todas as armadilhas utilizadas terem sido depositadas no chão da floresta. 
Nessa área era esperada a ocorrência de Marmosops paulensis, espécie muito semelhante a Marmosops incanus podendo ser diferenciada através de caracteres de crânio ou análise de cariótipo. M. paulensis foi registrada em Minas Gerais, São Paulo e Espírito Santo, ocorrendo em florestas montanas acima de 800 m (Mustrangi \& Patton, 1997). Com 25 exemplares coletados e 12 exames de cariótipo M. paulensis não foi registrada na Fazenda João XXIII, durante este trabalho.

\section{Metachirus nudicaudatus (Geoffroy, 1803) Cuíca-quatro-olhos}

Esta espécie ocorre em quase todo território brasileiro, com exceção da região nordeste. Na Floresta Amazônica distribui-se até a Venezuela (Streilein, 1982), e na América Central até a porção meridional da Nicarágua (Nowak, 1991).

M. nudicaudatus possui hábito terrestre (Voss \& Emmons, 1996) e noturno, construindo ninhos em buracos no chão da floresta (Miles et al., 1981). Poucos dados existem sobre os hábitos alimentares desta espécie; Robinson \& Redford (1986) sugerem que esta espécie tem hábitos insetívoro-onívoro e Hunsaker (1977) frugívoro-onívoro. Grelle (1996) encontrou apenas invertebrados em análise de fezes desta espécie coletadas no Parque Estadual do Vale do Rio Doce.

M. nudicaudatus aparece como uma das espécies mais abundantes ros estudos realizados por Bergallo (1994) e Grelle (1996), no entanto Philander frenata, nos dois trabalhos, foi capturada em baixas densidades. Na Fazenda João XXIII apenas dois indivíduos adultos de M. nudicaudatus foram verificados, uma fêmea com filhotes no marsúpio em julho de 1998 , quando foi realizado um levantamento de averiguação, e um macho em abril de 1999 recapturado em maio do mesmo ano. Bergallo (1994) encontrou uma fêmea com filhotes na bolsa em outubro na Estação Ecológica da Juréia-Itatins. 


\section{Micoureus demerarae (Thomas, 1905) \\ Cuíca}

A espécie $M$. demerarae é de ampla ocorrência pela América do Sul, da Colômbia ao Paraguai. (Gardner, 1993), incluindo todo território brasileiro (Eisenberg \& Redford, 1998). É 0 maior marsupial do gênero Micoureus, anteriormente pertencentes ao gênero Marmosa (Gardner, 1993).

É considerado insetívoro-onívoro por Leite et al. (1994). Grelle (1996), examinando amostras fecais de $M$. demerarae no Vale do Rio Doce, encontrou consumo apenas de insetos. Esta espécie possui hábitos arborícolas (Voss \& Emmons, 1996). Aspectos do comportamento desta espécie são pouco conhecidos.

Neste estudo foram capturados dois machos escrotados, um em julho de 1998 e outro em maio de 1999, sendo este último recapturado em junho e julho do mesmo ano. Estas capturas foram efetuadas em uma das trilhas nos fragmentos circundados por plantios de $E$. saligna. $O$ baixo sucesso de captura provavelmente se deve ao método empregado neste levantamento onde todas as armadilhas foram depositadas no chão da floresta.

\section{Gênero Monodelphis}

Gomes (1991), revisando o gênero reuniu as espécies em grupos. Dentro do grupo $M$. americana encontram-se cinco espécies: M. rubida, M. scalops, M. americana, M. umbristriata e M. iheringi. Este grupo está associado a formações florestais: Floresta Atlântica e Floresta Estacional Semidecidual (Gomes, 1991). No grupo designado pelo mesmo autor como Monodelphis brevicaudata, encontram-se três espécies: $M$. brevicaudata, $M$. rubida e Monodelphis sp. Na Fazenda João XXIII foram capturadas quatro espécies deste gênero, três delas Gomes (1991) identificou como pertencentes aos dois grupos acima relatados e um indivíduo capturada na floresta contínua não foi possível identificar seguindo este autor. Estas espécies foram: 


\section{Monodelphis americana (Muller, 1776) \\ Cuíca-três-listras}

A distribuição desta espécie é do Norte da Argentina ao litoral do Estado do Rio Grande do Norte, (Eisenberg \& Redford, 1999). Na literatura se encontram algumas controvérsias quanto ao padrão de atividade: é considerada noturna por Tate (1930) e Nowak (1991) e diurna por Emmons \& Feer (1990) e Voss \& Emmons (1996). Neste trabalho esta foi a espécie do gênero mais frequentemente capturada, sendo que a maioria das capturas ocorreram em pitfalls.

\section{Monodelphis scalops (Thomas, 1888)}

Cuíca

Os registros para esta espécie são na faixa costeira ao norte de São Paulo, Rio de Janeiro e Espírito Santo (Gomes, 1991). Pouquíssimas informações existem sobre a ecologia desta espécie. Davis (1947) relata a ocorrência M. scalops em floresta secundária no município de Teresópolis, Estado do Rio de Janeiro. Na Fazenda João XXIII foi registrada a ocorrência de um macho adulto em plantação de eucalipto, capturado em pitfall utilizados na captura de anfíbios por S.H. Oliveira5.

\section{Monodelphis brevicaudata (Erxleben, 1777) \\ Cuíca}

Este pequeno marsupial, segundo Gomes (1991), tem extensa distribuição, ocorrendo desde a Floresta Amazônica ao interior do Estado de São Paulo nas cidades de Sorocaba e Ribeirão Preto. Neste trabalho foram capturados dois indivíduos em pitfall na floresta contínua. Um macho escrotado e um filhote, capturados em janeiro e março de 1999 respectivamente. Apresenta coloração castanha clara com a base dos pelos cinzas sem listras no dorso.

5 De novembro de 1999 a novembro de 2000 foi desenvolvido, nas mesmas trilhas utilizadas neste trabalho, levantamento de anfíbios. Onde foi utilizado pitfall com recipientes de $90 \mathrm{~cm}$ de profundidade e $45 \mathrm{~cm}$ de diâmetro por S.H. Oliveira que cedeu as espécies de mamíferos capturadas para este levantamento. 


\section{Monodelphis sp (Erxleben, 1777) \\ cuica}

Esta espécie apresenta uma coloração castanha escura sem listras, ventre pouco mais claro. Na área de estudo foram capturados em floresta contínua dois machos escrotados durante o levantamento de anfíbios 5 .

Philander frenata (Linnaeus, 1758) Cuíca-quatro-olhos

A espécie $P$. frenata foi reconhecida como válida por Patton \& da Silva citado por Eisenberg \& Redford (1999), separando-a de Philander opossum, espécie do norte do Brasil. Portanto, P. frenata, ocorre na parte meridional do Brasil, do Sul da Bahia ao Paraná, incluindo 0 oeste de Minas Gerais e Goiás (Eisenberg \& Redford, 1998).

Segundo Nowak (1991) esta espécie habita áreas florestais e frequentemente é encontrada próxima a brejos e rios. Em conteúdo estomacal de Philander frenata, Grelle et al. (1996) encontrou diversos itens alimentares, dentre eles insetos, vertebrados e frutos, demonstrando hábito alimentar onívoro. Robinson \& Redford (1986) e Leite et al. (1994), classificam-na como insetívora-onívora. Neste trabalho foi a espécie mais abundante de pequeno mamífero correspondendo a $20,1 \%$ do total das capturas efetuadas.

\section{Ordem Xenarthra}

\section{Família Dasypodidae}

\section{Dasypus novencinctus (Linnaeus, 1758)}

\section{Tatu-galinha}

D. novencinctus ocorre do centro sul e sudeste dos Estados Unidos ao norte da Argentina (Nowak, 1991). Sua alimentação consiste de pequenos animais, principalmente 
insetos, como besouros e formigas. Em sua dieta podem estar inclusos pequenos mamíferos e outros vertebrados (Redford, 1987). Esta espécie é frequentemente encontrada em áreas rurais (Eisenberg \& Redford, 1989). Durante este estudo poucos registros desta espécie foram efetuados: pegadas próximas à floresta contínua, restos encontradas em fezes de $P$. concolor e uma carcaça nos arredores das casas dos moradores na Fazenda João XXIII.

\section{Dasypus septemcinctus (Linnaeus, 1758)}

\section{Tatu-mulita}

D. septemcinctus ocorre do centro sul e sudeste dos Estados Unidos ao norte da Argentina (Nowak, 1991). É a menor espécie do gênero e geralmente é confundida com $D$. novencinctus. A confirmação desta espécie na Fazenda João XXIII, foi possível através de uma captura em pitfall utilizados para captura de anfíbios ${ }^{5}$. Esta espécie de hábitos diurnos alimentase de invertebrados e pequenos vertebrados (Nowak, 1991).

\section{Euphractus sexcinctus (Linnaeus, 1758)}

\section{Tatu-peludo}

Esta espécie ocorre do oeste dos Andes à Amazônia brasileira até o norte da Argentina (Cabrera, 1957). Segundo Nowak \& Paradiso (1989) é mais comum em áreas abertas como 0 cerrado. É frequente o encontro deste tatu em áreas degradadas e plantios. Neste trabalho ocorreram apenas três registros, todos de pegadas na borda da floresta contínua. Sua dieta consiste principalmente de plantas e insetos, podem ser encontrados em grupo se alimentando de animais mortos; com exceção deste comportamento social, a espécie possui hábito solitário (Moeller citado por Nowak \& Paradiso, 1989). 


\section{Cabassous tatouay (Desmarest, 1804)}

\section{Tatu-do-rabo-mole}

A ocorrência de C. tatouay é do Sudeste do Brasil e oeste do Paraguai, todo território uruguaio ao nordeste da Argentina (Nowak \& Paradiso, 1989); é a única espécie do gênero Cabassous que ocorre no Estado de São Paulo (Eisenberg \& Redford, 1999). Esta é a espécie de tatu menos conhecida e menos registrada no Estado, são poucas as informações sobre a ecologia e o status de Cabassous tatouay. Na última lista de espécies ameaçadas de extinção do Estado de São Paulo, foi classificada como de relevante interesse. Esta espécie, como a anterior, foi registrada duas vezes na Fazenda João XXIII através de pegadas encontradas próximo ao fragmento maior.

\section{Família Myrmecophagidae}

\section{Myrmecophaga trydactyla (Linnaeus, 1758)}

\section{Tamanduá-bandeira}

Esta espécie é encontrada de Belize, Guatemala ao sul no Chaco Paraguaio e nordeste da Argentina (Eisenberg \& Redford, 1999). Ocupa uma ampla variedade de habitats, de floresta tropical a áreas secas como o cerrado. Podem ser encontrados com maior frequência em áreas abertas. Sua dieta é composta principalmente de cupins e formigas (Nowak \& Paradiso, 1989). Os registros desta espécie na Fazenda João XXIII se limitaram a poucas pegadas verificadas na estrada em frente à floresta contínua e relatos de trabalhadores e moradores da Fazenda.

\section{Tamandua tetradactyla (Linnaeus, 1758)}

\section{Tamanduá-mirim}

Esta espécie ocorre da Venezuela, sul do Paraguai ao norte do Uruguai e o nordeste da Argentina (Eisenberg \& Redford, 1999). Pode ser encontrado numa variedade incluindo florestas tropicais, cerrados e campos abertos. Alimenta-se de formigas e cupins (Eisenberg \& Redford, 
1999). É uma espécie de hábitos arbóreos e terrestres, diurno e noturno (Emmons, 1990). Na Fazenda João XXIII foram poucos os registros desta espécie, apenas pegadas foram verificadas próximas à floresta contínua.

\section{Ordem Primates}

\section{Família Cebidae}

\section{Cebus apella (Linnaeus, 1758)}

Macaco-prego

Ocorre na América do Sul a oeste dos Andes até o norte da Argentina (Emmons, 1990). No Estado de São Paulo é a espécie de primata mais frequentemente registrada, podendo ser encontrada em fragmentos secundários. Trata-se de uma espécie de fácil verificação pois apresenta hábito diurno, são encontradas em grandes bandos, variando de cinco a dez indivíduos, e apresenta vocalização conspícua. Dependendo do ambiente em que se encontra utiliza uma área de 25 a 40 ha (Eisenberg \& Redford, 1999). Sua dieta inclui frutos, sementes e uma considerável quantidade de insetos (Terborgh, 1983).

Entre os primatas é notável a ausência da maioria das espécies ocorrentes na região, Bhrachytelles arachnoides (mono-carvoeiro), Allouata fusca (bugio) e Callithrix aurita (mico-daserra). Cebus apella durante este trabalho foi registrado apenas na floresta contínua em apenas três encontros. As demais espécies de primatas são relatadas na Fazenda vizinha que faz limite ao Parque Estadual de Carlos Botelho.

\section{Ordem Carnivora}

\section{Família Canidae}

\section{Cerdocyon thous (Linnaeus, 1766)}

\section{Cachorro-do-mato}

De ampla distribuição, esta espécie ocorre da Venezuela e Colômbia ao norte da 
Argentina (Eisenberg \& Redford, 1999), incluindo todo o território brasileiro. É uma espécie muito comum no Estado e pode ser encontrada em áreas agrícolas bem como próxima a vilarejos e cidades. Apresentam uma pequena área de uso de 0,6 a 0,9 km² (Nowak, 1991).

C. thous é onívoro quanto à dieta alimentar. Em estudo de conteúdo estomacal na Venezuela foram encontrados $26,0 \%$ de pequenos mamíferos, $24 \%$ de frutas, $13 \%$ de anfíbios, $11 \%$ de insetos, $10 \%$ de répteis e $9 \%$ de aves (Eisenberg \& Redford, 1999). Na área de estudo foi amplamente registrado por encontros e pegadas em toda área amostrada.

\section{Família Procyonidae}

\section{Nasua nasua (Linnaeus, 1766)}

Coati

N. nasua ocorre do sudeste da Colômbia ao nordeste da Argentina, incluindo o sul do Paraguai (Eisenberg \& Redford, 1999). Apresenta hábito semi-arborícola e pode ser visto durante o dia em bandos que variam de quatro a vinte indivíduos. Os machos acima de dois anos são expulsos do bando e passam a se deslocar sozinhos (Emmons \& Feer, 1990).

Nowak \& Paradiso (1989) relataram que o nascimento dos filhotes ocorre durante a estação máxima de frutos. Kaufmann (1975) registrou no Panamá nascimentos de abril a junho; 0 autor relata que os filhotes deixam o ninho em cinco semanas e passam a se deslocar junto com o bando. Dois bandos com filhotes foram visualizados na Fazenda João XXIII, em novembro de 1998 e dezembro de 1999.

\section{Procyon cancrivorus (Cuvier, 1798)}

\section{Mão-pelada}

P. cancrivorus ocorre desde a parte oriental da Costa Rica ao Uruguai, incluindo todo território brasileiro (Eisenberg \& Redford, 1999). Esta espécie é comum em áreas alteradas. Possui hábitos terrestres, principalmente noturnos e geralmente utiliza áreas próximas a cursos d'água. Alimenta-se de pequenos vertebrados e frutos (Nowak \& Paradiso, 1989). Na Fazenda 
João XXIII foi verificada em todos os ambientes amostrados.

\section{Família Mustelidae}

\section{Eira barbara (Linnaeus, 1758) Irara}

E. barbara ocorre da região central do México ao norte da Argentina (Nowak, 1991). Pode formar pequenos grupos familiares porém é mais comum o encontro de um ou dois indivíduos. Alimenta-se de pequenos vertebrados, principalmente roedores. Frutos podem fazer parte de sua dieta. Em estudo de dieta realizado por Konecny (1989), foi encontrado $50 \%$ de pequenos vertebrados, sendo o restante dividido entre frutos e artrópodes.

É de hábitos diurnos mas pode ser ativa durante a noite (Nowak \& Paradiso, 1989). Foram obtidos três registros de $E$. barbara com a utilização de máquinas fotográficas de disparo automático na área de estudo, todos durante o dia (Alexandre Vogliotti, comun. pessoal).

\section{Galictis cuja (Thomas, 1907)}

\section{Furão}

G. cuja ocorre do sudeste do Peru, Paraguai e sudeste do Brasil ao Chile central, podendo ser encontrada na Argentina (Teixera, 1974; citado por Eisenberg \& Redford, 1999). Geralmente é encontrada em habitats onde ocorre presença de arsos d'água e cobertura florestal, bem como em áreas de cerrado (Emmons \& Feer, 1990). Esta espécie pode ser encontrada em pequenos grupos de três ou quatro indivíduos, geralmente mãe e filhotes (Silva, 1989). Os registros desta espécie durante este trabalho se restringiram a duas ocorrências de pegadas na floresta contínua. 


\section{Família Felidae}

\section{Leopardus pardalis (Linnaeus, 1758)}

\section{Jaguatirica}

L. pardalis ocorre do Sul do Texas ao norte da Argentina (Emmons \& Feer, 1990). Emmons (1987) encontrou 0,8 indivíduos por $\mathrm{km}^{2}$ no Peru, em todos os habitats disponíveis na área de estudo que incluía floresta, rios e bordas de lago. Esta espécie alimenta-se

principalmente de mamíferos terrestres perfazendo $59 \%$ de sua dieta, sendo também encontrado um grande número de répteis nas fezes examinadas por Emmons (1987). Esta espécie foi verificada através de pegadas e fezes em todas as áreas que foram estudadas na Fazenda João XXIII.

\section{Leopardus sp (Gray, 1842)}

\section{Gato-do-mato}

Com exceção da espécie acima relatada, esse gênero compreende as menores espécies de felino das Américas (Eisenberg \& Redford, 1999). Neste estudo foram registradas pegadas por toda a área estudada e duas visualizações ocorreram na estrada entre plantios de E. saligna. Segundo Voss \& Emmons (1996), para pequenos felinos é difícil identificar a espécie utilizandose apenas de pegadas e como as visualizações foram sempre muito rápidas optou-se por manter apenas o gênero.

\section{Herpailurus yagourundi (Geofroy, 1803)}

\section{Jaguarundi}

Esta espécie tem ocorrência do sul dos Estados Unidos à Argentina (Eisenberg \& Redford, 1999). Segundo Emmons \& Feer (1990) H. yagourundi pode ser mais comum em florestas decíduas ou secundárias do que em florestas tropicais. Este felino pode ser ativo durante 0 dia e à noite. É primariamente terrestre e se alimenta de uma ampla variedade de 
vertebrados. Manzani \& Monteiro-Filho (1989) encontraram aves, pequenos mamíferos, peixes e répteis na dieta desta espécie. Neste estudo foram registradas pegadas e fezes na estrada entre o fragmento maior e plantios de E. saligna. Na Fazenda João XXIII, esta espécie foi visualizada na estrada correndo para um talhão de eucalipto.

\section{Puma concolor (Linnaeus, 1771)}

\section{Sussuarana}

É o segundo maior felino das Américas, de ampla distribuição ocorre desde o Canadá à Argentina e Chile (Currier, 1983). A maior parte de sua dieta é composta por mamíferos, principalmente de médio porte, podendo alimentar-se de aves e répteis. No pantanal, Schaler et al. (1989) registraram área de uso de $60 \mathrm{~km}^{2}$ por indivíduo. P.concolor sobrepõe toda a distribuição de Panthera onca, estas duas espécies tem comportamentos muito diferentes para aceitarem a coexistência (Schaller \& Crawshaw, 1980; Emmons, 1997). Não ocorreram registros de $P$. onca na área deste estudo, apesar de ser registrada no Parque Estadual de Carlos Botelho.

Pegadas e fezes de P.concolor foram encontradas por toda a área coberta por este levantamento. Ocorreram três visualizações desta espécie durante o período deste estudo na estrada próxima à floresta contínua (George Camargo comun. pessoal). As três amostras de fezes coletadas na área de estudo continham restos de Dasypus novencinctus e cf Agouti paca. Segundo Chinchilla (1997), este felino é um carnívoro de dieta generalista. Esse autor encontrou predomínio de mamíferos nas fezes coletadas na Costa Rica.

\section{Ordem Perissodactyla}

\section{Família Tapiridae}

\section{Tapirus terrestris (Linnaeus, 1758)}

Anta

T. terrestris ocorre da Venezuela ao sul do Paraguai (Eisenberg \& Redford, 1999). Esta espécie pode ser encontrada em floresta tropical bem como em áreas secas no Paraguai e chaco 
argentino. É o maior herbívoro das Américas. Frutos podem estar inclusos em sua dieta. Possui hábito diurno ou noturno, dependendo da ocupação humana na área (Voss \& Emmons; 1996). É solitária e a cada gestação nasce um filhote que acompanha a fêmea por aproximadamente um ano.

Esta espécie foi verificada em todos os ambientes estudados na Fazenda João XXIII, foram registradas fezes dentro dos talhões de eucalipto, bem como em área de floresta nativa.

\section{Ordem Artiodactyla}

\section{Família Tayassuidae}

\section{Pecari tajacu (Linnaeus, 1758)}

Cateto

Esta espécie é encontrada do sul dos Estados Unidos à Argentina (Eisenberg \& Redford, 1999). Foi pouco verificado durante este estudo, ocorrendo dois registros de pegadas e duas visualizações, todas as ocorrências foram na floresta contínua. É uma das espécies preferenciais para caça, sendo provavelmente uma das razões dos baixos registros desta espécie e motivo da ausência de Tayassu pecari, rara em grande parte de sua área de ocorrência devido à caça excessiva.

P. tajacué exclusivamente diurna (Voss \& Emmons, 1996), vivem em pequenos grupos sociais e confinam suas atividades à mesma área de uso 0 ano todo. Alimenta-se de frutas, tubérculos e gramíneas, podendo predar pequenos animais (Eisenberg \& Redford, 1999).

\section{Família Cervidae}

\section{Mazama americana (Erxleben, 1777)}

Veado-mateiro

Esta espécie ocorre desde a porção oriental do México ao norte da Argentina (Eisenberg \& Redford, 1998), preferencialmente de florestas densas; alimenta-se de frutos e folhas, estas 
podem ser predominantes quando os frutos são escassos (Branam \& Marchinton, 1987). Demonstra ter hábitos diurnos e noturnos, predominando o diurno quando a pressão de caça é inexistente (Eisenberg \& Redford, 1998).

Um indivíduo foi coletado na estrada que margeia a floresta contínua. Provavelmente predado por Puma concolor, apresentava hematomas na região do pescoço e o abdômen estava rompido. No estômago deste animal foram encontradas sementes de uma espécies de Solanaceae, uma semente de Euterpe edulis e alguns frutos ainda não identificados (A.Vogliotti, comum. pessoal).

\section{Mazama gouazoupira (Fischer, 1814) Veado catingueiro}

A área de ocorrência desta espécie compreende o sul do Panamá, Colômbia, Venezuela ao norte da Argentina e Uruguai (Eisenberg \& Redford, 1998). O veado-catingueiro está sempre associado a florestas e depende delas para abrigo e alimentação, podendo se adaptar à terras cultivadas, próximas a pequenos fragmentos (Pinder \& Leeuwenberg, 1997). De hábito solitário,

alimenta-se principalmente de brotos, folhas tenras, flores e frutos variando conforme a disponibilidade desses recursos (Bodmer, 1989). Esta espécie se reproduz durante todo 0 ano, nascendo apenas um filhote (Pinder \& Leeuwenberg, 1997). Ocorreram muitos registros, pegadas e visualizações, desta espécie na Fazenda João XXIII, uma fêmea com filhote foi vista no mês de dezembro, em um talhão de eucalipto jovem.

\section{Ordem Rodentia}

\section{Família Sciuridae}

\section{Sciurus aestuans (Linnaeus, 1776)}

\section{Serelepe}

Distribui-se da Venezuela e Guiana ao norte da Argentina (Eisenberg \& Redford, 1999). É o único esquilo de ocorrência no Estado de São Paulo. São diurnos e de fácil visualização (Voss 
\& Emmons, 1996). Alimenta-se de diversos frutos, principalmente de palmeiras (Galetti et al., 1992).

Esta espécie na Fazenda João XXIII foi visualizada apenas na floresta contínua.

\section{Família Muridae}

\section{Delomys sublineatus (Thomas, 1903)}

Rato do mato

Espécie endêmica da Floresta Atlântica, distribui-se do Espírito Santo a Santa Catarina em altitudes menores que 800 m, podenso ser simpátrico com Delomys dorsalis (Voss, 1993). Esta espécie foi coletada na floresta contínua onde a altitude é de aproximadamente $900 \mathrm{~m}$.

Este gênero foi encontrado como mais abundante na comunidade de mamíferos, por Olmos (1991) em área com domínio de bambu no Parque Estadual de Intervales e por Carvalho (1965) em floresta primária na Boracéia, neste levantamento poucos exemplares foram coletados apenas em floresta contínua.

\section{Rhipidomys sp (Tschudi, 1844)}

Rato do mato

Este gênero é encontrado em florestas tropicais de terras baixas na América do Sul (Eisenberg \& Redford, 1999). As espécies pertencentes a este gênero possuem pés grandes e compridos, adaptados à vida arbórea (Nowak, 1991). Robson \& Redford (1986) citaram o gênero como frugívoro-onívoro. Neste levantamento apenas um indivíduo foi capturado em um dos fragmentos circundados por floresta contínua. Mesmo com a obtenção do número cariotípico (2n=24) ainda não foi possível a identificação da espécie. 


\section{Akodon montensis (Winge, 1887)}

Rato do mato

A. montensis ocorre desde o Sudeste do Rio de Janeiro ao oeste da Argentina (Eisenberg \& Redford, 1999). Em alguns trabalhos esta espécie pode ser encontrada como Akodon cursor (Musser \& Carleton, 1993). No entanto, estas duas espécies que apresentam características morfológicas praticamente indistintas, são diferentes cariotipicamente: Akodon montensis tem o número cariotípico 2n=24 e Akodon cursor 2n=14 (Christoff, 1997).

Stallings (1989), encontrou em estudo de conteúdo estomacal de Akodon cursor, uma alta proporção de insetos, sementes e frutos. É classificado como onívoro (Mares at al., 1986) ou frugívoro-onívoro (Robinson \& Redford, 1986). Stallings (1989) verificou um comportamento fortemente terrestre para esta espécie; Freitas (1999) atribuiu hábitos escansórios a este roedor. Este roedor pode ser encontrado como espécie dominante em estudos de comunidades de pequenos mamíferos (Stallings; 1989; Voltolini, 1997). Davis (1947), encontrou Akodon cursor como espécie mais abundante em florestas primárias e secundárias no Rio de Janeiro, o mesmo observado por Crespo (1982) para o Parque Nacional de Iguazu na Argentina. Neste trabalho foi a terceira espécie de roedor em abundância relativa.

\section{Blarinomys breviceps (Winge, 1887)}

rato do mato

Espécie endêmica da Floresta Atlântica, é extremamente rara em levantamentos de pequenos mamíferos. A ocorrência desta espécie era conhecida para os Estados de Minas Gerais, Bahia, Espírito Santo e Rio de Janeiro. No entanto, além deste registro para o Estado de São Paulo, no museu de Zoologia de São Paulo foram verificadas duas outras ocorrências em Santo André e Iporanga. Estendendo o limite sul de distribuição desta espécie ao município de Iporanga no Estado de São Paulo (Silva et al., no prelo).

Esta espécie apresenta hábito fossório (Abrawaya \& Matson, 1975) e insetívoro (Reis et al. 1996). Neste trabalho ocorreram duas capturas, um macho e uma fêmea no mês de outubro. A fêmea capturada tinha dois embriões, concordando com Abrawaya \& Matson (1975) que 
encontraram no mês de setembro fêmeas com dois ou um filhote. Estas duas capturas ocorreram em pitfall na floresta contínua.

\section{Bruciepattersonius igniventris (Hershkovitz, 1998)}

rato do mato

Esta espécie foi descrita por Hershkowitz (1998) através de um exemplar coletado no PETAR (Parque Turístico do Alta Ribeira), município de Iporanga. Até o presente momento a espécie era conhecida somente para a localidade tipo. No PETAR esta espécie foi coletada em uma área de foresta secundária. Os dois indivíduos coletados na Fazenda João XXIII foram capturados durante levantamento de anfíbios ${ }^{4}$, na floresta contínua.

\section{Oligoryzomys nigripes (Olfers, 1818)}

rato do mato

De ampla distribuição, ocorre no Uruguai, Argentina, Paraguai, Bolívia e sudeste do Brasil, incluindo todo o Estado de São Paulo (Honacki et al. 1982). É comumente encontrada em campos de cultivo abandonados, em pastos (Strelein, 1982) e em florestas secundárias, apresentando baixas densidades em florestas primárias (Alho, 1982, Fonseca \& Kierulf, 1989; Stallings, 1989). Apresenta hábitos noturnos e é considerada de hábitos terrestres e escansórios (Nitikman \& Mares, 1987). Ninhos desta espécie foram encontrados a um metro do solo (Alho \& Pereira, 1985; Alho et al. 1986; Stalling, 1989). Análise de conteúdo estomacal realizado por Fonseca \& Kierulf (1989) e por Stallings (1989) revelaram uma grande variedade de itens

alimentares, sendo eles, frutos, sementes, gramíneas e insetos. Neste estudo foi o roedor mais abundante, devido principalmente às capturas efetuadas nas plantios de $E$. saligna. 


\section{Oryzomys russatus (Wagner, 1886)}

rato do mato

$\mathrm{Na}$ área de estudo 0 . russatus foi o segundo roedor mais abundante capturado nos dois ambientes de floresta nativa. Bonvicino et al. (1997) encontrou esta espécie apenas em altitudes menores que 1400 m no P.N. da Serra do Caparaó e principalmente em florestas primárias. Segundo Robinson \& Redford (1986), várias espécies deste gênero utilizam mais de 50 \% de frutos em sua dieta. Sendo o gênero, classificado como frugívoro-onívoro e, segundo Nowak \& Paradiso (1991), a dieta inclui partes suculentas de gramíneas, frutas, sementes e insetos.

\section{Oxymycterus judex (Thomas, 1909)}

rato do mato

Segundo Oliveira, J. A. (comun. pessoal) esta espécie ocorre nos Estados do Rio de Janeiro, São Paulo e Paraná. Poucas informações sobre a ecologia deste gênero podem ser encontradas em literatura. Pertencente à Tribo Akodontinii formada pelas espécies de roedores neotropicais que apresentam hábitos extremamente terrestres ou semi-fossórios (Hershkowitz, 1998). Na Fazenda João XXIII esta espécie foi capturada apenas em uma das trilhas, em plantios de E. saligna.

\section{Thaptomys nigrita (Lichtenstein, 1829)}

rato do mato

T. nigrita ocorre do sul da Bahia ao Nordeste da Argentina, incluindo o leste do Paraguai (Musser \& Carleton, 1993), de hábito terrestre ou semi-fossório (Alho, 1982), ocupa áreas

florestais em buracos no solo (Hershkovitz, 1998). Esta espécie pode construir túneis na serapilheira (Davis, 1947). Neste levantamento T. nigrita foi capturado em todos os ambientes estudados. 


\section{Wilfredomys pictipes (Osgood, 1933)}

rato do mato

Esta espécie ocorre do sudeste do Brasil ao nordeste da Argentina (Nowak, 1991). Possui hábito arborícola. $\mathrm{Na}$ área de estudo foi capturado apenas um indivíduo com pitfall na floresta contínua; o baixo registro desta espécie durante este trabalho deve estar associado à ausência de armadilhas no dossel. No entanto, Voltolini (1997) utilizando armadilhas no dossel durante dois anos em Floresta Atlântica no Estado de Santa Catarina, capturou apenas 6 indivíduos desta espécie.

\section{Família Agoutidae}

\section{Agouti paca (Linnaeus, 1766)}

\section{Paca}

Ocorre do centro-oeste do México ao Paraguai (Eisenberg \& Redford, 1999). Ocupa diferentes habitats, mas geralmente é visto em áreas de florestas próximas a cursos d'água. Os registros para a área ocorreram através de pegadas encontradas na floresta contínua e nas plantios de E. saligna onde ocorreu a visualização de um indivíduo. Segundo Redford \& Robinson (1987), em diversas localidades neotropicais esta é a espécie mais caçada entre os mamíferos de médio e grande portes. A intensa pressão de caça tem reduzido as populações de A. pacapor todo o Estado de São Paulo.

\section{Família Cavidae}

\section{Cavia sp (Pallas, 1766)}

\section{Preá}

Este gênero ocorre na América do Sul e Central (Eisenberg \& Redford, 1999). Para a região sudeste podem ocorrer duas espécies deste gênero: C. aperea e C. insigna (Redford, 
1991). De hábitos noturnos, segundo Voss \& Emmons (1996) e crepusculares segundo Nowak \& Paradiso (1989). Apresentam hábitos terrestres e são herbívoros especialistas em gramíneas (Nowak \& Paradiso, 1991), podendo ser atribuídos, ao hábito alimentar, os baixos registros deste gênero obtidos em levantamentos de pequenos mamíferos. Este gênero utiliza uma ampla variedade de habitats, incluindo campo aberto, bordas de floresta e áreas rochosas (Nowak, 1991). Neste trabalho apenas um espécime foi capturado, em plantios de E. saligna, durante levantamento de anfíbios 5 .

\section{Família Dasyproctidae}

\section{Dasyprocta azarae (Lichtenstein, 1823)}

\section{Cotia}

D. azarae tem distribuição do Brasil Central ao nordeste da Argentina e Paraguai (Eisenberg \& Redford, 1999). Pode ser simpátrica com Dasyprocta agouti na Serra de Paranapiacaba (Ximenes, 1999).

As cotias podem ser encontradas em florestas, cerrado e áreas cultivadas. Possuem hábito diurno e os encontros são mais frequentes pela manhã e no final da tarde. Alimentam-se de sementes e frutas (Voss e Emmons, 1996). Espécie muito procurada pr caçadores, geralmente apresenta baixas densidades em áreas onde sofre pressão de caça (Emmons \& Feer, 1990). Os registros desta espécie na área de estudo ocorreram nos três ambientes estudados.

\section{Família Hydrochaeridae}

\section{Hidrochaeris hydrochaeris (Linnaeus, 1766) \\ Capivara}

Esta espécie ocorre no Panamá, estendendo-se pela América do Sul a oeste dos Andes; da Colômbia ao nordeste da Argentina (Eisenberg \& Redford, 1999). Ocupa áreas próximas a cursos d'água. Pode ser encontrada em bandos de mais de 20 indivíduos (Schaller \& Vasconcelos, 1978). Relatos sobre predações em culturas agrícolas são frequentes. Geralmente 
é mais ativa pela manhã e ao entardecer. Em áreas com intensa ocupação humana apresenta hábitos noturnos.

$\mathrm{Na}$ área de estudo esta espécie foi pouco verificada. Alguns vestígios foram encontrados próximo a uma das lagoas artificiais; a vegetação que circunda esta lagoa é caracterizada por capim denso e baixo estando localizada entre plantios de $E$. saligna.

\section{Família Erethizontidae}

Coendou villosus (Linnaeus, 1778)

Ouriço

O gênero Coendou ocorre na Venezuela, Guianas, Brasil e Bolívia. Espécie de roedor arborícola e noturno, tem comportamento lento e discreto, de difícil verificação em floresta tropical (Voss \& Emmons, 1996). Alimenta-se de uma ampla variedade de frutos e folhas (Silva, 1994). Esta espécie foi verificada na floresta contínua e nos fragmentos.

\section{Ordem Lagomorpha}

\section{Família Leporidae}

\section{Sylvilagus brasiliensis (Linnaeus, 1758)}

\section{Tapiti}

É a única espécie da Ordem Lagomorpha de ocorrência no Brasil, distribui-se do oeste do México à Argentina (Nowak e Paradiso, 1989). De hábitos solitários e noturnos, alimenta-se principalmente de gramíneas; frutos são utilizados em menores proporções (Nowak \& Paradiso, 1989). Habita bordas de matas em contato com áreas abertas (Handley, 1976). Na área de estudo foi visualizada por várias noites na beira da estrada, entre áreas de floresta nativa e plantios de E. saligna. Um indivíduo jovem foi capturado durante levantamento de anfíbios 5 . 
Tabela 1. Espécies de mamíferos não-voadores inventariados na Fazenda João XXIII, Município de Pilar do Sul, no período de julho de 1998 à dezembro de 2000.

\begin{tabular}{|c|c|}
\hline Classificação & Nome comum \\
\hline \multicolumn{2}{|l|}{ Classe Mammalia } \\
\hline \multicolumn{2}{|l|}{ Ordem Didelphimorphia } \\
\hline \multicolumn{2}{|l|}{ Família Didelphidae } \\
\hline Didelphis aurita (Wied-Neuwied, 1826) & gambá-de-orelha-preta \\
\hline Gracilinanus microtarsus (Wagner, 1842) & Marmosa \\
\hline Marmosops incanus (Lund, 1840) & Marmosa \\
\hline Micoureus demerarae (Thomas, 1905) & Cuíca \\
\hline Metachirus nudicaudatus (Geoffroy, 1803) & Cuíca \\
\hline Monodelphis americana (Muller, 1776) & cuíca-de-três-listras \\
\hline Monodelphis brevicaudata (Erxleben, 1777) & Cuíca \\
\hline Monodelphis scalops (Thomas, 1888) & Cuíca \\
\hline Monodelphis sp (Erxlebem, 1777) & Cuíca \\
\hline Philander frenata (Linnaeus, 1758) & cuíca-quatro-olhos \\
\hline \multicolumn{2}{|l|}{ Ordem Xenarthra } \\
\hline \multicolumn{2}{|l|}{ Família Dasypodidae } \\
\hline Dasypus novemcinctus (Linnaeus, 1758) & tatu-galinha \\
\hline Dasypus septemcinctus (Linnaeus, 1758) & tatu mulita \\
\hline Euphractus sexcinctus (Linnaeus, 1758) & tatu-peludo \\
\hline Cabassous tatouay (Desmarest, 1804) & tatu-do-rabo-mole \\
\hline \multicolumn{2}{|l|}{ Família Myrmecophagidae } \\
\hline Myrmecophaga trydactyla (Linnaeus, 1758) & tamanduá-bandeira \\
\hline Tamandua tetradactyla (Linnaeus, 1758) & tamanduá-mirim \\
\hline \multicolumn{2}{|l|}{ Ordem Primates } \\
\hline \multicolumn{2}{|l|}{ Família Cebidae } \\
\hline Cebus apella (Linnaeus, 1758) & macaco-prego \\
\hline \multicolumn{2}{|l|}{ Ordem Carnivora } \\
\hline \multicolumn{2}{|l|}{ Família Felidae } \\
\hline Leopardus sp (Gray, 1842) & gato-do-mato \\
\hline Leopardus pardalis (Linnaeus, 1758) & jaguatirica \\
\hline Puma concolor (Linnaeus, 1771) & sussuarana \\
\hline Herpailurus jagourundi (Geoffroy, 1803) & gato-morisco \\
\hline \multicolumn{2}{|l|}{ Família Canidae } \\
\hline Cerdocyon thous (Linnaeus, 1766) & cachorro-do-mato \\
\hline Família Procyonidae & \\
\hline Nasua nasua (Linnaeus, 1766) & coati \\
\hline Procyon cancrivorus (Cuvier, 1798) & mão-pelada \\
\hline
\end{tabular}


Tabela 1. Espécies de mamíferos não-voadores inventariados na Fazenda João XXIII, Município de Pilar do Sul, no período de julho de 1998 à dezembro de 2000.

\begin{tabular}{|c|c|}
\hline Classificação & Nome comum \\
\hline \multicolumn{2}{|l|}{ Família Mustelidae } \\
\hline Eira barbara (Linnaeus, 1758) & irara \\
\hline Galictis cuja (Thomas, 1907) & furão \\
\hline \multicolumn{2}{|l|}{ Ordem Perissodactyla } \\
\hline \multicolumn{2}{|l|}{ Família Tapiridae } \\
\hline Tapirus terrestris (Linnaeus, 1758) & anta \\
\hline \multicolumn{2}{|l|}{ Ordem Artiodactyla } \\
\hline \multicolumn{2}{|l|}{ Família Tayassudae } \\
\hline \multicolumn{2}{|l|}{ Família Cervidae } \\
\hline Mazama gouazoupira (Fischer, 1814) & veado-catingueiro \\
\hline Mazama americana (Erxleben, 1777) & veado-mateiro \\
\hline \multicolumn{2}{|l|}{ Ordem Rodentia } \\
\hline $\begin{array}{l}\text { Família Sciuridae } \\
\text { Sciurus aestuans (Linnaeus, 1776) } \\
\text { Família Agoutidae }\end{array}$ & serelepe \\
\hline $\begin{array}{l}\text { Agouti paca (Linnaeus, 1766) } \\
\text { Família Caviidae }\end{array}$ & paca \\
\hline $\begin{array}{l}\text { Cavia sp (Pallas, 1766) } \\
\text { Família Dasyproctidae }\end{array}$ & preá \\
\hline Dasyprocta azarae (Lichtenstein, 1823) & cutia \\
\hline Família Hydrochaeridae & \\
\hline $\begin{array}{l}\text { Hidrochaeris hydrochaeris (Wetzel, 1890) } \\
\text { Família Erethizontidae }\end{array}$ & capivara \\
\hline $\begin{array}{l}\text { Coendou villosus (Linnaeus, 1778) } \\
\text { Família Muridae }\end{array}$ & ouriço \\
\hline Rhipidomys sp (Tschudi. 1844) & rato do mato \\
\hline Oligoryzomys nigripes (Olfers, 1818) & rato do mato \\
\hline Oryzomys russatus (Wagner, 1886) & rato do mato \\
\hline Akodon montensis (Winge, 1887) & rato do mato \\
\hline Blarinomys breviceps (Winge, 1887) & rato do mato \\
\hline Bruciepatersonius igniventris, (Hersh., 1998) & rato do mato \\
\hline Oxymycterus judex (Thomas, 1909) & rato do mato \\
\hline Thaptomys nigrita (Lichtenstein, 1829) & rato do mato \\
\hline Delomys sublineatus (Thomas, 1903) & rato do mato \\
\hline Wilfredomys pictipes (Osgood, 1933) & rato do mato \\
\hline Ordem Lagomorpha & \\
\hline Família Leporidae & \\
\hline Sylvilagus brasiliensis (Linnaeus, 1758) & tapiti \\
\hline
\end{tabular}




\subsection{Abundância relativa da comunidade de pequenos mamíferos}

Durante nove meses de coleta, de setembro de 1998 a agosto de 1999, com um esforço de 7020 dias-armadilha e 3840 dias-pitfall, foram realizadas 539 capturas de 17 espécies. Os métodos utilizados foram responsáveis por um sucesso de captura de 6,1\% em armadilhas do tipo gaiola e 2,7 \% em pitfall.

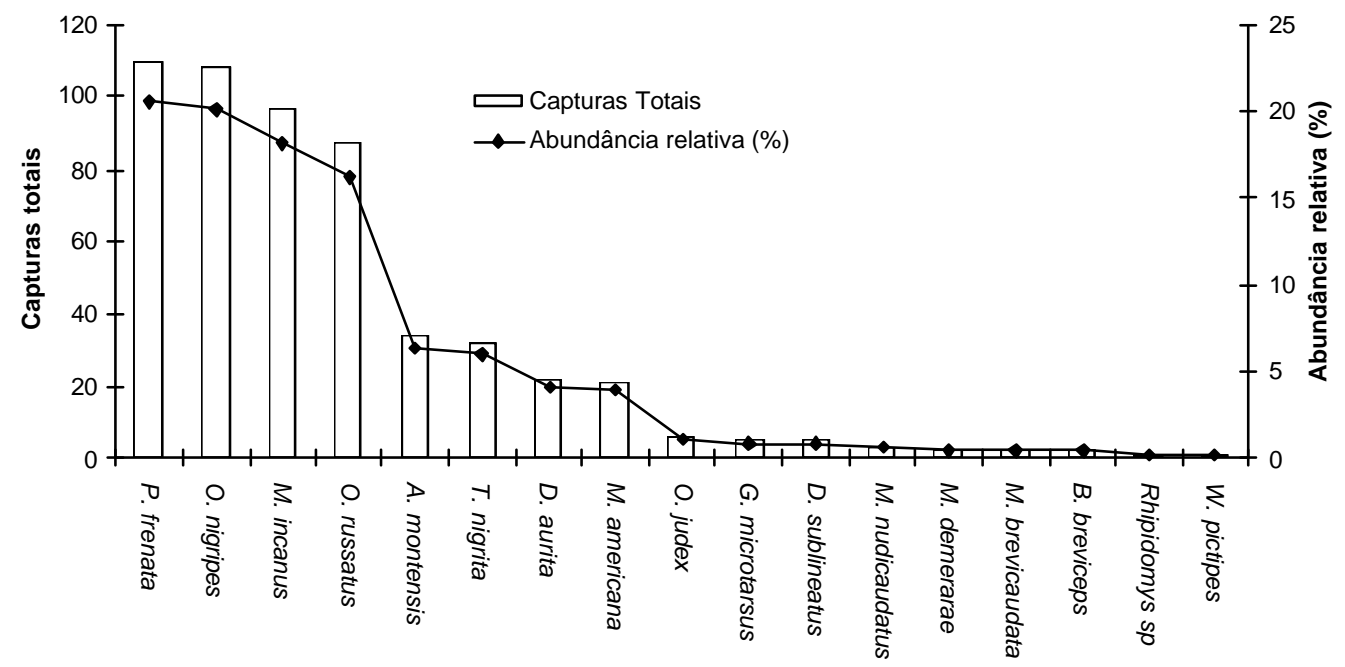

Figura 8 - Capturas totais e abundância relativa (\%) das espécies de pequenos mamíferos capturadas, no período de setembro de 1998 à agosto de 1999, na Fazenda João XXIII.

A comunidade de pequenos mamíferos capturada na Fazenda João XXIII, mostrou poucas espécies dominantes; $O$. nigripes, $P$. frenata, $M$. incanus e $O$. russatus, correspondendo a 74,6 \% das capturas (Figura 8). Enquanto várias espécies apareceram como espécies raras neste levantamento, individualmente com abundância relativa abaixo de $2 \%$, juntas estas espécies corresponderam a 5,0 \% da abundância relativa de pequenos mamíferos na Fazenda João XXIII. Dentre estas, estão espécies encontradas na literatura como de hábitos arborícolas: G. microtarsus, M. demerarae, Rhipidomys sp e W. pictipes. Espécies de hábitos estritamente terrestres, como M. brevicaudata, M. nudicaudatus, B. breviceps, O. judex e D. sublineatus, também foram raras na amostragem, mesmo utilizando-se dois métodos de captura depositados 
no chão da floresta. A. montensis, T. nigrita, D. aurita, e M. americana formaram um grupo intermediário correspondendo a 20,4 \% das capturas efetuadas na área de estudo.

\subsection{Comparação entre os métodos utilizados na captura de pequenos mamíferos}

O sucesso de captura de roedores foi de 3,0 \% em armadilhas do tipo gaiola e de 1,8\% em pitfall. Para marsupiais foi verificado um maior sucesso de captura em armadilhas do tipo gaiola 3,28 \%, do que em pitfall 0,9\%.

Em pitfall capturou-se 12 espécies das 17 verificadas, sendo 3 exclusivamente neste método, B. breviceps, W. pictipes e M. brevicaudata. Com a utilização de pitfall foram efetuadas 17 capturas de M. americana e 2 de M. brevicaudata. Apenas uma captura de M. americana ocorreu em armadilha do tipo gaiola (Figura 9). Em armadilhas do tipo gaiola, foram capturadas 14 espécies, sendo cinco exclusivamente por este método, D. aurita, $M$. demerarae, $M$. nudicaudatus, O. judex e Rhipidomys sp (Figura 9).

Dentre as 7 espécies mais capturadas neste estudo6, 83,3\% das capturas ocorreram em armadilhas do tipo gaiola (Tabela 2). Armadilhas do tipo gaiola mostraram maior eficiência na captura de $M$. incanus $(p=0,0041), P$. frenata $(p=0,0001), A$. montensis $(p=0,0002), 0$. nigripes $(p=0,0001)$ e 0 . russatus ( $p=0,0001)$. Pitfall mostrou-se mais eficiente na captura de $M$. americana ( $p=0,0041$ ), sendo que $81,2 \%$ das capturas desta espécie ocorreram por este método. Não houve diferença significativa entre os métodos na eficiência de captura de T. nigrita $(p=0,5791)$.

\footnotetext{
${ }^{6}$ Nesta análise foram consideradas apenas as espécies com mais de dez capturas totais.
} 


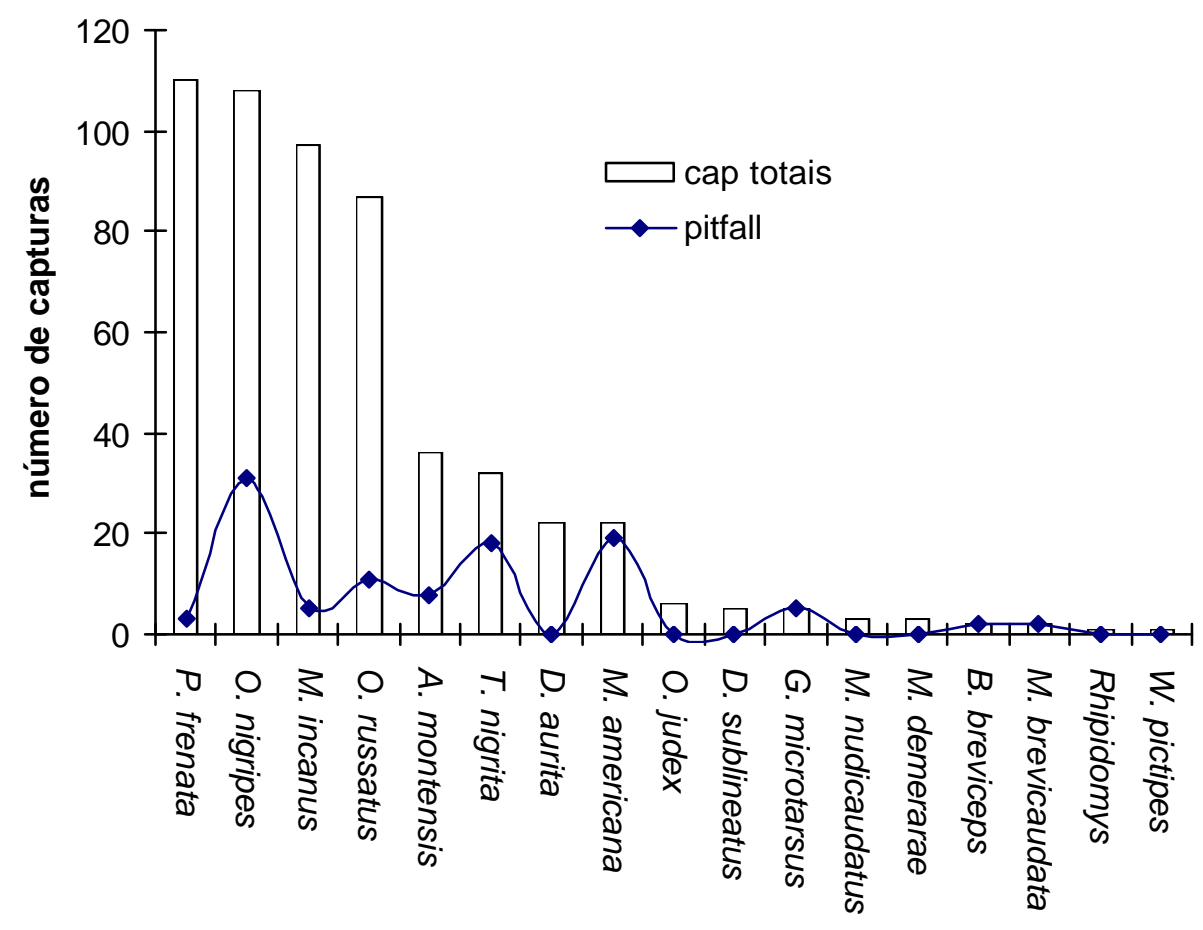

Figura 9 - Número de capturas totais e com a utilização de pitfall, para pequenos mamíferos na Fazenda João XXIII.

Tabela 2. A eficiência de armadilhas do tipo gaiola e pitfall, testado com o uso de Qui-quadrado, na captura das 7 espécies de pequenos mamíferos mais abundantes na Fazenda João XXIII.

\begin{tabular}{lccc}
\hline \multicolumn{1}{c}{ Espécies } & Gaiola (\%) & pitfall (\%) & $\mathrm{P}$ \\
\hline Marmosops incanus & 94,3 & 6,7 & 0,0041 \\
Monodelphis americana & 18,8 & 81,2 & 0,0041 \\
Philander frenata & 81,1 & 18,9 & 0,0001 \\
Akodon montensis & 81,8 & 19,2 & 0,0002 \\
O. nigripes & 76,2 & 23,8 & 0,0001 \\
Oryzomys russatus & 90,4 & 10,6 & 0,0001 \\
Thaptomys nigrita & 46,15 & 53,85 & $0,5791^{\star}$ \\
\hline
\end{tabular}

* não significativo ao intervalo de $95 \%$ de confiança 


\subsection{A influência do período na captura de pequenos mamíferos.}

Observando a Figura 10, pode-se perceber que os dados de captura obtidos com a utilização de pitfall apresentaram maior sucesso de captura nos meses de setembro, novembro, janeiro e julho. Nas capturas obtidas com a utilização de gaiolas foram verificados maior sucesso de captura nos meses de novembro e julho. As capturas de pequenos mamíferos diferiram mensalmente em cada método (gaiola $X^{2}=66,06$; pitfall $X^{2}=25,41$ ) e mantiveram essa diferença quando testadas utilizando os dados obtidos com a utilização dos dois métodos.

As capturas em pitfall não apresentaram diferença entre os meses secos e úmidos. Com a utilização de gaiola apesar de um surpreendente sucesso de captura em novembro (Figura 10), as coletas nos meses úmidos ainda se mantiveram inferiores aos meses secos.

O número acumulado de espécies capturadas por cada método aumentou mensalmente. As armadilhas do tipo gaiola capturaram mais espécies que pitfall. No entanto, o número acumulado de espécies capturadas pelos dois métodos se manteve maior mensalmente (Figura 11). A curva acumulada de espécies sugere que com uma maior amostragem o número de espécies aumentaria.

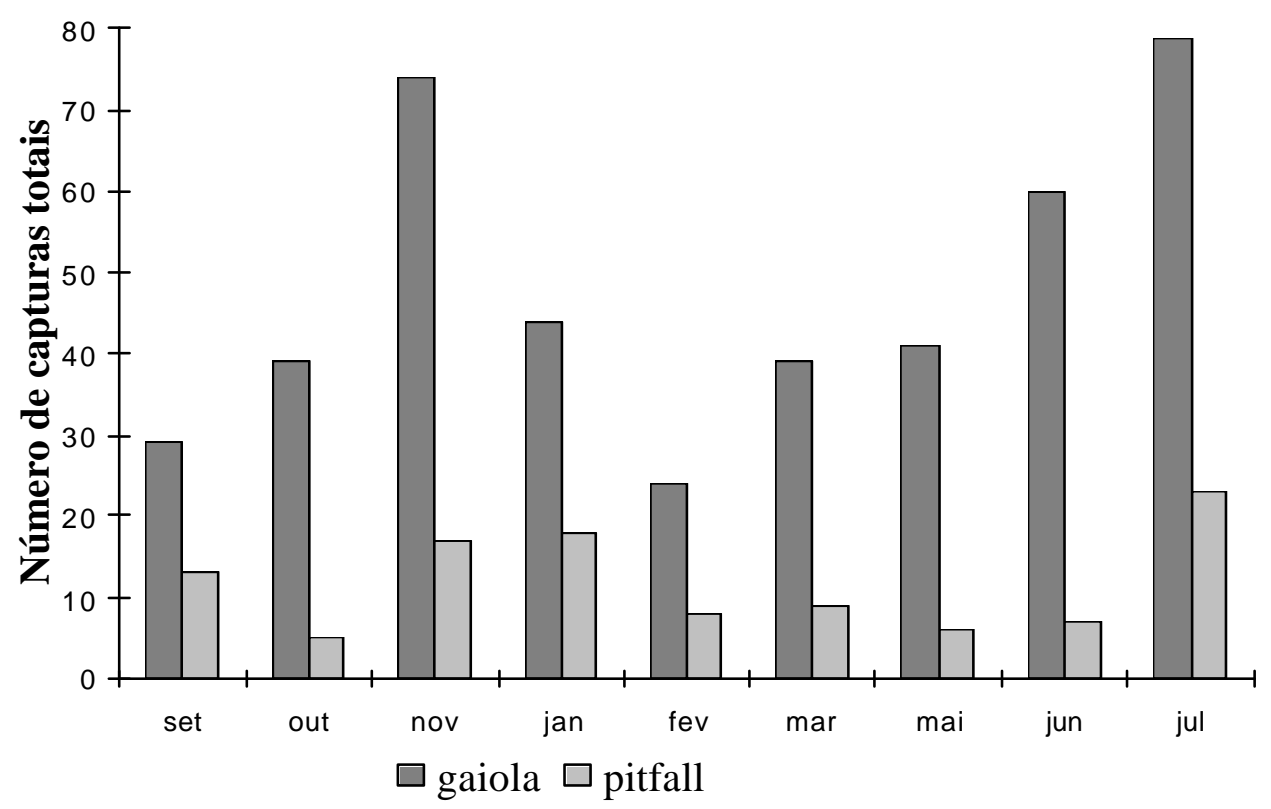

Figura 10 - Capturas totais de pequenos mamíferos com a utilização de armadilhas do tipo gaiola e pitfall durante o período de setembro de 1998 a julho de 1999, na Fazenda João XXIII, Município de Pilar do Sul. 


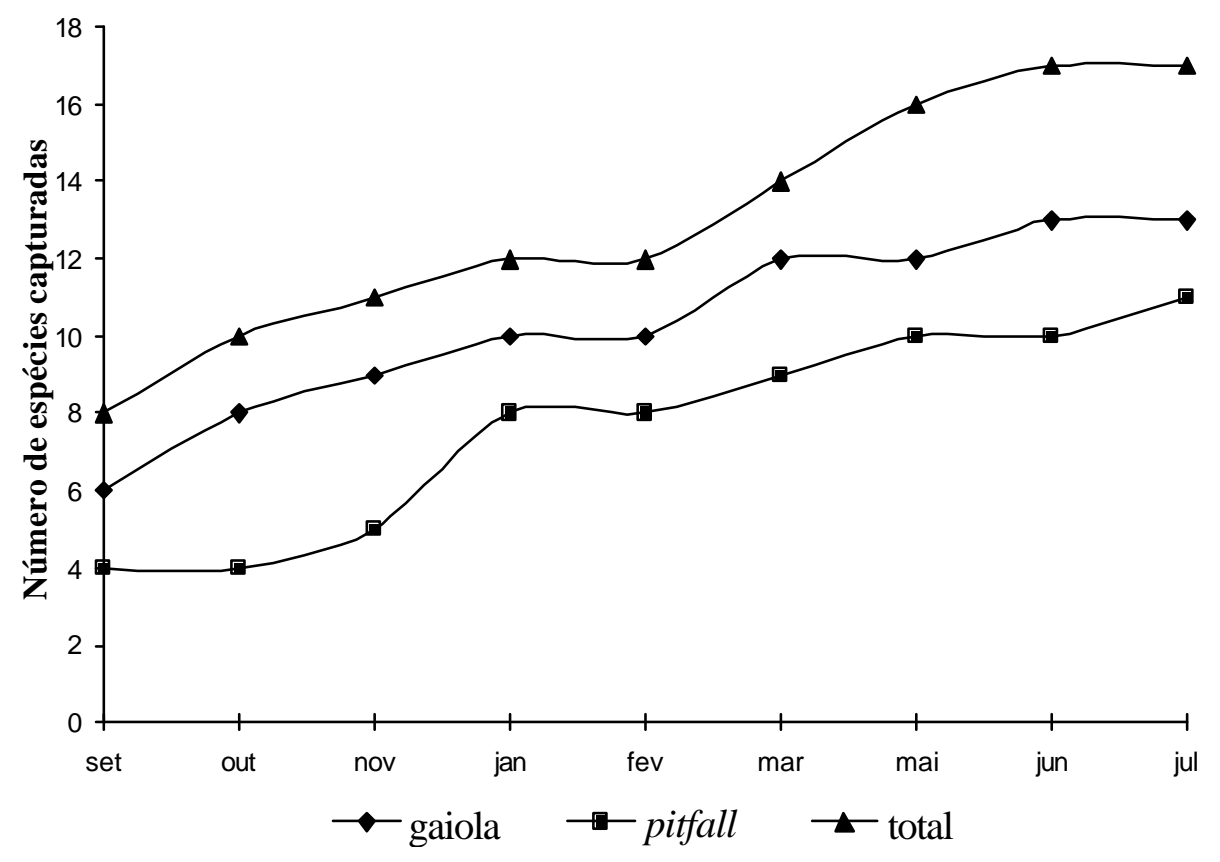

Figura 11 - Curva de espécies capturadas com a utilização de armadilhas do tipo gaiola e pitfall durante o período de setembro de 1998 a julho de 1999.

\subsection{Riqueza, diversidade e abundância relativa das espécies de pequenos mamíferos em floresta contínua, plantios de E. saligna e fragmentos circundados por plantios de E. saligna.}

Na fazenda João XXIII foi encontrada uma riqueza semelhante de espécies de marsupiais e roedores: 8 e 9 respectivamente. Em abundância relativa as espécies também demonstraram pouca diferença, sendo que marsupiais participaram com 49\% da abundância relativa e roedores com $51 \%$.

Em floresta contínua a riqueza de roedores, 7 espécies, foi maior que a de marsupiais, 5 espécies. A abundância relativa de marsupiais e roedores foi semelhante, 52,11 \% e 47,87 \%. Nos fragmentos foi verificada uma maior abundância de marsupiais correspondendo a 72,29 \%. Neste ambiente foram capturadas 6 espécies de roedores e 5 espécies de marsupiais. Nos plantios de E. saligna estudados observou-se uma maior abundância de roedores, 89,98 \%, e um 
número muito próximo quanto à riqueza de espécies, 5 espécies de roedores e 4 espécies de marsupiais (Tabela 3).

Tabela 3. Riqueza e abundância relativa de marsupiais e roedores nos ambientes estudados na Fazenda João XXIII.

\begin{tabular}{|c|c|c|c|c|c|c|}
\hline Grupo & \multicolumn{2}{|c|}{ Floresta } & \multicolumn{2}{|c|}{ Plantios de E. saligna } & \multicolumn{2}{|c|}{ Fragmento } \\
\hline & $\begin{array}{l}\text { Núm. de } \\
\text { espécies }\end{array}$ & $\begin{array}{l}\text { Abundância } \\
\text { relat. (\%) }\end{array}$ & $\begin{array}{l}\text { Núm. de } \\
\text { espécies }\end{array}$ & $\begin{array}{l}\text { Abundância } \\
\text { relat. (\%) }\end{array}$ & $\begin{array}{l}\text { Núm. de } \\
\text { espécies }\end{array}$ & $\begin{array}{l}\text { Abundância } \\
\text { relat. (\%) }\end{array}$ \\
\hline Marsupiais & 5 & 52,11 & 5 & 19,02 & 6 & 72,29 \\
\hline Roedores & 7 & 47,87 & 4 & 80,98 & 5 & 27,71 \\
\hline
\end{tabular}

Nos dois ambientes de floresta nativa estudados foram capturadas 14 espécies de pequenos mamíferos, sendo 12 em floresta contínua e 11 nos fragmentos. Os plantios de $E$. saligna apresentaram uma riqueza de 9 espécies de pequenos mamíferos. Com a utilização da Análise Fatorial de Variância, comparando-se a riqueza e o período amostrado não se detectou diferença entre a riqueza de espécies, ou seja entre o número de espécies capturadas em cada ambiente e entre os períodos amostrados.

A abundância total de pequenos mamíferos com a utilização da Análise Fatorial de Variância, entre os ambientes $(0,88)$, floresta nativa e floresta implantada, e entre os períodos $(p=0,20)$ desta amostragem, também não se mostraram significativamente diferentes. No entanto utilizando-se da Análise de Correspondência para verificar se houve um padrão de variação na composição e abundância de cada espécie nos ambientes estudados, foi possível verificar uma associação entre espécies e ambientes. As variáveis originais passaram a ser representadas por dois eixos principais, que juntos explicaram 84,05 \% (eixo 1) e 15,95 \% (eixo 2) da inércia total ou seja, das variâncias das associações entre as espécies e os ambientes estudados.

$\mathrm{Na}$ figura 12, observa-se que existe uma oposição de intervalos entre os ambientes. Sendo que plantio de $E$. saligna (EUC) se encontra do lado negativo do eixo 1, e ambientes de floresta nativa: floresta contínua $(F C)$ e fragmentos circundados por plantios de $E$. saligna (FRAG), se encontram do lado positivo do eixo. Os plantios de E. saligna tiveram a maior contribuição para a formação deste eixo $(-0,4638)$ e menores para a floresta contínua $(0,2319)$ e fragmentos $(0,231867)$. 
Pela observação da figura 12 pode-se notar que algumas espécies estão associadas ao plantio de $E$. saligna (EUC) também do lado negativo do primeiro eixo: em primeiro lugar $O$. nigripes (OL), seguido por O. judex (OX) e G. microtarsus (GR), depois por M. americana (MO), A. montensis (AK) e $T$. nigrita $(\mathrm{TH})$. E associadas ao lado positivo (floresta contínua e fragmentos) estão: Rhipidomys sp (RH), M. demerarae (MI), M. nudicaudatus (ME), O. russatus (OR) seguidas por Delomys sublineatus (DE), W. pictipes (WI), B. breviceps (BL), $M$. brevicaudata (MO2), M. incanus (MA), P. frenata (PH) e D. aurita (DI).

$O$ fragmento e a mata apresentaram como espécies dominantes: $P$. frenata, $O$. russatus e M. incanus (Figura 13), pela Análise de Correspondência (Figura 12) estas espécies estão associadas aos ambientes de florestas naturais. Quando observamos o segundo eixo percebe-se uma oposição de intervalos entre os ambientes. Sendo que, floresta contínua (FC) se encontra do lado negativo do eixo, e fragmentos circundados por plantios de E. saligna (FRAG), se encontram do lado positivo do eixo 2. Neste eixo os plantios de $E$. saligna colaboraram apenas com 0,0175 , floresta contínua com $-0,4222$ e fragmento com 0,4047 . Este eixo demonstrou uma associação menor que no primeiro eixo, no entanto pode se perceber que as espécies mais abundantes nestes dois ambientes estão associadas aos mesmos, as espécies periféricas que separaram os dois ambientes foram as espécies exclusivas, como em floresta: $W$. pictipes (WI), M. brevicaudata (MO2) e B. breviceps (BL). Enquanto nos fragmentos: Rhipidomys sp (RH) e M. demerarae (MI).

Na floresta contínua, $P$. frenata foi a espécie dominante com 29,5 \% da abundância relativa. $O$. russatus e $M$. incanus apresentaram neste ambiente uma abundância relativa de $25,8 \%$ e 20,5\%. Nos fragmentos circundados por plantios de $E$. saligna houve uma inversão entre essas três espécies, $M$. incanus foi a espécie dominante com 29,9\% seguida por $P$. frenata com 25,5 \% e O. russatus correspondeu a 20,7 \% (Figura 13). Através da Análise de Correspondência foi possível detectar uma distância entre os ambientes de floresta nativa e floresta implantada quanto a abundância das espécies capturadas. A distância entre floresta e fragmento através do eixo 2 é menor que a distância entre estes ambientes e os plantios de $E$. saligna no eixo 1 . 0 eixo 1 foi responsável por $84,05 \%$ de inércia.

A diversidade de espécies de pequenos mamíferos segundo o Índice de ShannonWienner, não demonstrou diferença entre a floresta contínua e o fragmento sendo de 1,79 e 1,77 
respectivamente $(t=0,21)$. Os plantios de $E$. saligna apresentaram menor diversidade por este índice, 1,49 ( $\mathrm{t}=2,80$ e $\mathrm{t}=2,65)$. Utilizando o Índice de Simpson, os valores mantiveram o mesmo padrão, sendo 4,85 para a floresta contínua e 4,8 para o fragmento e para os plantios de $E$. saligna 0 valor foi de 2,92. A equitabilidade também mostrou-se maior nos ambientes de floresta nativa $(0,72$ e 0,74$)$ e menor nos plantios de $E$. saligna $(0,68)$.

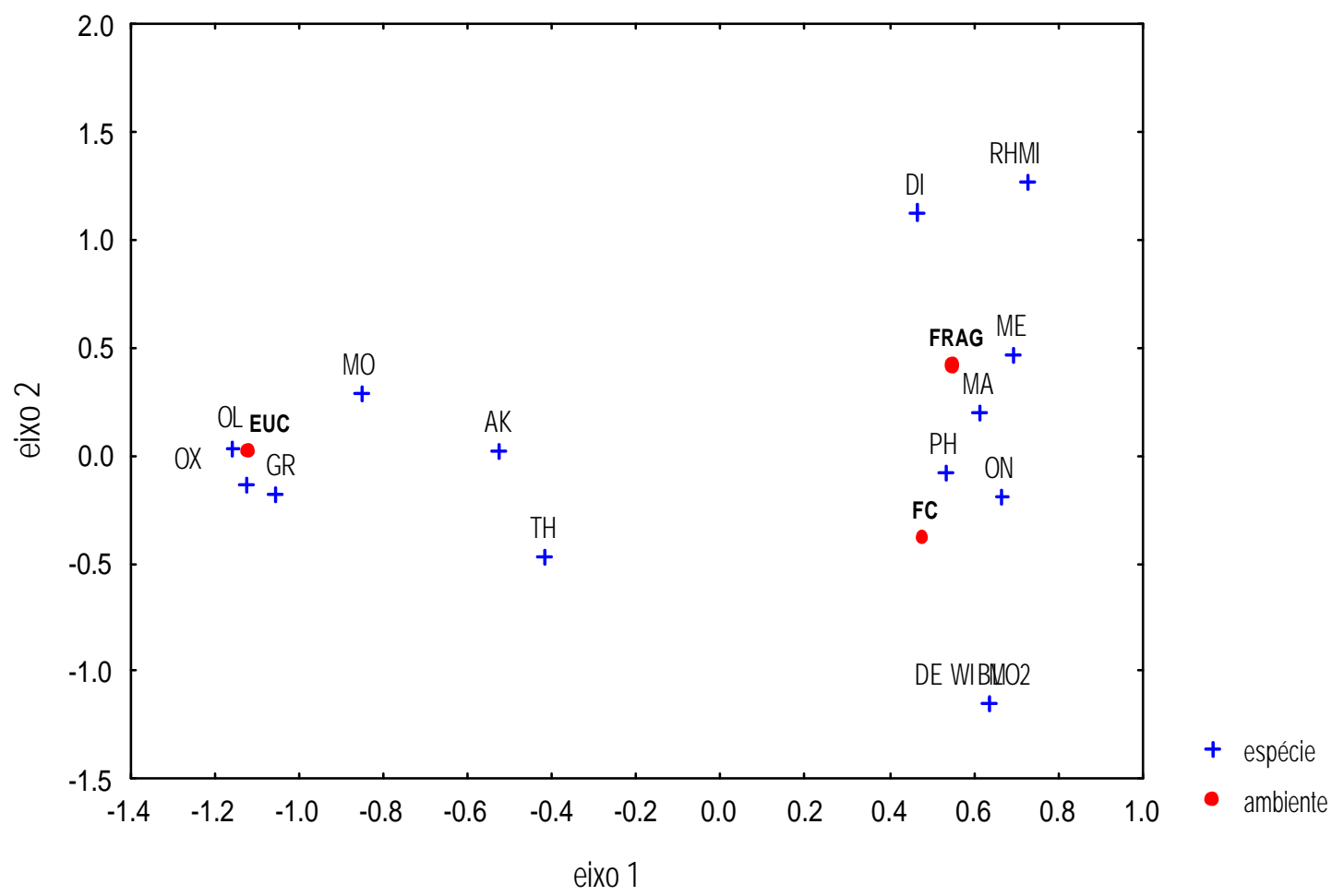

Figura 12: Ordenação dos ambientes e das espécies nos dois primeiros eixos resultantes da Análise Fatorial de Correspondência. FC = Floresta Contínua, FRAG = Fragmento circundado por plantios de E. saligna, $E U C=$ Plantios de E. saligna, $\mathrm{ON}=\mathrm{O}$. nigripes, $\mathrm{OX}=\mathrm{O}$. judex, $\mathrm{GR}=\mathrm{G}$ microtarsus, $\mathrm{MO}=\mathrm{M}$. americana, $\mathrm{AK}=\mathrm{A}$. montensis, $\mathrm{WI}=\mathrm{W}$. pictipes, $\mathrm{TH}=\mathrm{T}$. nigrita, $\mathrm{MI}=\mathrm{M}$. demerarae, $\mathrm{DI}=\mathrm{D}$. 
albiventris, $\mathrm{ME}=\mathrm{M}$. nudicaudatus, $\mathrm{MA}=\mathrm{M}$. incanus, $\mathrm{PH}=\mathrm{P}$. frenata, $\mathrm{OR}=\mathrm{O}$. russatus e $\mathrm{RH}=$ Rhypidomys sp.

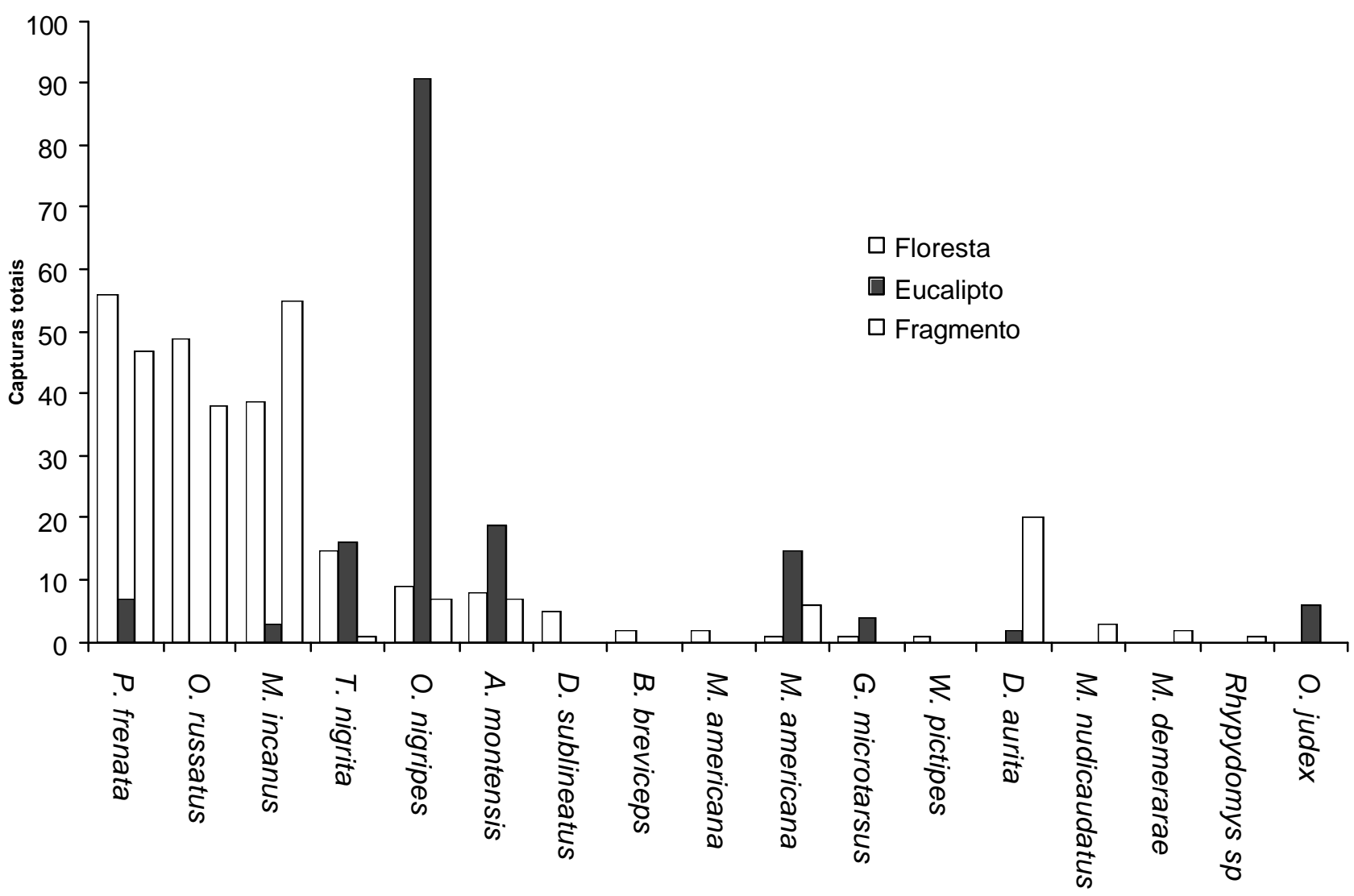

Figura 13 - Abundância relativa das espécies de pequenos mamíferos em floresta contínua, fragmentos circundados por plantios de $E$. saligna e plantios de $E$. saligna.

\subsection{Relação entre estrutura de habitat e a ocorrência de pequenos mamíferos em floresta contínua, fragmentos e plantios de E. saligna na Fazenda João XXIII.}

A floresta contínua e os fragmentos apresentaram características muito próximas entre as variáveis amostradas (Tabela 4). Esses ambientes se caracterizaram por uma grande densidade de árvores jovens, com sub-bosque bastante desenvolvido. Nestes ambientes a obstrução de luz medida variou de $60 \%$ a $90 \%$ nas parcelas. Esta variável, cobertura de dossel, teve uma correlação positiva com a ocorrência de $M$. incanus $(0,43), O$. russatus $(0,45)$ e $P$. frenata $(0,49)$, espécies dominantes nesses ambientes, conforme discutido acima. 
A cobertura herbácea na floresta contínua, assim como nos fragmentos, foi de aproximadamente $50 \%$ em todas as parcelas. As espécies em desequilíbrio foram encontradas em $30 \%$ das parcelas na floresta contínua e $40 \%$ nos fragmentos, com predomínio de bambu e de cipó, respectivamente. Esses ambientes foram significativamente diferentes para a densidade do sub-bosque, sendo que a floresta contínua apresentou o sub-bosque mais denso $(p=0,000015)$.

Os plantios de E. saligna apresentaram uma maior entrada de luz, devido a menor densidade de árvores no estrato arbóreo, e domínio de uma única espécie, E. saligna. Apenas em duas parcelas foi encontrado Guapira opposita fazendo parte do dossel. A. montensis e $O$. nigripes demonstraram uma correlação negativa com maior cobertura de dossel sendo de $-0,53$ e - 0,59, respectivamente.

A serapilheira foi maior nos plantios de $E$. saligna que em floresta nativa $(p=0,0006$ e $\mathrm{p}=0,0032)$, apresentando correlação positiva com as espécies 0 . nigripes $(0,75)$ e $T$. nigrita $(0,45)$. O número de troncos encontrados no solo foi diferente entre os ambientes de floresta nativa e plantios de E. saligna, sendo que este último ambiente apresenta poucos troncos no solo.

O. russatus apresentou correlação positiva com características que demonstram maior complexidade no ambiente como maior riqueza de espécies compondo o dossel $(0,44)$, e subbosque mais abundante $(0,48)$, e teve correlação negativa com serapilheira mais desenvolvida $(-0,43)$, característica presente nos plantios de $E$. saligna. Contrário a $O$. nigripes, que se comportou como espécie generalista na ocupação dos plantios de E. saligna, que apresentou uma associação negativa com abundância e riqueza das espécies que compõem o dossel (-0,43 e - 0,73$)$, com sub-bosque mais alto $(-0,42)$ e com maior obstrução de luz $(-0,78)$; apresentando associação positiva com serapilheira mais desenvolvida $(0,75)$, facilmente percebível nos plantios de E. saligna, onde a maioria dos indivíduos desta espécie soltos depois de capturados se escondiam. Provavelmente este pequeno roedor constrói seus ninhos na serapilheira. 
Tabela 4. Valores médios de heterogeneidade ambiental nos três ambientes estudados na Fazenda João XXIII.

\begin{tabular}{lccc}
\hline Variáveis ambientais amostradas & Floresta & Eucalipto & Fragmento \\
\hline Espécies oportunistas & $30 \%$ & $60 \%$ & $40 \%$ \\
Inclinação do terreno & $13,2^{\circ}$ & $7,3^{\circ}$ & $14,6^{\circ}$ \\
Obstrução da luz & $81,2 \%$ & $53,5 \%$ & $77,8 \%$ \\
Cobertura herbácea & $41,7 \%$ & $45,1 \%$ & $42,4 \%$ \\
Serapilheira & $2,9 \mathrm{~cm}$ & $6,2 \mathrm{~cm}$ & $2,8 \mathrm{~cm}$ \\
Densidade de árvores no dossel & 24,8 & 14,2 & 20,7 \\
Número de morfo-espécies no dossel & 15,2 & 1,7 & 11,5 \\
Densidade de arbustos no sub-bosque & 18,9 & 12,2 & 15,9 \\
Número de morfo-espécies no sub-bosque & 10,4 & 6,9 & 7,2 \\
Presença de troncos & 27,7 & 1 & 14,9 \\
\hline
\end{tabular}

Tabela 5. Correlação entre as características do ambiente e a ocorrência de pequenos mamíferos.

\begin{tabular}{|c|c|c|c|c|c|c|c|c|}
\hline \multirow{2}{*}{$\begin{array}{c}\text { Variáveis ambientais } \\
\text { amostradas }\end{array}$} & \multicolumn{8}{|c|}{ Espécies } \\
\hline & A. mo & D. $\mathrm{al}$ & M. inc & M. am & O. nigri & O. rus & P. fren & T. nigr \\
\hline Espécies desequilíbrio & $-0,12$ & 0,56 & 0,12 & 0,18 & $-0,12$ & $-0,26$ & $-0,04$ & $-0,31$ \\
\hline Cobertura de dossel & $-0,47$ & 0,13 & 0,43 & $-0,44$ & $-0,62$ & 0,45 & 0,49 & $-0,26$ \\
\hline Cobertura & $-0,01$ & 0,17 & 0,21 & $-0,16$ & $-0,20$ & $-0,12$ & 0,08 & $-0,14$ \\
\hline Serrapilhe & 0,31 & $-0,29$ & $-0,46$ & 0, & & & $-0,52$ & 45 \\
\hline Abund & $-0,18$ & 0,23 & 0,06 & $-0,16$ & $-0,4$ & 0,13 & 0,48 & $-0,13$ \\
\hline Riquez & $-0,32$ & 0,18 & 0,35 & $-0,41$ & $-0,73$ & 0,44 & 0,52 & $-0,16$ \\
\hline CAP do & 0,14 & $-0,03$ & $-0,04$ & $-0,10$ & 0,0 & $-0,08$ & 0,04 & 0,35 \\
\hline Altura do $\mathrm{C}$ & 0,15 & $-0,09$ & $-0,17$ & $-0,15$ & 0,08 & $-0,22$ & $-0,12$ & $-0,12$ \\
\hline & $-0,08$ & & & -0 , & & & & $-0,11$ \\
\hline$s q$ & $-0,10$ & 0,12 & 0,09 & 0,02 & 0,0 & 036 & 0,18 & 0,02 \\
\hline CAP do st & $-0,19$ & $-0,07$ & 0,01 & $-0,13$ & $-0,34$ & $-0,04$ & 0,06 & 0,07 \\
\hline Altura do sub-bosque & $-0,22$ & 0,01 & 0,19 & $-0,13$ & $-0,42$ & $-0,04$ & 0,53 & $-0,18$ \\
\hline
\end{tabular}




\subsection{Recaptura de pequenos mamíferos em floresta secundária, plantios de E. saligna e fragmentos circundados por plantios de E. saligna.}

Nas Tabelas 6, 7 e 8 são apresentados os dados das espécies recapturadas durante 0 trabalho de campo. Foram retirados os indivíduos que foram coletados ou morreram acidentalmente nas armadilhas, principalmente em pitfall devido, às chuvas ou baixas temperaturas.

A espécie que apresentou maior índice de recaptura foi $P$. frenata, sendo capturada 3,3 vezes na floresta contínua, 1,5 vezes nas plantações de eucaliptos e 2,2 vezes no fragmento. $O$. nigripes, foi a espécie mais capturada nos plantios de E. saligna e apresentou, assim como 0 maior sucesso de captura, o maior índice de recaptura neste ambiente, sendo de 3,4 e apresentou índices menores, coerentemente com os dados de captura, na mata e no fragmento, 1,7 e 1,5 respectivamente. 0 . russatus teve um índice de recaptura de 2,5 para a mata e 2,0 para 0 fragmento; esta espécie não foi capturada nos plantios de $E$. saligna.

Tabela 6. Capturas totais, primeiras capturas e índice de recaptura em floresta contínua, na Fazenda João XXIII, Município de Pilar do Sul.

\begin{tabular}{lccc}
\hline & \multicolumn{3}{c}{ Floresta } \\
\cline { 2 - 4 } \multicolumn{1}{c}{ Espécies } & Capturas totais & Primeiras capturas & Índice de recaptura \\
\hline Marmosops incanus & 27 & 15 & 1,8 \\
Philander frenata & 45 & 12 & 3,7 \\
Akodon montensis & 5 & 4 & 1,3 \\
Oligoryzomys nigripes & 5 & 3 & 1,7 \\
Oryzomys russatus & 35 & 14 & 2,5 \\
Thaptomys nigrita & 10 & 9 & 1,1 \\
\hline
\end{tabular}


Tabela 7. Capturas totais, primeiras capturas e índice de recaptura em plantios de E. saligna, na Fazenda João XXIII, Município de Pilar do Sul.

\begin{tabular}{lccc}
\hline & \multicolumn{3}{c}{ Plantios de E. saligna } \\
\cline { 2 - 4 } \multicolumn{1}{c}{ Espécies } & Capturas totais & Primeiras capturas & Índice de recaptura \\
\hline Didelphis aurita & 3 & 2 & 1,5 \\
Gracilinannus microtarsus & 3 & 3 & 1 \\
Marmosops incanus & 3 & 1 & 3 \\
Monodelphis americana & 9 & 5 & 1,8 \\
Philander frenata & 6 & 4 & 1,5 \\
Akodon montensis & 11 & 9 & 1,2 \\
Oligoryzomys nigripes & 58 & 17 & 3,4 \\
Thaptomys nigrita & 8 & 3 & 2,7 \\
\hline
\end{tabular}

Tabela 8. Capturas totais, primeiras capturas e índice de recaptura nos fragmentos, na Fazenda João XXIII, Município de Pilar do Sul.

Fragmento

\begin{tabular}{lccc}
\cline { 2 - 4 } \multicolumn{1}{c}{ Espécies } & Capturas totais & Primeiras capturas & Índice de recaptura \\
\hline Didelphis aurita & 17 & 9 & 1,9 \\
Marmosops incanus & 42 & 19 & 2,2 \\
Metachirus nudicaudatus & 3 & 1 & 3 \\
Micoureus demerarae & 3 & 1 & 1,5 \\
Monodelphis americana & 3 & 3 & 1 \\
Philander frenata & 40 & 18 & 2,2 \\
Akodon montensis & 2 & 1 & 2 \\
Oligoryzomys nigripes & 6 & 4 & 1,5 \\
Oryzomys russatus & 28 & 14 & 2 \\
Thaptomys nigrita & 0 & 0 & 2,2 \\
\hline
\end{tabular}

\subsection{0 uso do ambiente por mamíferos de médio e grande portes}

Durante o período de julho de 1998 a julho de 1999 foram registradas 15 espécies utilizando as parcelas de areia depositadas nos três ambientes estudados. Dentre as 38 espécies de mamíferos de médio e grande porte registradas na área, 8 não foram verificadas por este método: Dasypus septencinctus, Myrmecophaga tetradactyla, Cebus apella, Herpaylurus jagouroundi, Galictis cuja, Nasua nasua e Pecari tajacu. Apenas uma espécie; Euphractus septencinctus, foi registrada somente por este método. 
As espécies com mais de 10 registros corresponderam a 53,8 \% do total de registros verificados ou seja, $46,2 \%$ dos registros em parcelas de areia, foram espécies registradas menos de 10 vezes por este método.

Somente para as espécies com mais de 10 registros durante 0 ano realizou-se uma comparação, usando o Teste de Qui-quadrado entre o uso de floresta nativa e plantios de $E$. saligna. E. barbara não demonstrou preferência entre os ambientes de floresta nativa e plantios de E. saligna $(p=0,291)$. Os felinos $L$. pardalis $(p=0,001)$ e Leopardus $s p(p=0,010)$, foram as únicas espécies que utilizaram mais dos plantios de $E$. saligna do que das áreas de floresta nativa. Mazama sp $(p=0,001)$ e $T$. terrestris $(p=0,010)$ utilizaram mais áreas de floresta nativa. $D$. novencinctus foi registrado apenas nas áreas de floresta nativa. 


\section{DISCUSSÃO}

\subsection{Captura de pequenos mamíferos em floresta tropical}

A maioria dos trabalhos desenvolvidos em florestas tropicais apresenta um pequeno sucesso de captura, menor que $10 \%$ por noite (Voss \& Emmons, 1996). Segundo Rudd (1979) as metodologias empregadas para captura de pequenos mamíferos em florestas temperadas são geralmente pouco satisfatórias em florestas tropicais. Voss \& Emmons (1996), sugeriram uma associação de diferentes métodos para obtenção de resultados mais completos. Em Floresta Atlântica, o sucesso de captura de pequenos mamíferos tem sido de aproximadamente 5 \% (Freitas, 1998; Grelle; 1996; Fonseca, 1997). Poucos trabalhos alcançaram maiores índices de capturas como Olmos (1991), que amostrando uma pequena área na Reserva Estadual de Intervales obteve um sucesso de captura de 17,23\%. Neste estudo o sucesso de captura, com a utilização de armadilhas do tipo gaiola e pitfall, foi de 6,3\% por dia concordando com os valores encontrados em trabalhos anteriores.

Trabalhos em Floresta Atlântica utilizando pitfall para captura de pequenos mamíferos são recentes Reis et al. (1996), obteve captura de pequenos mamíferos utilizando esta metodologia para capturas de répteis no Espírito Santo. Voss e Emmons (1996) sugeriram que esta metodologia provavelmente se tornará imprescindível na captura de pequenos marsupiais que raramente são atraídos por iscas, como espécies dos gêneros Gracilinanus e Monodelphis. A opção de utilizar pitfall neste trabalho visou a captura de espécies que geralmente são subestimadas em inventários utilizando apenas armadilhas com iscas, como marsupiais insetívoros e terrestres e roedores fossórios ou semi-fossórios como B. breviceps. As capturas deste pequeno roedor efetuaram-se principalmente com a utilização de ratoeiras (Davis, $1944 \mathrm{e}$ Abrawaya \& Matson, 1975), e em menor escala à mão (Goeldi, 1902, Abrawaya \& Matson; 1975).

Neste trabalho foram capturados dois exemplares em pitfall. Esta espécie que tinha sido 
capturada pela última vez em 1975, tem aparecido em inventários empregando piffall (Reis et al., 1996; Silva et al., no prelo). A captura de três espécies do gênero Monodelphis em pitfall ressalta a importância deste método em inventários de pequenos mamíferos; este gênero de hábito estritamente terrestre, provavelmente, é ignorado na maioria dos levantamentos. Neste estudoM. americana foi a terceira espécie em abundância relativa em plantios de $E$. saligna.

Alguns autores encontraram um padrão de efeito sazonal na atividade de pequenos mamíferos com maior sucesso de captura durante os períodos mais secos do ano (Grelle, 1996, Stalllings, 1991; Fonseca \& Kierulf, 1989). Uma das hipóteses para a explicação deste padrão seria a menor disponibilidade de alimentos durante o período de seca, que resultaria em uma maior procura, culminando com maior captura em armadilhas com iscas (Janzen, 1973; Wolda, 1978). Gregory \& Thomas (1997), estudando a densidade de Proechimys semispinosus em ilhas no Panamá, encontraram uma relação negativa entre a captura deste roedor frugívoro e árvores e lianas frutificando. Em floresta tropical, a maior disponibilidade de frutos e insetos ocorre nas estações de primavera e verão, quando se verifica uma redução nas capturas de pequenos mamíferos (Fonseca \& Kierulf, 1989; Stallings, 1991).

Na Fazenda João XXIII foi verificado um maior sucesso de captura nos meses de novembro e julho. Estes meses tiveram incidência de chuvas fortes durante as coletas de campo, o que pode ter refletido em maior movimentação dos animais e consequente maior captura nos dois métodos. No mês de janeiro as capturas reduziram com a utilização de armadilhas com iscas; no entanto o sucesso de captura com pitfall, onde as capturas são acidentais não contando com nenhum atrativo, manteve-se constante reduzindo a partir do mês de fevereiro. Apesar do mês de novembro ter sido responsável por um sucesso de captura alto, neste trabalho verificouse um maior sucesso de captura nos meses secos, para armadilha do tipo gaiola, o que pode ser decorrência da procura de alimentos, visto que em pitfall não se encontrou diferença entre as capturas efetuadas nos meses mais secos e meses chuvosos. Os meses de setembro, outubro e novembro demostraram-se como meses chuvosos devido à pluviosidade atípica verificada no período deste estudo, sendo que estes três meses tiveram pluviosidade maiores que os meses de verão: janeiro, fevereiro e março (Figura 3).

\subsection{Utilização das plantações de eucalipto como habitat por pequenos mamíferos.}


Na Fazenda João XXIII verificou-se uma maior abundância de marsupiais concordando com Charles-Dominique et al. (1981), que estudando uma área de floresta secundária na Guiana Francesa, encontraram maior diversidade e abundância na comunidade de marsupiais. Segundo os mesmos autores, esta classe seria capaz de alcançar altas densidades, em áreas com grande abundância de recursos alimentares. Alguns autores sugeriram que uma grande alteração na paisagem local poderia favorecer a abundância de marsupiais em detrimento dos roedores (Fonseca, 1997; Fonseca, 1989; Stallings, 1988).

Na Estação Ecológica da Juréia-Itatins, uma das áreas mais conservadas de Floresta Atlântica do Estado de São Paulo, roedores tiveram maior abundância relativa que marsupiais (Bergallo, 1994). A grande abundância de roedores verificada na Fazenda João XXIII se deve a dominância de $\mathrm{O}$. nigripes na plantação de eucalipto que correspondeu a 55 \% da abundância relativa de pequenos mamíferos neste ambiente.

A abundância e diversidade de mamíferos silvestres são influenciadas pela estrutura do habitat, apresentando uma correlação positiva com maior estratificação vertical e maior complexidade nas características que seriam utilizadas como abrigo ou para alimentação (Alho, 1981; Malcolm, 1991; Paglia, 1996). Não houve diferença entre a diversidade de pequenos mamíferos em floresta nativa e floresta implantada, no entanto a diversidade de pequenos mamífeos foi menor nas plantios de E. saligna . Neste plantios foi verificada uma menor obstrução de luz e menor riqueza de espécies arbórea compondo o dossel, visto que trata-se de uma monocultura. O sub-bosque também apresentou menor riqueza de espécies que os remanescentes de Floresta Atlântica. Este ambiente portanto, demonstrou maior simplificação se comparado às florestas nativas. No entanto quanto à abundância de pequenos mamíferos não se verificou esta relação de maior abundância nos ambientes mais complexos, devido ao grande número de capturas de $O$. nigripes nos plantios de $E$. saligna.

A complexidade estrutural da vegetação, é conhecida como um fator que aumenta a riqueza de espécies (August, 1983; Fonseca, 1989). No entanto na Fazenda João XXIII não se verificou diferença entre riqueza de espécies nos ambientes estudados. Porém quanto à composição específica observa-se diferenças entre os ambientes de floresta natural e floresta implantada, tendo espécies associadas a ambientes florestais como dominantes nos ambientes 
de floresta nativa e uma única espécie dominante nos plantios.

As espécies de pequenos mamíferos mais abundantes nas florestas nativas, $P$. frenata, O. russatus e M. incanus, são principalmente de hábitos florestais (Stallings, 1991). Estas espécies possuem uma dieta frugívora-onívora e geralmente estão associadas a ambientes florestais. $P$. frenata e $M$. incanus possuem hábitos escansórios, sendo esperada uma maior ocorrência em locais onde a vegetação arbustiva seja mais densa e com maior oferta de frutos. Freitas (1996) encontrou M. incanus associada a sub-bosque desenvolvido e Palma (1996) associou a ocorrência desta espécie com a presença de cipós, neste estudo no entanto $M$. incanus teve associação com maior cobertura de dossel, no entanto não apresentou associação com espécies em desequilíbrio. P. frenata foi a espécie mais abundante na floresta contínua; Freitas (1996) encontrou uma associação entre a ocorrência desta espécie e foliço bem desenvolvido. Porém nos plantios de E. saligna onde a serapilheira pode ser encontrada em maior quantidade, se comparado às florestas nativas, esta espécie foi pouco registrada correspondendo a menos de $5 \%$ do número total de capturas neste ambiente.

Algumas espécies ocupam determinado habitat em densidades populacionais altas como O. nigripes que correspondeu a $55 \%$ das capturas nas plantações de eucaliptos estudadas e nos ambientes de floresta nativa é encontrada como espécie rara. Alho (1981) encontrou Bolomys lasiurus como espécie dominante em cerrado, cerradão e campo. Em floresta de galeria a espécie dominante foi Proechimys roberti, ausente nos três outros habitats. Stallings (1990), encontrou Marmosa cinerea (Micoureus cinereus) como espécie mais abundante em área de Floresta Atlântica. Esta espécie foi relativamente rara no campo sujo e em plantação de eucaliptos. Estes resultados demonstram que as características estruturais do ambiente influenciam na distribuição e abundância de pequenos mamíferos. Brown (1973) argumenta, que se um grupo de espécies tem oportunidade de colonizar um certo habitat, mudanças nas características da comunidade são esperadas refletindo em características ecológicas que permitam a coexistência entre as espécies.

Diversos autores sugeriram que o aumento da heterogeneidade estrutural fornece uma maior diversificação dos recursos, resultando em maior amplitude de habitat, permitindo a coexistência de um número maior de espécies (Simpson, 1964; Richards; 1969; Krebs, 1966). As comunidades de pequenos mamíferos demonstram organizar-se de forma distinta entre os 
ambientes estudados na Fazenda João XXIII. Em floresta nativa foram capturadas espécies com hábitos escansórios e alimentação onívora ou frugívora. Das cinco espécies de roedores capturadas nas plantações de eucaliptos, três delas (O. judex, T. nigrita e A. montensis) são pertencentes à Tribo Akodontini, onde reúnem-se as espécies terrestres e insetívoras. Bonvicino et al (1997) encontrou os roedores pertencentes a esta Tribo como espécies exclusivas em campos montanhosos e dominantes em vegetação arbustiva e floresta montana úmida.

Dentre os marsupiais, a espécie mais abundante nos plantios de $E$. saligna foi Monodelphis americana que também apresenta hábito terrestre (Robinson \& Redford, 1986) e supostamente insetívora, apesar do baixo conhecimento sobre a dieta desses pequenos marsupiais. As plantações de eucaliptos apresentam uma grande quantidade de serapilheira que pode ser utilizada como refúgio pelas espécies de pequenos porte e hábito terrestre. Davis (1947), relatou que T. nigrita pode cavar túneis na serapilheira, esta foi a terceira espécie de roedor em abundância nas plantações de eucaliptos. No Parque Nacional da Serra do Caparaó esta espécie foi encontrada em diferentes elevações altitudinais e diferentes formas de habitat, segundo Bonvicino et al., (1997), para esta espécie nenhuma elevação ou vegetação é limitante em sua distribuição na Floresta Atlântica

A comunidade de pequenos mamíferos, apesar de apresentar uma organização diferente entre as florestas implantada e nativa, apresenta espécies em comum que exploram estes ambientes em menores densidades ou em densidades semelhantes como T. nigrita. Espécies como $D$. aurita, $P$. frenata e $M$. incanus apresentam dispersão para este ambiente, sendo capturadas em pequenos números neste ambiente, principalmente $P$. frenata e $M$. incanus abundantes nos remanescentes de floresta nativa. No entanto, $O$. russatus foi encontrado, como uma das espécies mais abundantes nas florestas nativas e não foi capturado nos plantios de $E$. saligna. Este ambiente demonstra ser uma barreira à dispersão desta espécie, na Fazenda João XXIII. O. russatus aparentemente apresenta limitação a alterações intensas em seu habitat, como as encontradas em monoculturas. Esta espécie na Fazenda João XXIII se mostrou associada aos ambientes mais complexos, com maior riqueza e densidade de espécies arbóreas, amostrados durante este estudo. Bonvicino et al. (1997) capturou O. russatus (intermedius) somente em florestas primárias no P.N. da Serra do Caparaó.

Fonseca (1997) não encontrou diferenças entre a riqueza e abundância de pequenos 
mamíferos em plantação de eucalipto e fragmento circundado por esta. A autora ressaltou que este ambiente não demonstra ser uma barreira às espécies que foram verificadas no fragmento. Stallings (1989), trabalhando em talhões de eucaliptos abandonados, encontrou um índice de recaptura de 7,7 para $M$. demerarae, demonstrando uma alta taxa de permanência. $O$ autor atribuiu este fato ao aspecto de ilha demonstrado pelos talhões de eucalipto que eram cercados por imensas áreas inóspitas. Neste estudo, em que os talhões de eucalipto estudados estão em contato direto com floresta rativa, os resultados diferem dos trabalhos anteriores. Com uma maior diversificação de habitat encontrada em floresta nativa, estes ambientes demonstraram maior diversidade. Com a utilização dos dois métodos de captura empregados e o mosaico formado por dois habitats diferenciados resultou em uma alta riqueza de espécies de pequenos mamíferos (19 espécies) considerando B. igniventris, M. scalops e Cavia sp. Os plantios de $E$. saligna na Fazenda João XXIII demonstraram favorecer algumas espécies de pequenos mamíferos como 0 . nigripes, em detrimento de espécies de hábitos escansórios, como $M$. incanus, ou de maior porte e hábito frugívoro-onívoro, como $P$. frenata e O. russatus.

\subsection{O uso das plantações de eucalipto por mamíferos de médio e grande porte.}

A grande dificuldade na obtenção de dados quantitativos sobre mamíferos de médio e grande portes se deve principalmente à grande diversidade de tamanhos, hábitos e comportamentos das espécies, razão pela qual existem poucas informações sobre este grupo, com exceções dos trabalhos de auto-ecologia. A metodologia utilizada neste trabalho demonstra ser uma boa opção para comparação de ambientes, concordando com Dirzo \& Miranda (1991); no entanto, apresenta pouca eficiência na detecção de espécies de hábitos arborícolas e/ou que se deslocam em bandos. As espécies Pecari tajacu, Cebus apella e Nasua nasua, foram registradas na área de estudo através de visualização ou indícios, no entanto nenhum registro foi observado nas armadilhas de pegadas. Nos plantios de $E$. saligna nenhum indício foi verificado.

Dentre as espécies registradas pelas parcelas de areia, duas espécies de felinos, $L$. pardalis e Leopardus sp demonstram utilizar-se mais das plantações de eucaliptos do que das áreas de floresta nativa. Segundo Crawshaw (1993) os felinos utilizam-se de áreas abertas, como estradas, para se deslocarem. Provavelmente estes plantios por serem mais abertas facilitem 0 
deslocamento e a caça por estas espécies. As pegadas mais registradas foram de Mazama sp e Tapirus terrestris.

Com a utilização das parcelas de areia, bem como pelo levantamento de indícios, espécies como Agouti paca e Dasyprocta azarae foram pouco registradas na área de estudo. Tayassu pecari não foi registrado durante este trabalho e Pecari tajacu foi pouco encontrado, estes animais são diurnos e se deslocam em bando, sendo portanto de fácil visualização. A caça predatória sobre estas espécies pode explicar a baixa ocorrência de $P$. tajacu e a ausência de $T$. pecari durante este levantamento. No entanto entre os grandes mamíferos a espécie mais frequentemente encontrada na Fazenda João XXIII foi Tapirus terrestris que apresenta aspectos ecológicos e cinegéticos muito semelhantes às duas espécies de Tayassudae acima comentado, ressalta-se a necessidade de um estudo com estas espécies na Fazenda João XXIII.

Uma plantação homogênea como a de eucalipto, oferece uma menor diversificação na estrutura horizontal da vegetação, visto que, o dossel é composto de uma única espécie. A intensa alteração ocorrida nos remanescentes de Floresta Atlântica na Fazenda João XXIII resultou em diminuição da altura do dossel e raridade de espécies arbóreas de grande porte. Espécies de hábitos arborícolas apresentaram uma baixa ocorrência na área. Cebus apella foi 0 único primata registrado na área de estudo e esta espécie não foi verificada nas plantios de $E$. saligna ou nos fragmentos. Stallings (1991) estudando talhões próximos ao Parque do Vale do Rio Doce, também não registrou nenhuma espécie de primata.

A perda de habitat é um dos processos decorrentes da fragmentação que afeta diretamente as espécies de mamíferos de médio e grande porte que se utilizam de áreas extensas para deslocamento. O ambiente em forma de mosaico com vegetação nativa intercalada a plantios de E. saligna, auxilia no deslocamento das espécies. Provavelmente alternativas que viabilizem o desenvolvimento de espécies nativas no dossel, favoreça a estruturação da comunidade de mamíferos e propicie a dispersão de espécies que não exploram este ambiente. 


\subsection{Considerações finais}

Neste trabalho os resultados encontrados ressaltam a importância dos remanescentes de Floresta Atlântica em áreas particulares para a conservação da fauna de mamíferos. Para a fauna de pequenos mamíferos encontrou-se espécies residentes e exploratórias nos plantios estudados na Fazenda João XXIII, com exceções, como O. russatus que é encontrada entre as espécies mais abundantes nos ambientes de floresta nativa e nenhuma captura ocorreu em plantios de E. saligna. É perceptível a diferença entre as espécies que ocupam as duas formações florestais na Fazenda João XXIII, remanescentes de Florestas Atlântica e plantios de E. saligna.

A fauna de mamíferos de médio e grande portes no entanto, demonstrou uma densidade baixa para a área, verificada com a utilização das armadilhas de pegadas e coleta de indícios. Durante o registros de pegadas obteve-se uma baixa ocorrência de registros, com exceção de Mazama sp e T. terrestris. Observou-se que as espécies de mamíferos de médio e grande portes nos fragmentos e na floresta contínua foram as mesmas e estas espécies utilizam dos plantios de E. saligna para deslocamento, sendo verificado latrinas de $T$. terrestris em meio a um dos talhões, ressaltando o uso deste ambiente por esta espécie. A ausência de registros de espécies com hábitos arborícolas como C. apella e N. nasua nos plantios de E. saligna, espécies estas verificadas nos remanescentes naturais, ressalta a importância de um incremento nestes plantios que favoreça e amplie a fauna de mamíferos que o utiliza, seja como habitat ou para deslocamento.

Um manejo nos plantios de E. saligna, na Fazenda João XXIII, que favoreça a fauna de mamíferos não-voadores poderia aumentar a diversidade de espécies e não propiciar a ocupação deste ambiente por espécies generalistas como 0 . nigripes. Uma rotatividade no corte, por exemplo, mantendo talhões de idades diferentes serviria como refúgio para os animais, não expondo-os repentinamente a uma alteração tão brusca de extensas áreas abertas. Talhões com corte seletivos onde não fossem retirados todos os indivíduos serviria de refúgio ao menos à fauna de pequenos mamíferos. Aumentar os corredores de florestas nativas unindo os fragmentos disponibilizaria refúgios para os animais durante o período de corte de $E$. saligna. Bem como a manutenção de uma borda de eucaliptos nos fragmentos para que estes não sejam danificados a cada ciclo de corte, quando são expostos a ação dos ventos e variações climáticas 
aumentando o efeito de borda dos mesmos.

É importante ressaltar que os dados desta dissertação só podem ser aplicados localmente visto a situação em mosaico em que os plantios de $E$. saligna estudados estão inseridos e mesmo à proximidade da Fazenda João XXIII à extensas áreas de Floresta Atlântica como o Parque Estadual de Carlos Botelho e a Serra de Tapiraí. 


\section{CONCLUSÕES}

1) Os dois métodos utilizados neste trabalho são complementares e indispensáveis para um levantamento acurado de pequenos mamíferos.

2) Pitfall com baldes de 20 litros são eficientes na captura de roedores terrestres de menor porte e imprescindível para captura de marsupiais do gênero Monodelphis.

3) Oligoryzomys nigripes, espécie dominante nos plantios de E. saligna estudados, apresenta-se como espécie generalista se mantendo nestes ambientes em altas densidades.

4) Oryzomys russatus foi a única espécie de pequeno mamífero, verificada neste estudo, com limitação no uso do plantios de E. saligna como habitat.

5) As espécies de mamíferos não-voadores utilizam os plantios de $E$. saligna, com exceção das espécies de hábitos arborícolas como C. apella.

6) Devido a alta riqueza e diversidade encontrada na área conclui-se que áreas formadas por plantios de $E$. saligna intercalados a florestas nativas, formando mosaicos, diminuem os impactos da fragmentação sobre as espécies de mamíferos na Fazenda João XXIII.

7) Alternativas de manejo que visem diminuir a entrada de luz neste ambiente e aumentar a densidade do sub-bosque favoreceriam as espécies de pequenos mamíferos e de mamíferos de médio e grande portes com hábitos arborícolas, que se mostram ausentes neste ambiente. 


\section{REFERÊNCIAS BIBLIOGRÁFICAS}

ABRAWAYA, J.P.; MATSON, J.O. Notes on a Brazilian Mouse Blarynomys breviceps. Contributions Sciences Natural History Museum, v. 270, p. 1-8, 1975.

ALHO, C.J.R. Small mammal populations of brazilian Cerrado: the dependence abundance on diversity habitat complexity. Revista Brasileira de Zoologia, v 41, p. 223-230, 1981.

ALHO,C.J.R. Brazilian rodents: Their habitats and habits. In: MARES, M. A; GENOWAYS, H.H. (Ed.). Mammalian biology in South America. Pittsburgh: Univ. Pittsburgh, Pymatuning Lab. Ecol., 1982. p. 232- 300. (Special Publication Series).

ALHO, C.J.R.; PEREIRA, L.A. Population ecology of a cerrado comunity in central Brazil. Revista Brasileira de Biologia, v. 45, p. 597-607, 1985.

ALHO, C.J.R.; PEREIRA, L.A.; PAULA, A. C. Patterns of habitat utilization by small population cerrado biome of central Brazil. Mammalia, v 50, n. 4, p. 447-460, 1986.

AUGUST, P.V. The role of habitat complexity and heterogeneity in structuring tropical mammal communities. Ecology, v. 64, p. 1495-1513, 1983.

AUGUST, P.V. Population ecology of small mammals in the Llanos of Venezuela. In: MARTIN, R.E.; CHAPMAN, B.R. (Ed.). Contributions in mammalogy in honor of Robert L. Packard. Lubbock, Texas Tech. Univ., 1984. p. 515-530.

AVILLA-PIRES, F.D.; GOUVEIA, E. Mamíferos do Parque Nacional de Itatiaia. Boletim Museu Nacional do Rio de Janeiro (Zool.), v. 291, p. 1-29, 1977. 
BECCALONI, J.E GASTON, C. Predicting the species richness of Neotropical forest butterflies: Ithomininae (Lepidoptera: Nymphalidae) as indicators. Biological Conservation, v. 71, p. 7786, 1995.

BENNET, A.F. Habitat corridors and the conservation de small mammals in a fragmented forest environment. Landscape Ecology, v. 4, p. 109-122, 1990.

BERGALLO, H.G. Ecology of a small mammal community in an Atlantic Forest area in southeastern Brazil. Studies on Neotropical Fauna and Environment, v. 29, p.197-217, 1994.

BONVICINO, C.R. WEKSLER, M.. A new species of Oligoryzomys from northeastern and central Brazil. Zeitschrift Saugetierkunde, v. 63, p. 90-103, 1998.

BONVICINO, C.R., LANGGUTH, A., LINDBERGH, S.M. and PAULA, A.C. An elevational gradient study of small mammals at Caparaó National Park, South Eastern Brazil. Mammalia, v. 61, n. 4, p. 547-560, 1997.

BODMER, R.E. Ungulate biomass in relation to feeding strategy within Amazonian forests. Oecologia, v. 81, p. 547-550, 1989.

BRANAM, W.V.; MARCHINTON, R.L. Reproductive ecology of white-tailed and red brocket deer in Suriname. In: WEMMER, C.M. (Ed.) Biology and management of the Cervidae. Washington: Smithsonian Institution Press, 1987. p. 334-351.

BROWN, J.H. Species diversity of seed-eating desert rodents in sand dune habitats. Ecology, v. 54, p. 61-72, 1973.

BROWN Jr., K.S.; BROWN, G.G. Habitat alteration and species bss in Brazilian forests. In: WHITMORE, T.C., SAYER, J.A. (Ed.) Tropical deforestation and species extinction, London; Chapman and Hall; 1992. p. 119 - 142. 
CABRERA. A., Catálogo de los Mamíferos de América del Sur I. Revista Museu Ciências Naturais "Bernardino Rivadavia", v. 4, p. 1-309, 1957.

CARVALHO, C.T. Bionomia de pequenos mamíferos. Revista de Biologia Tropical, v. 13, n. 2, p. 239-257, 1965.

CHARLES - DOMINIQUE, P. Ecology and social adaptations didelphid marsupials: Comparision with similar ecology. In: EISENBERG, J.F.; KLEIMAN, D.G. (Ed.) Advances in study mammalian behavior. Shippensburg; Amer. Soc. Mamm.; Pensylvania, 1983. p. 392-425. (Special Publication, 7).

CHARLES-DOMINIQUE P.; ATRAMENTOWICS, M.; CHARLES-DOMINIQUE, H.; GERARD, A. HLADIK, A.; PREVOST, M.S. Les mamifères frugivores arboricoles nocturnes d'une forêt guyanaise: inter-relations plantes animaux. Revue d'Ecologie. (La Terre et la Vie), v. 35, p. 341-435, 1981.

CHIARELLO, A.G. Effects of the Atlantic forest on mammal communities in south-eastern Brazil. Biological Conservation, v. 89, p. 71-82, 1999.

CHINCHILLA, F.A. La dieta del jaguar (Panthera onca), el puma (Felis concolor) y el manigordo (Felis pardalis) (Carnivora:Felidae) en el Parque Nacional Corcovado, Costa Rica. Revista de Biologia Tropical, v. 45, n 3, p. 1223-1229, 1997.

CHRISTOFF, A. Contribuição à siatemática das espécies do gênero Akodon (Rodentia: Sigmodontinae) do leste do Brasil: estudos anatômicos, citogenéticos e de distribuição geográfica. São Paulo, 1997. 209 p. Tese (Doutorado) - Instituto de Biologia, Universidade de São Paulo.

CRAWSHAW Jr, P.G. Recomendações para um modelo de estudo para projetos de pesquisa de felídeos neotropicais. Wildlife Conservation and Management Training 
Program; The National Zoological Park-Smithsonian Institution; Instituto de Pesquisas Ecológicas; Fundo Nacional do Meio Ambiente; Instituto Florestal de São Paulo, 1996. Instituto Florestal de São Paulo, 1996. 90 p.

CRESPO, J.A. Ecologia de la comunidad de mamíferos del Parque Nacional de Iguazú, Missiones. Revista Museu Ciências Naturais "Bernardino Rivadavia", v. 3, p. 45-162, 1982.

CURRIER, M.P.J. Felis concolor. Mammalian Species, v. 200, p. 1-7, 1983.

DAVIS, D.E. Notes on the life histories of some Brazilian Mammals. Journal of Animal Ecology, v. 26, p. 119-127, 1945.

DAVIS, D.E, Notes on the life history of some Brazilian mammals in two Brazilian forest. Boletim do Museu Nacional, v. 76, p. 1-8, 1947.

DIETZ, J. M.; COUTO, E.A.; ALFENAS, A.C.; FACCINI, A.; SILVA, G.F. Efeitos de duas plantações de florestas homogêneas sobre populações de mamíferos pequenos. Brasil Florestal, v. 6, p. 54-57, 1975.

DIRZO, R.; MIRANDA, A. Altered patterns of herbivory and diversity in the forest understory: a case study of the possible consequences of contemporary defaunation. In: Plant-animal interactions: evolutionary ecology in tropical and temperate regions. New York: John Wiley, 1991, p. 45-47.

DUESER, R.D; SHUGART, H.H. Microhabitats in a forest-floor small mammal fauna. Ecology, v. 59, n. 1, p. 89-97, 1978.

EISENBERG, J.F.; REDFORD, K. H. Mammals of the neotropics: the central neotropics. Chicago: The University of Chicago Press, 1998. 190 p. 
EMMONS, L.H. Geographic variation in densities and diversities of non-flying mammals in Amazonia. Biotropica, v. 16, n. 3, p. 210-222, 1984.

EMMONS, L.H. Comparative feeding ecology of felids in a neotropical rainforest. Behavior Ecology Sociobiology, v. 20, p. 271-283, 1987.

EMMONS, L.H.; FEER, F. Neotropical rainforest mammals, a field guide. Chicago, University of Chicago Press, 1990. 187 p.

FAO. Forest resources assessment. Rome, 1993. 35 p. (FAO Forestry Paper).

FLEMING, T.H. Population ecology of three species of neotropical rodents. Miscelanion Publication Museum of Zoology, v. 143, p. 1-77, 1971.

FONSECA, G. A. B. The vanishing brazilian atlantic forest. Biology Conservation, v. 34, p. 17-34, 1985.

FONSECA, G.A.B. Small mammal species diversity in brazilian tropical prymary and secondary forests of different sizes. Revista Brasileira de Zoologia, v. 6, n. 3, p. 381-422, 1989.

FONSECA, G.A.B. Muitas reserva pequenas: uma solução? Ciência Hoje, v.13 n. 76, p. 18-19, 1991.

FONSECA, G.A.B.; KIERULF, M.C.M. Biology and natural history of Atlantic forest mammals. Bulletin Florida State Museum Biological Science, v. 34, n. 3, p. 99-152. 1989.

FONSECA, G.A.B.; REDFORD, K.H. The mammals of IBGE's ecological reserve and an analysis of the role of gallery forests in increasing diversity. Revista Brasileira de Biologia, v. 44, p. 517-523, 1984. 
FONSECA, G. A. B.; ROBINSON, J. G. Forest size and structure: competitive and predatory effects on small mammal communities. Biological Conservation, v. 53, n. 4, p. 265-294, 1990.

FONSECA, G.A.B.; HERRMANN, G.; LEITE, Y. L. R.; MITTERMEIER, R.A.; RYLANDS, A.B.; PATTON, J.L. Lista anotada dos mamíferos do Brasil. Occasional Papers in Conservation Biology, v. 4, p. 1-38, 1996.

FONSECA, M. T. A estrutura da comunidade de pequenos mamíferos em um fragmento de Mata Atlântica e monocultura de eucalipto: a importância da matriz de habitat, Belo Horizonte, 1997. 52 p. Dissertação (M.S.) - Instituto de Ciências Biológicas, Universidade Federal de Minas Gerais.

FORMAN, R.T.T. Land mosaics: the ecology of landscapes and regions, Cambridge: Cambridge University Press, 1997. $190 \mathrm{p}$.

FREITAS, S.R. Variação Espacial e Temporal na Estrutura do Habitat e Preferência de Microhabitat por Pequenos Mamíferos na Mata Atlântica., Rio de Janeiro, 1998. 168 p. Dissertação (M.S.) - Museu Nacional do Rio de Janeiro, Universidade Federal do Rio de Janeiro.

FREITAS, S.R.; ASTÚA DE MORAES, S; SANTORI, R.T.; CERQUEIRA, R. Habitat preferences and food use by Metachirus nudicaudatus and Didelphis aurita (Didelphimorphia, Didelphidae) in a restinga forest at Rio de Janeiro. Revista Brasileira de Biologia, v. 57, p. 93-98, 1998.

FUNDAÇÃO SOS MATA ATLÂNTICA, Mata atlântica ameaçada. São Paulo, 1995. 53 p.

GARDNER, A.P. Order Didelphimorphia. In: WILSON, D.E.; REEDER, M.D. (Ed.) Mammals species of the world: a taxonomic and geographic reference. 2. ed. New York: Smithsonian Institution Press and American Society of Mammalogists, 1993. p. 112- 123 
GENTILE, R.; FERNANDEZ, F.A.S. Influence of habitat structure on a streamside small mammal community in a Brazilian rural area. Mammalia, v. 63, n. 1, p. 32-39, 1999.

GIRAUdOUX, P.; DELATTRE, P.; QUÉRÉ. J.; AND DAMANGUE, J. Structure and kinetics of rodents populations. in a region under agricultural land abandonment, Acta Ecologica, v. 15, n. 4 , p. 385-400, 1994.

GLIWICZ, J. Population dinamics of the spiny rat, Proechimys spinosus on Orchid Island (Panama). Biotropica, v. 16, p. 73-78, 1984.

GOELDI, E.A. Dois roedores notáveis da família dos ratos do Brasil. Boletim do Museu Paraense de História Natural e Ethnografia, v. 3, p. 166-180, 1902.

GOMES, N. Revisão sistemática do gênero Monodelphis (Didelphidae-Marsupialia), São Paulo, 1991. Dissertação (M.S.) - Instituto de Biologia, Universidade de São Paulo.

GREGORY, H.A.;THOMAS, D.L. Ecological correlates of trap response of a Neotropical forest rodent, Proechimys semispinosus. Journal of Tropical Ecology, v. 13, p. 59-68, 1997.

GRELLE, C.E.V. Análise tridimensional de uma comunidade de pequenos mamíferos, Belo Horizonte, 1996. 64 p. Dissertação (M. S.) - Instituto de Ciências Biológicas, Universidade Federal de Minas Gerais.

GRIGIONE, M.M.; BURMAN, P.; BLEICH, V.C.; PIERCE, B.M.; Identifying individual mountain lions Felis concolor by their tracks: refinement of na innovative technique. Biological Conservation, v. 88, p. 25-32, 1998.

HAFFER, J. Avian speciation in Tropical South America. Nuttal Ornithologycal Club, University Science Bulletin, v. 20, p. 1-91, 1974. 
HANDLEY, Jr., C.O. Mammals of the Smithsonian Venezuelan Project Brigham Young. University Science Bulletin, v. 20, n. 1, p. 1-89. 1976.

HEMMER, $\mathrm{H}$, The evolututionary systematics of living Felidae: present status and currents problems. Carnivore, v 1, p. 71-79, 1978.

HERSKOWITZ, P. The South American Gracile Mouse Opossums, Genus Gracilinanus microtarsus Gardner and Greighton, 1989 (Marmosidae, Marsupialia): a taxonomic review with notes on general morphology and relationships. Fieldiana, v. 70, p. 108, 1992.

HERSKOWITZ, P. The description of a new species of South American Hacicudo, or Long-Nouth Mouse, Genus Oxymycterus (Sigmodontinae, Muroidea), with a Critical Review of the Generic Content. Fieldiana, v. 79, p. 70, 1994.

HERSKOWITZ, P. Report on some sigmodontine rodents collected in southeastern Brazil with descriptions of a new genus and six new species. Zoological Beitrardt, v. 47, n. 3/4, p. $193-256,1998$.

HONACKI,J.H., KINMAN,K.E.; KOEPPL, J.W. Mammal species of the world: a taxonomic and geographic reference. New York., Allen Press, 1982. 150 p.

HUNSAKER, D.I.I. Ecology of new world marsupials. In: HUNSAKER, I.I. (ed) The biology of marsupials. New York: Academic Press, 1977. p. 95-156.

JAMES, F.C. Ordinations of habitat relationships among breeding birds. The Wilson Bulletin v. 83, n. 3, p. 215-236, 1971.

JANZEN, D.H. Sweep samples of tropical foliage insects: effects of seasons, vegetation types, elevation, time of day and insularity. Ecology, v. 54, p. 687-708, 1973. 
KARIMI, Y.; ALMEIDA, C.R.; PETTER, F. Note sur les rongeurs du nort Est du Brèsil. Mammalia, v. 40, p. $257-266,1976$.

KONECNY, M.J. Movement patterns and food habitats of four sympatric carnivore species in Belize, Central America. In: EISENBERG, J.F. (Ed.) Advances in neotropical mammalogy. Gainesville: Sandhill Cran Press, 1989. p. 60- 68.

LE BOULENGE-NGUYEN, P.; LE BOULENGE, E. A new ear-tag small mammals, Journal of Zoology, v. 209, n. 2, p. 20-29, 1986.

LEITÃO FILHO, S.H.F Aspectos taxonômicos das florestas do Estado de São Paulo. In: CONGRESSO NACIONAL DE ESSÊNCIAS NATIVAS, São Paulo, 1982, Silvicultura em São Paulo, v. 1, p. 197-206.

LEITE, Y.L.; STALLINGS, J.; COSTA, L.P. Partição de recursos entre espécies simpátricas de marsupiais na Reserva Biológica de Poço das Antas, Rio de Janeiro. Revista Brasileira de Biologia, v. 54, p. 525-536, 1994.

LIMA, W.P. Impacto ambiental do eucalipto. São Paulo: EDUSP, 1993, 301p.

MacARTHUR, R.H.; MacARTHUR, J.W. On bird species diversity. Ecology, v. 42, p. 594- 598, 1961.

MAGURRAN, M.E. Ecological diversity and its measurement. Princeton: Princeton University Press, 1988. $178 \mathrm{p}$.

MALCON, J.R. Small mammals abundances in isolated and non-isolated primary forest reserves near Manaus, Brazil. Acta amazonica, v. 18, p. 67-83, 1988.

MALCOLN, J.R., LOWMAN, M.D., NADKAMI, N.M. Forest structure and the abundance and diversity of neotropical small mammalls. In: MALCOLN, J. R; LOWMAN, M. D. (Ed.), Forest- 
canopies. Princeton: Princeton University Press, 1995. p. 179-197.

MARES, J.R.; ERNEST, K.A. Population and Community Ecology of Small Mammals in a Gallery Forest of Central Brazil. Journal of Mammalogy, v.76 n 3, p. 750-768, 1995.

MEDELLIN, R.A. EQUIHUA, M. Richness and diversity of litle mammals, Journal of Appliedd Ecology, v. 35, p. 13-23, 1998.

MELLO, D. A. Estudo populacional de algumas espécies de roedores do cerrado (norte do município de Formosa, Goiás). Revista Brasileira de Biologia, v. 40, n. 4, p. 843-860, 1980.

MELLO, D.A.; MOOJEN, L. E. Nota sobre uma coleção de roedores do cerrado (norte do município de Formosa, Goiás). Revista Brasileira de Pesquisa em Medicina Biológica, v. 12, p. 287-291, 1979.

METZGER, J.P.; DECAMPS, H.; The structural connectivity threshold: an hypothesis in conservation biology at the landscape scale. Acta Ecologica, v. 18, n. 1, p. 28-31, 1997.

MILLES, M. A.; SOUZA, A.A.; POVOA, M.M. Mammal tracking and nest lacation in Brazilian forest with na improved spool-and-line device. Journal of Zoology, v. 195, p. 331-347. 1981.

MIRANDA, E.E.; MATTOS, C. Brazilian rain forest colonization and biodiversity. Agricultural Ecosystems and Environnmental, v. 40, p. 275-296, 1992.

MITTERMEIER, R.A.; COIMBRA-FILHO, A.F.; CONSTABLE. I.D.; RYLANDS. A.B.; VALLE, Conservation of primates in the Atlantic forests of Brazil, New York, Zoological Yearbook, 1982. $58 \mathrm{p}$.

MULLER, P. The dispersal centers of terrestrial vertebrates in the Neotropical realm., The Hague: W. Junk, 1973. 244p. 
MUSSER, G.G.; CARLETON, M.D. Family Muridae. In: WILSON, D.E.; REEDER, D.M. (Ed.) Mammal species of the world: a taxonomic and geographic reference. 2 ed. Smithsonian Institution Press; American Society of Mammalogists, 1993.

MUSTRANGI, A.M.; PATTON, J.L. Phylogeographic and Systematics of the Slender Mouse Opossum Marmosops (Marsupialia, Didelphidae), Berkeley: University of California Press, 1997. $130 \mathrm{p}$.

NITIKMAN,L.; MARES, M. Ecology of small mammals in a gallery forest of central Brazil. Annual Carnegie Museum, v. 56, n. 2, p. 75-95, 1987.

NOWAK, R.M. Walker's mammals of the world. 5. ed. Baltimore: The Johns Hopkins University Press, 1991. 2v.

OLMOS, F. Observations on the behavior and population dynamics of some brazilian atlantic forest rodents. Mammalia, v. 55, n. 4, p. 555-565, 1991.

PAGGliA, A. P.; DE MARCO, P. Jr; COSTA, F. M.; PEREIRA, R. F.; LESSA, G. Heterogeneidade estrutural e diversidade de pequenos mamíferos em um fragmento de mata secundária de Minas Gerais, Brasil. Revista Brasileira de Zoologia, v. 12, n. 1, p. 67-79, 1995.

PALMA, A.R.T., Separação de nichos entre pequenos mamíferos de Mata Atlântica. Campinas, 1996. 81 p. Dissertação (M.S.) - Instituto de Biologia, Universidade Estadual de Campinas.

PINDER, L.; LEEWENBERG, F. Veado Catingueiro Mazama gouazoubira, Fisher 1814). In: DUARTE, J.M.B. (Ed.) Biologia e conservação de cervídeos sul-americanos: Blastocerus, Ozotocerus e Mazama, Jaboticabal: FUNEP, 1997. p. 12- 13.

PRICE, M.C. The role of microhabitat in structuring desert rodent communities. Ecology, v. 59 , n. 5, p. 910-921, 1978. 
REDFORD, K.H. and FONSECA, G.A.B. The role of gallery forests in the zoogeography of the Cerrado's non-volant mammalian fauna. Biotrópica, v. 18, n. 2, p. 126-135, 1986.

REIS, S. F.; POMBAL, Jr., J.P.; NESSIMIAN, J.L.; PESSÔA, L.M. Altitudinal distribution and feeding habits of Blarinomys breviceps (Winge, 1888), v. 61, p. 253-255, 1996.

ROBINSON, J.G.; REDFORD, K.H. Body size, diet and population density of neotropical forest mammals. American Naturalist, v. 128, n. 5, p. 665-680, 1986.

ROSENWEIG, M.L.; WINAKUR, J. Population ecology of desert rodent communities: habitats and environmental complexity. Ecology, v. 50, p. 558-572, 1969.

ROTENBERY, J.T.; WIENS, J.A. Temporal variation in habitat structure and shrubsteppe bird dynamics. Oecologia, v. 47, p. 1-9, 1980.

RUDD, R.L. Is the tropical small mammals collector a fruiting tree? Malayan Natural Journal v. 33, p. 71-74, 1979.

SAMPAIO N.A, O eucalipto. Jundiaí, Companhia Paulista de Estrada de Ferro, 1961. 78 p.

SÃO PAULO (Estado) Secretaria do Estado do Meio Ambiente. Coordenadoria de Informações Técnicas. Inventário Florestal do Estado de São Paulo. São Paulo, 1993. 98 p.

SCHALLER, G.B.; CRAWSHAW Jr, P.G. Movement patterns of jaguar. Biotropica, v. 12, n. 3, p. 161-168, 1980.

SCHALLER, G.B.; VASCONCELOS, J.M.C. Jaguar predation on capybara. Z. Saugetier, v. 43, p. 296-301, 1978.

SILVA, N.J.; SITES Jr., J. W. Patterns of diversity of Neotropical squamate reptile species with 
emphasis on the Brazilian Amazon and conservation potential of indigenous reserves. Conservation Biology, v. 9, p. 873-901, 1995.

SIMPSON, G.G. Species density of North American Recent mammals. Systematic Zoological, v. 13, p. 57-73, 1964.

SNEDECOR, G.W.; COCHRAN, W.G. Statical Methods. Ames: Iowa State University Press, 1980. $220 \mathrm{p}$.

STALLINGS, J.R. Small mammal inventories in an Eastern Brazilian Park. Bulletin Florida State Museum, Bioligical Scientific, v. 34, n. 4, p. 153-200, 1989.

STALLINGS, J.R. The importance of understorey on wildlife in a Brazilian eucalipt plantation. Revista Brasileira de Zoologia, v. 7, p. 267-276, 1991.

STALLINGS, J.R.; FONSECA, G.A.B.; PINTO, L.P.S.; AGUIAR, L.M.S.; SABATO, E.L. Mamíferos do Parque Florestal Estadual do Rio Doce, Minas Gerais, Brazil. Revista Brasileira de Zoologia, v. 7, p. 663-667, 1991.

STREILEIN, K.E. Behavior ecology and distribution of the South american marsupials. In: MARES, M.A.; GENOWAYS, H.H. (Ed.) Mammalian of South American. Pittsburgh: University of Pittsburgh, 1982. p. 232-250.

TALAMONI, S.A. Ecologia de uma comunidade de pequenos mamíferos da Estação Ecológica de Jataí, Município de Luiz Antônio, SP. São Carlos, 1996. 179 p. Tese (Doutorado), Centro de Ciências Biológicas e da Saúde, Universidade Federal de São Carlos.

TATE, G.H.H. Systematic revision of the marsupial genus Marmosa. Bulletim American Museum Natural History, v. 66, n. 1, p. 1-246, 1933. 
TAYLOR, P.D.; FAHRIG, L.; HENEIN, K.; MERRIAN, G.; Connectivity is a vital element of landscape structure. Oikos, v. 55, p. 121-129, 1993.

TERBORGH, J. Five new record world primates: a study in comparative ecology. Princenton: Princenton University Press, 1983. 120 p.

VELOSO, H.P. Classificação da vegetação brasileira, adaptada a um sistema universal. Rio de Janeiro: IBGE, Departamento de Recursos Naturais e Estudos Ambientais, 1991. $72 \mathrm{p}$.

VIEIRA, C.O.C., Lista remissiva dos mamíferos do Brasil. Arquivos de Zoologia, v. 8, p. 341-474, 1955.

VOLTOLINI, J.C. Estratificação vertical de marsupiais e roedores na Floresta Atlântica do Sul do Brasil. São Paulo, 1997. 98 p. Dissertação (M.S.) - Instituto de Biologia, Universidade de São Paulo.

VOSS, R.S.; EMMONS, L.H. Mammalian diversity in neotropical lowland rainforest: a preliminary assessment. Bulletin American Museum Natural History, v. 230, p. 1-117, 1996.

XIMENES, G.Y. Sistemática da família dasyproctidae (Bonaparte, 1838, Rodentia, Histricognathi) no Brasil. São Paulo, 1999. 230 p. Dissertação (M.S.) - Instituto de Biologia, Universidade de São Paulo.

WOLDA, H. Seasonal fluctuations in rainfall, food and abundance of tropical insects. Journal of Animal Ecology, v. 47, p. 369-381, 1978. 